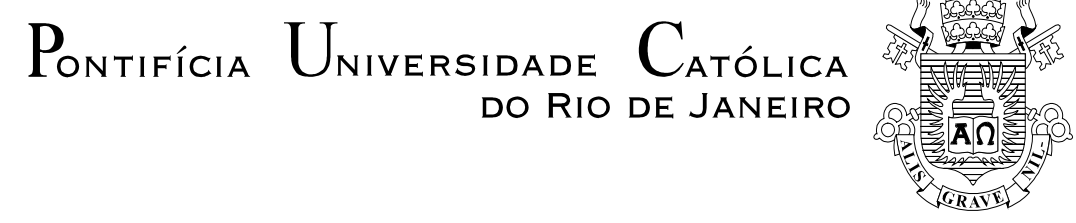

Fabiano Castro Torrini

\begin{abstract}
Modelos de Lógica Fuzzy para a Previsão de Longo Prazo de Consumo de Energia
\end{abstract}

Dissertação de Mestrado

Dissertação apresentada ao Programa de PósGraduação em Engenharia Elétrica da PUC-Rio como requisito parcial para obtenção do título de Mestre em Engenharia Elétrica.

Orientador: Prof. Reinaldo Castro Souza

Rio de Janeiro

Setembro de 2014 


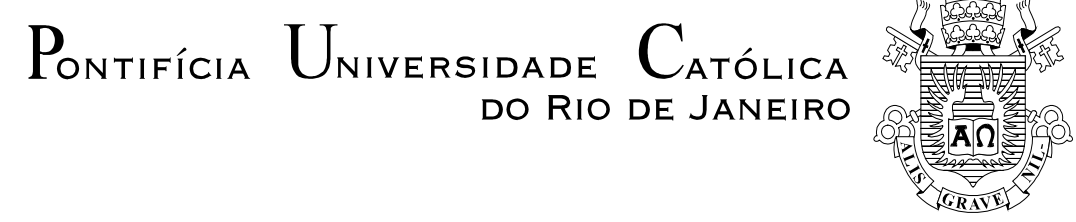

Fabiano Castro Torrini

\section{Modelos de Lógica Fuzzy para a Previsão de Longo Prazo de Consumo de Energia}

Dissertação apresentada como requisito parcial para obtenção do grau de Mestre pelo Programa de Pós-Graduação em Engenharia Elétrica do Departamento de Engenharia Elétrica do Centro Técnico Científico da PUC-Rio. Aprovada pela Comissão Examinadora abaixo assinada.

Prof. Reinaldo Castro Souza

Orientador

Departamento de Engenharia Elétrica - PUC-Rio

Prof. Fernando Luiz Cyrino Oliveira Co-Orientador

Departamento de Engenharia Industrial-PUC-Rio

Prof. Jose Francisco Moreira Pessanha

UERJ

Profa. Karla Tereza Figueiredo Leite Departamento de Engenharia Elétrica - PUC-Rio

Prof. José Eugenio Leal Coordenador Setorial do Centro

Técnico Científico

Rio de Janeiro, 15 de setembro de 2014 
Todos os direitos reservados. É proibida a reprodução total ou parcial do trabalho sem autorização da universidade, do autor e do orientador.

\section{Fabiano Castro Torrini}

Graduou-se em Ciências estatísticas pela Escola Nacional de Ciências Estatísticas em 2010. Durante o mestrado atuou em nome de empresas de grande porte tendo trabalhado com métodos estatísticos de previsão em diversos projetos no mercado

Ficha Catalográfica

Torrini, Fabiano Castro

Modelos de Lógica Fuzzy para a previsão de longo prazo de consumo de energia / Fabiano Castro Torrini; orientador: Reinaldo Castro Souza. - 2014.

89 f. : il. (color) ; $30 \mathrm{~cm}$

Dissertação (Mestrado em Engenharia Elétrica) Pontifícia Universidade Católica do Rio de Janeiro, 2014

Incluí referências bibliográficas.

1. Engenharia Elétrica - Teses. 2. Lógica fuzzy, 3. Previsão de longo prazo, 4. Consumo de energia elétrica. I. Souza, Reinaldo Castro. II. Pontifícia Universidade Católica do Rio de Janeiro. Departamento de Engenharia Elétrica. III. Título.

CDD: 621.3 
Aos meus pais, Jorgina e Renato, por teriam me guiado por todos estes anos de vida. É na educação dos filhos que se revelam as virtudes dos pais. 


\section{Agradecimentos}

Gostaria de agradecer primeiramente a Deus, por me proporcionar uma vida plena e saudável.

Agradeço aos meus pais que foram e têm sido fundamentais em todas as vitórias da minha vida, sempre me apoiando nos momentos difíceis e me dando o máximo de suporte possível ao longo de todos os meus anos de estudo.

Agradeço à minha namorada, Nayara, pelo seu amor e carinho e por ter entendido e dividido todos os momentos difíceis nestes anos de mestrado, me ajudando sempre a supera-los.

Ao meu irmão, Renato, exemplo de pessoa e profissional, que me faz a cada dia mais ter orgulho de tê-lo como espelho em minha carreira.

À minha irmã, Paula, por sempre me dar os melhores conselhos e me guiar para as melhores oportunidades. Sem dúvida, meus grandes sucessos tiveram uma parcela sua.

Ao meu orientador, Prof. Reinaldo Castro Souza, por seus ensinamentos ao longo do curso, pela oportunidade e confiança depositada em mim e me guiar neste trabalho de forma ilustre, sempre disposto a esclarecer minhas dúvidas e debater sobre os temas que surgiram no projeto.

Ao meu co-orientador Prof. Fernando Cyrino, grande profissional, por se mostrar sempre muito solícito às minhas dúvidas e me guiar ao longo da dissertação sempre com os melhores conselhos.

Ao Prof. José Francisco, profissional fora de escala, por todos os seus ensinamentos dados ao longo do período de minha dissertação. Sua ajuda foi com certeza primordial para a realização deste trabalho. 
À Prof. Karla Figueiredo, por ter aceitado o convite de fazer parte da minha banca e pelos ensinamentos dados ao longo da disciplina de Mineração de Dados.

Ao amigo, ex-chefe e exemplo de profissional, Adriano Esteves, por ter me dado sempre grandes oportunidades e o apoio de cursar meu mestrado com liberdade, trabalhando na CILOG Consultoria. Sua ajuda foi essencial para o meu crescimento como profissional.

Á todos os funcionários que tive oportunidade de trabalhar junto na Petrobrás. Pelas conversas no café, ensinamentos e convivência amistosa. Com certeza o convívio com vocês me transformou em um profissional e pessoa melhor.

Aos funcionários da Sulamérica, em especial à Fernanda Fernandes, Marcos Spiguel e André Caldeira. Pela liberdade dada nestes momentos críticos de dissertação e pela oportunidade de mostrar meu trabalho, me fazendo sentir valorizado profissionalmente.

Aos professores e funcionários do Departamento de Engenharia Elétrica da PUCRio, pelos ensinamentos e presteza.

À Petrobrás, por financiar o projeto do qual nasceu minha dissertação de mestrado e dar subsídios para a realização da mesma.

Aos meus amigos que percorreram parte deste mesmo caminho ao meu lado na PUC, Plínio Leal, Juliana Fernandes, Nicole Pessanha e Gustavo Galluzzi. A companhia de vocês me proporcionou momentos inesquecíveis nestes anos.

Aos meus grandes amigos da vida, por me apoiarem ao longo destes anos, prezando sempre pelo o meu sucesso.

Meus sinceros agradecimentos! 


\section{Resumo}

Torrini, Fabiano Castro; Souza, Reinaldo Castro (Orientador). Modelos de Lógica Fuzzy para a previsão de longo prazo de consumo de energia. Rio de Janeiro, 2014. 89p. Dissertação de Mestrado Departamento de Engenharia Elétrica, Pontifícia Universidade Católica do Rio de Janeiro.

O consumo de energia elétrica no Brasil tem sido amplamente discutido nos últimos tempos. A crise do abastecimento de energia em 2001, fez com que o Governo Federal tomasse uma série de medidas para tentar corrigir os erros do modelo em vigência. Hoje, entende-se que a situação do setor energético é delicada, fazendo com que o risco de um novo racionamento volte a ser considerado. Neste contexto, as companhias de energia estão se deparando com o desafio de obter previsões de carga mais precisas. Consequentemente, uma vez que esta demanda encontra-se inserida em um cenário instável de economia, estas estimativas requerem métodos mais eficientes e inovadores. O objetivo principal deste estudo é fornecer uma nova abordagem para o problema de previsão do consumo de eletricidade. A metodologia de lógica fuzzy é proposta com o objetivo de extrair regras das variáveis de entrada e fornecer previsões de longo prazo para a demanda de eletricidade no Brasil. Através da modelagem estatística, a identificação das estruturas de dependência e defasagens entre estas variáveis, fornece suporte para os modelos independentes com previsões anuais. A grande vantagem dos modelos de lógica fuzzy vem da habilidade destes de imitar o pensamento humano em cenários de incerteza e imprecisão. $\mathrm{Na}$ literatura recente, a formulação destes tipos de modelo tem se limitado a tratar as variáveis explicativas de maneira univariada, ou então envolvendo somente o PIB. Este trabalho propõe a extensão do modelo desenvolvido na literatura, começando com variáveis como a população do Brasil e o valor adicionado do PIB por estados e setores, juntamente com suas variações. Com isso, o modelo proposto será comparado com a formulação oficial vigente fornecida pela EPE.

\section{Palavras-chave}

Lógica fuzzy; previsão de longo prazo; consumo de energia elétrica. 


\section{Abstract}

Torrini, Fabiano Castro; Souza, Reinaldo Castro (Advisor). Long-term electricity demand forecast by fuzzy logic approach. Rio de Janeiro, 2014. 89p. MSc Dissertation - Departamento de Engenharia Elétrica, Pontifícia Universidade Católica do Rio de Janeiro.

The consumption of electricity in Brazil has been widely discussed recently. The energy supply crisis in 2001 forced the Federal Government to take a series of measures trying to fix the actual model. Nowadays, it is understood that the energy sector is going through bad times, making the risk of a new rationg plan be considered. In this context, energy companies are facing the challenge of making more accurate load forecast. Consequently, once this need is inserted into a scenario of unstable economy, these estimates require efficient methods combined with innovative features. The aim of this study is to provide a new approach to this electricity prediction problem. A Fuzzy logic methodology is proposed in order to extract rules from the input variables and provide Brazil's Long-term annual electricity demand forecasts. From a statistical modeling point of view, an identification of dependence and lags structure between the input variables provide support for independent models with annual estimates. The advantage of the fuzzy logic model lies on the ability to mimic the human thinking in an environment of uncertainty and imprecision. In recent literature, the formulation of these types of models has been limited to treating the explanatory variables in the univariate form, or involving only the GDP. This study proposes an extension of this model, starting with the Brazilian population and the additional value of the state GDP by sectors with their variations. Then, the proposed model is compared with the official formulation provided by EPE.

\section{Keywords}

Fuzzy logic; long-term forecast; electricity demand. 


\section{Sumário}

1 Introdução 12

1.1. Apresentação 12

1.2. Crises no abastecimento de energia elétrica 13

1.3. Necessidade de uma formulação para o longo prazo 14

1.4. Organização do estudo 15

2 Revisão bibliográfica $\quad 17$

2.1. Previsão de consumo de energia elétrica 17

2.2. Previsão de demanda no longo prazo 19

2.3. Lógica Fuzzy $\quad 22$

2.3.1. Previsão utilizando lógica Fuzzy $\quad 24$

2.3.2. Introdução à técnica $\quad 26$

2.3.3. Função de pertinência 28

$\begin{array}{lr}\text { 2.3.4. O sistema fuzzy } & 29\end{array}$

2.3.5. Aplicação para séries temporais 32

2.4. Modelos de séries temporais $\quad 36$

$\begin{array}{ll}\text { 2.5. Qualidade de ajuste } & 37\end{array}$

3 Análise exploratória e descrição da base $\quad 39$

3.1. Descrição da base $\quad 39$

3.2. Análise de tendência e sazonalidade $\quad 40$

3.2.1. Análise de tendência $\quad 40$

3.2.2. Decomposição dos fatores sazonais 42

4 Aplicação e resultados dos modelos propostos 44

4.1. Especificação dos modelos 44

4.2. Modelo Holt com dois parâmetros 45

4.3. Modelo Fuzzy univariado 47

4.4. Modelos Fuzzy causais $\quad 55$

4.4.1. Modelo Brasil $\quad 55$

4.4.2. Modelos por classes de consumo $\quad 61$

$\begin{array}{ll}5 \text { Conclusões e considerações finais } & 67\end{array}$

6 Referências Bibliográficas $\quad 69$

$\begin{array}{ll}\text { Apêndice A - Rotina gerada no R } & 74\end{array}$ 


\section{Lista de figuras}

Figura 3.1 - Conjuntos fuzzy e funções de pertinência para a variável consumo de energia

Figura 3.2 - Arquitetura geral de um sistema fuzzy. $\quad 29$

Figura 3.3 - Modelo Mandani. 31

Figura 3.4 - Divisão dos intervalos de domínio em conjuntos fuzzy da série histórica do PIB Brasil.

Figura 3.5 - Mapeamento das variáveis de entrada e saída. 33

Figura 3.6 - Ativação dos conjuntos fuzzy.

Figura 4.1 - Séries de consumo de energia elétrica por classes de consumo. 41

Figura 4.2 - Séries de consumo de energia elétrica por classes com a aplicação de uma diferença.

Figura 4.3 - Fatores sazonais multiplicativos por classes de consumo. 43

Figura 5.1 - Gráfico das componentes do modelo Holt para o total Brasil. $\quad 45$

Figura 5.2 - Valores ajustados x realizados do modelo Holt para classes de consumo. 46

Figura 5.3 - Gráfico das previsões do modelo de Holt por classes de consumo. 47 Figura 5.4 - Valores Ajustado x Realizado para amostra de validação do modelo fuzzy com janela de três antecedentes.

Figura 5.5 - Valores Ajustado x Realizado para amostra de validação do modelo fuzzy com janela de quatro antecedentes.

Figura 5.6 - Valores Ajustado x Realizado para amostra de validação do modelo fuzzy com janela de cinco antecedentes.

Figura 5.7 - Funções de pertinência estimadas para um padrão de 5 conjuntos fuzzy

Figura 5.8 - Comparação da projeção dos modelos propostos para o consumo total de energia elétrica no Brasil.

Figura 5.9 - Gráfico de comparação da projeção de consumo de energia

elétrica dos modelos propostos e cenários da EPE.

Figura 5.10 - Gráfico das previsões até 2030 do modelo fuzzy univariado para o consumo de energia elétrica por classes.

Figura 5.11 - Valores Ajustado x Realizado para amostra de validação do modelo fuzzy Brasil com PIB.

Figura 5.12 - Gráfico de comparação da projeção de consumo de energia elétrica do modelo fuzzy Brasil com PIB versus cenários da EPE.

Figura 5.13 - Valores Ajustado x Realizado para amostra de validação do modelo fuzzy Brasil com PIB e População.

Figura 5.14 - Gráfico de comparação da projeção de consumo de energia elétrica do modelo fuzzy Brasil com PIB e População versus cenários da EPE. 59 Figura 5.15 - Gráfico das previsões até 2030 do modelo fuzzy causal para o consumo de energia elétrica por classes. 


\section{Lista de quadros}

Quadro 3.1 - Pertinências das variáveis de entrada e saída aos conjuntos fuzzy ativados

Quadro 4.1 - Resumo das variáveis consideradas no estudo 40

Quadro 4.2 - Fatores sazonais multiplicativos por classes de consumo 42

Quadro 5.1 - Previsões do modelo Holt para o total de consumo no Brasil 46

Quadro 5.2 - MAPE da etapa de validação dos modelos propostos 51

Quadro 5.3 - Valores da projeção anual no horizonte 2030 dos modelos

propostos

52

Quadro 5.4 - Valores da projeção pontual do ano de 2030 para os modelos proposto e cenários da EPE.

Quadro 5.5 - Valores das previsões até 2030 do modelo fuzzy para o consumo de energia elétrica por classes

Quadro 5.6 - Matriz de correlação das classes de consumo de energia elétrica. 56

Quadro 5.7 - Base de regras do modelo total Brasil com o PIB 58

Quadro 5.8 - Base de regras do modelo total Brasil completo. 60

Quadro 5.9 - Projeções dos modelos Brasil estimados e expectativas da EPE 60

Quadro 5.10 - Estatísticas de ajuste para os modelos fuzzy Total Brasil 62

Quadro 5.11 - Estatísticas de ajuste para os modelos fuzzy do setor residencial 62

Quadro 5.12 - Estatísticas de ajuste para os modelos fuzzy do setor comercial 62

Quadro 5.13 - Estatísticas de ajuste para os modelos fuzzy do setor industrial 63

Quadro 5.14 - Estatísticas de ajuste para os modelos fuzzy de outros setores 63

Quadro 5.15 - Valores das previsões fornecidas da EPE para 2014 - $2023 \quad 65$

Quadro 5.16 - Valores das previsões até 2030 do modelo fuzzy para o

consumo de energia elétrica por classes

Quadro 5.17 - Desvios relativos das previsões por classe da EPE em relação às projeções geradas pelos modelos fuzzy 


\section{1 \\ Introdução}

\section{1.}

\section{Apresentação}

O consumo de energia elétrica no país transformou-se numa variável bastante discutida recentemente. Com a crise do abastecimento de energia elétrica em 2001, o Governo Federal foi forçado a tomar uma série de medidas para tentar corrigir os erros do modelo em vigência e garantir maior estabilidade no suprimento de energia elétrica. A Lei ${ }^{\circ}$ 1040848/04 acompanhada do Decreto ${ }^{\circ}$ 5.163/04 criou uma nova estrutura regulatória para o setor, que além de garantir a oferta de energia, teve como objetivo promover a universalização do acesso à eletricidade e a modicidade tarifária.

A previsão do consumo é uma ferramenta de suporte essencial para a tomada de decisões, tornando-se de grande utilidade, como por exemplo, na programação da geração e planejamento para transações de energia. Neste contexto, as empresas do setor energético se depararam com o desafio de se realizar previsões de carga cada vez mais precisas para o longo prazo. Consequentemente, uma vez inseridas em um cenário de economia instável, estas estimativas requerem métodos eficientes e, que acima de tudo possam apresentar características inovadoras.

Este trabalho tem como objetivo propor novas previsões de longo prazo para o consumo de energia elétrica a serem comparadas com o modelo vigente. Uma vez que estas novas previsões forem obtidas, um melhor planejamento no suprimento de energia poderá ser obtido, assim como, os investimentos em infraestrutura e operação tendem a ser mais bem aproveitados.

Os previsões que a serem propostas partem de uma nova abordagem que têm como foco os modelos de previsão baseados em Lógica Fuzzy, cuja técnica fornece fundamentos para efetuar o raciocínio aproximado com proposições imprecisas, permitindo tratar dados vagos ou imprecisos. Através das extrações de regras das variáveis de entrada e da modelagem estatística para a identificação de 
estruturas de dependência e defasagens entre estas variáveis, serão propostos modelos independentes com previsões anuais. Feito isto, estas previsões serão desagregadas para mensais, através de fatores sazonais gerados por procedimentos estatísticos de análise de séries temporais e por patamares de carga.

$\mathrm{Na}$ literatura recente, a formulação destes tipos de modelo tem se limitado a tratar as variáveis explicativas de maneira bivariada, envolvendo somente o PIB (Kucukali \& Baris, 2009). Este trabalho propõe a extensão do modelo desenvolvido na literatura, passando a considerar além desta, outras variáveis explicativas como a VA Estadual da Indústria Geral por setores, a Variação do Valor Adicionado dos Estados, a População Brasileira, entre outras.

\section{2.}

\section{Crises no abastecimento de energia elétrica}

A principal crise de abastecimento de energia elétrica foi apresentada pelo governo de Fernando Henrique Cardoso em março de 2001. Existiam assim, duas alternativas de atuação governamental: a primeira, a imposição de um racionamento por cortes de carga gerais, setoriais ou regionais; a segunda, a atribuição dos consumidores de energia da tarefa de reduzir seu consumo segundo critérios próprios. Cabe frisar que se optou pela segunda (Pires, Giambiagi, \& Sales, 2002)

No dia $1^{\circ}$ de julho de 2001 a população brasileira foi obrigada a mudar seus hábitos de consumo drasticamente. Entre as medidas impostas pelo governo federal no plano de racionamento criado estava a meta de diminuição em pelo menos $20 \%$ do consumo de energia para cada lar que consumisse acima de 100 quilowatts/hora por mês, ficando os consumidores que não cumprissem esta meta passiveis de terem a luz cortada ${ }^{1}$. Com a melhoria da situação energética advinda da recuperação dos reservatórios, a GCE mediante a Resolução n n 117/02 decretou o fim do racionamento em 28 de fevereiro de 2002.

Após toda uma década sem investimentos na geração e distribuição de energia elétrica no Brasil, o racionamento de energia citado foi elaborado às pressas. Pode-se creditar como causa desta crise uma soma de fatores: as poucas

\footnotetext{
${ }^{1}$ A região sul não participou do racionamento, tendo em vista que suas represas estavam cheias e houve retomada de investimentos no setor.
} 
chuvas, a falta de planejamento e a ausência de investimentos em geração e distribuição de energia.

Atualmente, o setor energético nacional encontra-se também em uma situação de risco. O baixo nível nos reservatórios constatado desde 2013 e intensificado em 2014 obrigaram o acionamento de usinas térmicas gerando grandes prejuízos no setor e fazendo com que o risco de racionamento se convertesse para uma situação de risco de “em alerta”.

O ano de 2014 iniciou com vazões extremamente baixas, situação que permaneceu até o final de março. Com isso, o preço "spot" atingiu seu valor máximo histórico de R\$ 822,83/MWh e, mesmo com o acionamento contínuo das termelétricas, os reservatórios chegaram a níveis similares aos observados em 2001, ano do racionamento (Pires A. , 2014).

Ainda segundo Pires A. (2014), o período úmido foi encerrado em situação crítica, com o nível médio dos reservatórios do Sudeste/Centro-Oeste e Nordeste em $40 \%$, sendo superior somente ao nível obtido em 2001. Consequentemente as termelétricas estavam operando em tempo integral, com programas de manutenção revisados, podendo parar somente em situações críticas

A forma com que o governo vem monitorando a atual situação gera grandes preocupações para os especialistas do setor. A falta de planejamento é evidente visto que não houve medidas de restrição de consumo e a tarifa não refletiu os custos adicionais do setor. Todas estas consequências apontam para uma das causas mais visíveis desta falta de investimento e planejamento, a necessidade de um modelo capaz que refletir os cenários mais realistas do setor.

\section{3.}

\section{Necessidade de uma formulação para o longo prazo}

Somado ao fato de hidrologia desfavorável, o aumento contínuo do consumo de energia devido ao crescimento populacional e o aumento de produção pelas indústrias serviram como evidência de um planejamento falho no setor que repercute numa já considerada atual crise energética.

Em um cenário de incerteza afetado ainda mais pelo longo horizonte de previsão, uma projeção mal feita do consumo de energia pode acarretar não só em maus investimentos de infraestrutura no país, como também em eventos 
inesperados que requerem tomadas de decisão importantes em um curto espaço de tempo.

Sendo assim, uma boa formulação do modelo de longo prazo garante grandes avanços de cunho estratégico, orientando tendências e balizando as alternativas de expansão desse segmento nas próximas décadas.

\section{4 . \\ Organização do estudo}

O presente trabalho está estruturado em seis capítulos. Inicialmente, após esta introdução (primeiro capítulo), apresenta-se no segundo capítulo a revisão de literatura contendo uma síntese da evolução dos modelos de previsão de carga existentes em diversas economias do mundo, assim como uma ideia geral da técnica de lógica fuzzy aplicada a modelos de previsão juntamente com um resumo dos estudos mais recentes desta técnica para previsões de carga elétrica.

O terceiro capítulo refere-se à principal metodologia utilizada no trabalho, Lógica Fuzzy. É feita uma descrição detalhada da técnica passando por todas as etapas de execução até a previsão. Em seguida, tem-se uma explicação geral dos modelos de séries temporais abordados neste estudo e os procedimentos utilizados no emprego destes modelos. O capítulo segue com explicações e definições básicas para o entendimento do modelo empregado.

O quarto capítulo refere-se à descrição da base utilizada para alimentar os modelos, juntamente com a descrição de cada variável presente nas equações. Ainda neste capitulo, é apresentada uma análise exploratória das séries de consumo consideradas, com uma descrição das componentes de tendência e sazonalidade destas séries.

No quinto capítulo serão expostos os resultados obtidos através do modelo proposto e uma comparação destes resultados com as formulações econométricas existes na literatura. Esta seção é de grande importância pelo fato de apresentar ao leitor o quanto a nova metodologia empregada perde ou ganha em relação à precisão das estimativas.

Finalmente, no capítulo seis são expostas as conclusões do trabalho, assim como as considerações finais e sugestões de possíveis novas investigações e 
aprofundamentos acerca dos modelos de previsão de consumo de energia elétrica para o longo prazo.

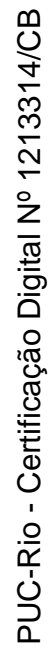




\section{2 Revisão bibliográfica}

\section{1. \\ Previsão de consumo de energia elétrica}

A grande maioria dos métodos de previsão de demanda elétrica é dividida em modelos de curto-prazo (de minutos até 24 horas), modelos de médio-prazo (de dias até meses) e modelos de longo-prazo (de 1 a 10 anos). Geralmente, estes modelos podem ser classificados em métodos paramétricos ou métodos baseados em inteligência artificial (Al-Hamadi, 2011)

Os trabalhos mais citados na literatura dedicados à previsão de carga elétrica utilizam a abordagem econométrica para realizar projeções do consumo de energia através de sua relação com variáveis econômicas. Neste tipo de abordagem, a relação direta existente entre a variável dependente e o Produto Interno Bruto (PIB) local tem sido uma unanimidade entre os principais artigos.

Feinberg \& Genethliou (2002, 2003) citam e analisam a modelagem pelos métodos econométrico, end-use e suas combinações como sendo as mais utilizadas para previsões no médio e longo prazo. É citado que, variáveis como a idade dos equipamentos dos usuários e mudanças tecnológicas são normalmente utilizadas no método end-use, que embora possa gerar projeções precisas com um histórico de dados menor, é um método sensível à qualidade das informações relativas dos usuários.

Uma das grandes complexidades de trabalhar com estes tipos de modelos, é a falta de informação de usuários específicos, uma vez que, a concessionária tem informações agregadas de diversos consumidores, mantendo uma espécie de média por tipos de consumidores. Por este fato, a previsão de carga por regiões fica difícil de ser executada.

Com o objetivo de simplificar as previsões de médio prazo e evitar o problema das informações não disponíveis, Feinberg \& Genethliou (2002, 2003) desenvolveram através de um estudo comparativo de modelos de consumo de energia, um modelo estatístico capaz de aprimorar os parâmetros de carga com 
base nos dados históricos. A conclusão do estudo levou ao seguinte modelo multiplicativo:

$$
L(t)=F(d(t), h(t)) \cdot f(w(t))+R(t)
$$

onde $L(t)$ é a carga atual no instante $t, d(t)$ é o dia da semana, $h(t)$ é a hora do dia, $F(d, h)$ representa o componente referente a data e hora da informação, $w(t)$ é referente ao clima (temperatura e humidade) com $f$ representando seu fator e $R(t)$ o erro aleatório. Assim, partindo da conclusão de que o consumo de energia elétrica depende não somente das condições climáticas atuais, mas também da condições passadas, é proposto um modelo regressivo para estimar este fator de clima.

Ainda a respeito da abordagem econométrica, o uso da metodologia de análise de séries temporais é bastante comum na previsão de carga elétrica. Os modelos ARMA, ARIMA, ARMAX ${ }^{2}$ e $\operatorname{ARIMAX}^{3}$ são frequentemente utilizados quando o objetivo do estudo é uma previsão a curto-prazo. Fan e McDonald (1994) e Cho, Hwang e Chen (1955) descrevem a implementação dos modelos ARIMAX para previsão de carga.

Huang et al (1996) usaram programação evolucionária para identificar os parâmetros do modelo ARMAX para previsão de uma semana à frente de dados horários de carga.

Yang e Huang (1998) propuseram um modelo Fuzzy autoregressivo de média móvel com variáveis exógenas de entrada (FARMAX) para previsão de um ano à frente de dados horários de carga.

\footnotetext{
${ }^{2}$ Autoregressivo de média móveis com variáveis exógenas

${ }^{3}$ Autoregressivo integrado de médias móveis com variáveis exógenas
} 


\section{2 . \\ Previsão de demanda no longo prazo}

Segundo Al-Hamadi (2011), a precisão das previsões de carga elétrica no longo prazo tem um efeito significativo no desenvolvimento futuro e no planejamento da distribuição de energia. Uma projeção feita sempre de forma sobrestimada pode gerar investimentos desnecessários feitos em instalações de energia. Ao passo que, uma projeção subestimada pode acarretar no descontentamento do consumidor.

Devido à incerteza dos fatores que possuem grande influência no consumo de energia e a dificuldade de prevê-los em um largo horizonte tempo, a falta de precisão nas projeções finais da variável dependente acaba por ser uma característica natural destes tipos de modelo.

Um dos estudos pioneiros na previsão de demanda no longo prazo no Brasil ocorreu em Outubro de 1969 em uma análise do mercado de energia elétrica da região Sudeste. No estudo "Power Market Study and Forecast - South Central Brazil” (PMS \& F), o objetivo era fornecer ao Banco Mundial uma previsão do consumo de energia na região Sudeste visando o financiamento de obras. Foram utilizados dados de 1950 à 1968 e as projeções de demanda de energia elétrica foram fundamentadas em quatro coordenadas econômicas: o crescimento do PIB (um cenário otimista e outro conservador), o crescimento da população (2,8\% ao ano), a taxa de urbanização regional (75\% em 1980) e a questão tarifária.

Como foi dito anteriormente, a utilização do PIB como variável independente em um modelo de previsão de consumo de energia tem se mostrado vital para a precisão do mesmo. Imtiaz et al (2006) sugerem além do PIB da Malásia, a população, o consumo de eletricidade per capita, o número de consumidores de eletricidade e a demanda de pico.

Terpathy (1997) desenvolveu projeções no longo-prazo de carga elétrica baseadas em modelos de regressão linear e log-linear de seis setores prédeterminados.

Barakat e AL-Rashid (1992) obtiveram bons resultados para a previsão no longo-prazo da demanda de pico na Arábia, quando aplicaram um modelo 
logístico estendido em um sistema de rápido crescimento. A comparação foi feita com a demanda atual e com modelos de metodologia mais clássica.

Nguyen e Fu (2003) investigaram alternativas para aumentar a precisão das previsões de carga no longo prazo. O uso de transformadas Wavelet e a inclusão de variáveis relacionadas à temperatura indicaram ganhos significativos quando comparados a modelos econométricos baseados somente em variáveis socioeconômicas. Um dos aspectos principais apresentados no estudo foi de que a função wavelet usada no modelo conservou a sua forma dinâmica no procedimento de treinamento do mesmo, isso fez com que a estabilidade e a precisão das previsões aumentassem quando usadas no longo prazo.

Mahmoud et al (2008) propuseram em seu estudo uma metodologia particular para a previsão de carga em países com rápida taxa de crescimento. Foi aplicado aos dados de consumo de energia da Arábia Saudita um modelo usando redes neurais com um método de extrapolação, o qual envolve a estimativa de curvas que visam refletir a tendência existente nos dados. Como conclusão, obteve-se que a curva que melhor se adaptava nos dados era dada por uma parábola.

Hongyan, Liya \& Xiaojuan (2008) realizaram um estudo para a previsão de longo prazo da demanda de eletricidade na China. Inicialmente foi proposto um modelo Grey devido a seu rápido cálculo e facilidade de implementação. Porém, como este modelo se mostrou inadequado para lidar com a volatilidade do sistema elétrico foi proposta uma correção através de um novo modelo de redes neurais RBF. Com esta correção, foram obtidas previsões mais rápidas e precisas.

Spackman, Sivakumar, C. Nair, \& Yeung (2006) apresentam uma nova metodologia para a previsão no longo prazo da demanda de pico de eletricidade para áreas pequenas. Para estimar a demanda de carga na região de Auckland na Nova Zelândia é proposto um modelo com uma abordagem baseada em políticas governamentais adotadas na região. Estas previsões foram feitas com o auxilio de um software de GIS ${ }^{4}$ e com base na decomposição da análise end-use e da análise espacial land-use. Como resultado, o modelo adotado se mostrou coerente quando comparado com outras metodologias.

\footnotetext{
${ }^{4}$ Geographical Information System
} 
Ghelardoni \& Ghio (2012) comentam que geralmente quando há a generalização de uma técnica usada para previsões no curto prazo para previsões mais no longo prazo o resultado que se obtem é uma performace escassa. Neste paper em questão, o uso do filtro de Savitzky-Golay é mostrado juntamente com o algoritmo de Máquinas de Vetores-Suporte para regressão. O filtro de SavitzkyGolay é utilizado para separar a tendência da série caracterizada por baixas oscilações de frequencia das altas frequencias.

Ghelardoni, Ghio, \& Anguita (2013) citam a dificuldade em encontrar um método consistente para as previsões de carga no longo prazo, no seu trabalho é descrito um novo procedimento, o qual utilizam o método de Decomposição em Modos Empíricos para desagregar a série temporal em duas componentes: a tendência e as oscilações dos valores de consumo de energia local. Estas componentes são então usadas para treinar o algoritmo de máquinas de vetoressuporte para regressão. Foram obtidos resultados que validam a eficiência deste método perante a comparação com outros mais tradicionais.

Ardakani \& Ardehali (2014) mostram os impactos sobre o consumo de energia elétrica e uma análise de seus efeitos sobre a previsões no longo prazo. O objetivo do estudo foi investigar os efeitos dos dados históricos sobre a precisão dos modelos de consumo de energia elétrica. Os dados utilizados são: o consumo de energia dos EUA em 1967-2009 (41 anos); indicadores sócio-econômicos (PIB, as importações de energia, a exportação de energia) e a população. Foram utilizados para uma previsão de 2010 até 2030, modelos de redes neurais artificiais, modelos baseados em melhoras na otimização do exame de partículas e algoritmos frog-leaping (pulo do sapo). Como resultados, os modelos propostos mostraram que o uso de indicadores sócio-econômicos como dados de entrada atinge menor percentual de erro médio absoluto (MAPE) para a previsão de consumo de energia elétrica no longo prazo

Amlabu, Agber, Onah, \& Mohammed (2013) estudam a previsão de demanda de carga utilizando a técnica de mínimos quadrados em quatro regiões com diferentes cenários de geração de energia na Nigéria. Apresentando a lacuna histórica existente entre a demanda por energia e o fornecimento na Nigéria, conclui-se que para manter o país a par dos outros países em desenvolvimento que exibiram um crescimento substancial no desenvolvimento econômico, este problema tem de ser resolvido realizando expansões do sistema elétrico. No 
mesmo estudo, é feita uma revisão de literatura dando ênfase a previsões de demanda elétrica a longo-prazo na África e no mundo e mostra as vantagens de se aplicar a técnica de mínimos quadrados assim como suas equações matemáticas. Os resultados para as quatro regiões são baseados no período de seis anos (20042009) e o horizonte de previsão é de 2010 até 2020.

Huayllas \& Ramos (2010) fazem uma comparação das principais metodologias para a previsão de energia elétrica utilizadas em países da América do Sul. O estudo traz a ideia de algumas variáveis explicativas utilizadas em modelos econométricos feitos para previsão da demanda em outro países como por exemplo: a taxa de emprego/ desemprego, a produção de aço e alumínio, índices medidores da inflação, etc. O resultado de algumas destas técnicas é analisado quando aplicado ao mercado elétrico brasileiro para classes (residencial, industrial, comercial e rural).

Souza \& Cyrino (2014) apresentam em seu paper um estudo com a proposição de duas metodologias diferentes para a previsão de consumo e produção de energia elétrica no Brasil no horizonte de 2050. O estudo inicia com uma análise descritiva das séries anuais de consumo e produção de energia para os quatro subsistemas do Brasil, indicando alguns dos periodos relevantes de quebra na serie como a crise do racionamento de 2001 que afetou principalmente o subsistema Sudeste + Centro-oeste. São propostos dois modelos de previsão: um modelo univariado de Holt de 2 parâmetros e um modelo bivariado de regressão dinâmica utilizando o PIB como variável explicativa. Ambos os modelos aplicados apresentam bons resultados e as previsões feitas indicam um acréscimo ainda maior com o tempo no "gap” entre produção e consumo de energia já existente.

\section{3.}

\section{Lógica Fuzzy}

Em diversos setores, métodos computacionais baseados em inteligência artificial para resolver problemas, estão ficando mais conhecidos. Principalmente, devido as suas flexibilidades e capacidades de explicação (Jebaraj \& Iniyan, 2006). 
Nos últimos tempos a lógica Fuzzy vem se tornando uma importante ferramenta em diferentes aplicações, tanto em áreas como a engenharia, quanto nos negócios (Cox, 1995) e (Tanaka \& Nimura, 2007). Além de outras vantagens desta metodologia, podemos destacar a ausência de necessidade de um modelo matemático para mapear variáveis de entrada ou saída, assim como, que não é necessário ter variáveis de entrada precisas.

Enquanto os sistemas fuzzy são geralmente associados à aproximadores universais para funções algébricas, este não é o atributo que torna esta técnica valiosa na resolução de novos problemas. Em vez disso, o principal benefício da teoria dos sistemas fuzzy é a aproximação do comportamento do sistema onde não existem funções analíticas ou relações numéricas, (Ross, 2004).

Basicamente, a lógica Fuzzy consiste em uma técnica inteligente que tem como objetivo modelar o modo aproximado de raciocínio, imitando a habilidade humana de tomar decisões em um ambiente de incerteza e imprecisão. Devido as suas características intrínsecas, a Lógica Fuzzy é capaz de incorporar tanto o conhecimento objetivo (a partir de dados numéricos) quanto o conhecimento subjetivo (a partir de informações linguísticas).

Segundo Ross (2004), a lógica fuzzy é bastante útil em dois contextos gerais: (1) em situações que envolvem sistemas com um alto grau de complexidade, os quais seus comportamentos não são bem entendidos, e (2) em situações onde a solução é mais rapidamente garantida.

Quando desejamos descrever situações, geralmente acabamos usando conceitos como: pequeno, grande, muito pouco, etc. Estas situações não são nitidamente definidas e não podem ser precisamente descritas. Para descrever um sistema real de forma completa, muitas vezes precisamos de dados extremamente detalhados e muito além do que um ser humano poderia processar e entender. No entanto, grande parte das vezes executamos tarefas complexas que para serem descritas precisam destes termos imprecisos que não podem ser modelados pela matemática tradicional de conjuntos. 


\subsection{1.}

\section{Previsão utilizando lógica Fuzzy}

A metodologia de Lógica Fuzzy quando utilizada para a previsão de séries temporais parte de uma extração de regras específica. Seja $x(k), k=1,2, \ldots$, uma série temporal, o objetivo da previsão é determinar o valor de $\mathrm{x}$ "i" pontos à frente. Ou seja, dada uma janela $x(k-n+1), x(k-n+2), \ldots, x(k)$, com " $n$ " medidas de $x(k)$ devemos determinar $x(k+i)$.

Especificam-se previamente os conjuntos fuzzy dividindo-se a faixa de valores possíveis da série em um número ímpar de conjuntos. Assim, determinase o tamanho $\mathrm{n}$ da janela e o horizonte i de previsão. Para cada regra j são executados, portanto os seguintes procedimentos: (1) determinam-se os graus de pertinência dos elementos de $x(j),(2)$ atribui-se, a cada variável, o conjunto com o maior grau e (3) obtém-se uma regra para cada par entrada-saída.

A determinação do tamanho $\mathrm{n}$ da janela varia dependendo da aplicação, analisam-se quantos e quais valores passados têm mais influência no valor a ser previsto. Dá mesma que forma que o tamanho i do horizonte de previsão é definido em função de quantos valores a frente se deseja fazer a previsão.

O uso de modelos de inteligência artificial tem nos últimos anos se mostrado bastante eficaz em previsões no longo prazo. Khoa et al (2004) utiliza variáveis como o PIB por estado e o Índice de Preços ao Consumidor para a entrada de modelos de redes neurais e redes wavelet.

Srinivas \& Jain (2011) apresentam uma metodologia para a previsão de carga no curto prazo usando a abordagem fuzzy. Para obter a estimativa do dia seguinte, é usada lógica fuzzy para modificar as curvas de carga de dias similares, os quais são obtidos através de uma norma euclidiana em fatores ponderados. É citada a utilidade desta abordagem quando feita em situações em que há rápidas oscilações na carga e temperatura, nestes casos a lógica fuzzy mostra-se em vantagem quando comparada a uma previsão feita via redes neurais, pois a mesma lida melhor com as partes não lineares das curvas de carga, além de lidar melhor também com as grandes mudanças nas variáveis relacionadas ao tempo ou temperatura.

Chow \& Tram (1997) propuseram uma forma geral para utilizar a abordagem de lógica fuzzy para a previsão da distribuição espacial de carga. Foi 
então, proposta uma metodologia para descrever a relação entre as variáveis de entrada e saída. A distância e a preferência foram descritas respectivamente por três e cinco tipos de qualidade ou membros. Com isso, obteve-se a diminuição relevante nos erros de previsão.

Recentemente, vêm surgindo na literatura alguns artigos envolvendo previsão de carga para longo-prazo através da metodologia de lógica Fuzzy. AlHamadi (2011) desenvolveu um modelo de regressão linear fuzzy utilizando fatores de grande influência nas cargas de energia, como valores de carga dos anos passados, população e fatores de crescimento anuais. Este modelo, quando comparado às outras metodologias vistas mais frequentemente na literatura, obteve vantagem significativa nas estatísticas de ajuste das previsões.

Kucukli e Baris (2009) realizaram um estudo de previsão da demanda de energia elétrica anual na Turquia, aplicando a metodologia de lógica fuzzy. Neste estudo, diferentemente de outros, optou-se por explicar a variável dependente de forma univariada, utilizando somente o PIB baseado na paridade do poder de compra.

Como conclusão, Kucukli et al (2009) chegaram em resultados que demonstraram a forte relação entre a demanda de eletricidade e o PIB. Em seu artigo, são citadas como vantagens desta metodologia: (i) o raciocínio humano no processo ser minimizado, (ii) a possibilidade de capturar o comportamento do sistema dinâmico incluindo suas incertezas, (iii) ser basicamente empírico.

Iranmanesh, Abdollahzade, \& Miranian (2011) aplicam uma abordagem híbrida entre um modelo Neuro-Fuzzy linear (LLNF) e um modelo de transformação fuzzy (F-transform) para a previsão de longo prazo do consumo de energia nos EUA e Canada. Os resultados são comparados a uma previsão feita por um modelo Multilayer perceptron (MLP) de redes neurais e mostram a superioridade do modelo proposto, quando a precisão de ambos é testada. O modelo Neuro-Fuzzy se mostra bastante adequado e inovador para as aplicações atuais.

Ghods \& Kalantar (2011) fazem uma análise geral de vários métodos de previsão de demanda de energia elétrica para o longo prazo, passando pelas metodologias mais clássicas até às mais atuais. São analisados métodos como: modelos econométricos, redes neurais, algoritmo genético, wavelet, lógica fuzzy, 
etc. O paper cita a lógica fuzzy como uma metodologia que geralmente retorna um modelo mais preciso em relação aos demais.

Ronald Reagan \& Sari, (2014) utilizam uma abodagem neuro fuzzy para a previsão de carga no longo-prazo do estado de Tamil Nadu na índia. Na metodologia proposta, são consideradas variáveis explicativas como a População, o PIB, a Demanda anual de pico e o consumo total em Tamil Nadu. O erro do modelo é comparado ao final com o de outras metodologias existentes. O resultado final demonstra as evidências do potencial das aplicações destes tipos de modelos para a previsão em ambientes de incerteza que são esperados para horizontes de longo-prazo.

\subsection{2.}

\section{Introdução à técnica}

O entendimento da maioria dos processos físicos é amplamente baseado no impreciso raciocínio humano. Esta imprecisão (quando comparada com os valores precisos requeridos por computadores) não deixa de ser uma forma de informação que pode ser bastante útil para os seres humanos. A capacidade de incorporar tal raciocínio em problemas até então insolúveis e complexos é o critério pelo qual a eficácia da lógica fuzzy é julgada (Ross, 2004).

$\mathrm{Na}$ lógica tradicional os problemas são tratados sempre com a possibilidade de apenas dois estados: verdadeiro (1) ou falso (0). Em grande parte dos casos esta lógica consegue ser suficiente para determinar soluções, entretanto, existem situações em que uma extensão desta lógica é necessária, através de valores intermediários (entre 0 e 1 ).

$\mathrm{Na}$ lógica fuzzy, ao contrário do que ocorre na lógica clássica, o grau de verdade de uma declaração é representado por um número no intervalo [0,1]. Esta característica da lógica fuzzy é útil em muitas situações práticas onde o grau de intensidade de um fenômeno é descrito de maneira imprecisa por meio de variáveis lingüísticas: muito baixo, baixo, médio, alto ou muito alto. Exemplos desta situação são as sentenças temperatura baixa, temperatura normal, temperatura alta, carga leve, carga média e carga pesada, onde a separação entre os conjuntos, por exemplo, normal e alta ou entre leve e média não é precisa. A 
maior contribuição da lógica fuzzy reside justamente no tratamento destas questões lingüísticas por meio de funções de pertinência aos conjuntos fuzzy.

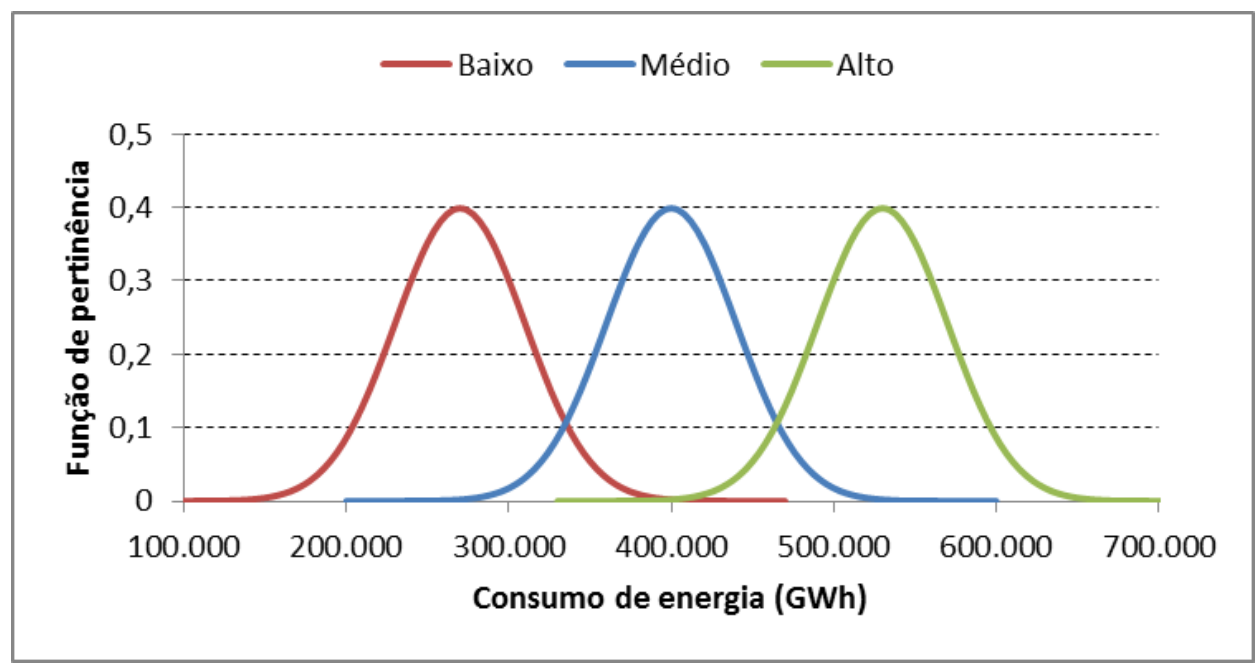

Figura 3.1 - Conjuntos fuzzy e funções de pertinência para a variável consumo de energia. Fonte: O autor (2014).

Na Figura 3.1, é apresentado um exemplo onde a variável consumo de energia no Brasil foi modelada por três conjuntos fuzzy, com funções de pertinência gaussiana, que representam as situações de consumo baixo, médio e alto. Estes três conceitos linguísticos não são delimitados de forma precisa. Esta característica é representada pela sobreposição entre os conjuntos fuzzy para determinadas taxas de consumos. Por exemplo, um consumo de 300.000 GWh é baixa ou médio? A lógica fuzzy responde esta questão atribuindo um grau de pertinência de 0,3 ao conjunto fuzzy de consumo baixo e 0,02 ao conjunto fuzzy consumo médio e desta forma consegue tratar um conceito definido de forma imprecisa.

A teoria dos conjuntos fuzzy e os conceitos de lógica fuzzy podem ser utilizados para traduzir em termos matemáticos a informação imprecisa expressa por um conjunto de regras linguísticas, sentenças fornecidas por um especialista e expressas através de implicações lógicas da forma SE antecedente ENTÃO consequente (Vellasco, 2007), por exemplo: 
Segundo Vellasco (2007) podemos definir a lógica fuzzy como um sistema não-linear de mapeamento de um vetor de entrada em uma saída escalar, capaz de incorporar tanto o conhecimento objetivo quanto o conhecimento subjetivo. Entende-se por conhecimento objetivo tudo que conseguimos quantificar por modelos matemáticos, dados por informações historicas. Ao passo que, conhecimento subjetivo é o que não conseguimos quantificar usando a matemática tradicional, representado geralmente por informações linguisticas como por exemplo qualidades de estado (frio, morno, quente, etc).

Para cada variável linguística, tem-se uma função associada denominada função de pertinência. O papel desta função é determinar o grau de pertinência do valor real da variável em questão em relação ao valor linguístico representado pela função (Klir \& Yuan, 1995).

\subsection{3.}

\section{Função de pertinência}

A lógica fuzzy é bastante útil quando os conjuntos que desejamos trabalhar apresentam certa transição gradual entre os grupos, ou onde o limite entre pertinência e não pertinência não é tão fácil de obter.

O objetivo da função de pertinência é basicamente fazer a correspondência de um valor ou uma variável linguística em conjuntos fuzzy. O valor gerado pela função de pertinência varia no intervalo [0,1], o grau de pertinência 0 significa que o valor não pertence ao conjunto, ao passo que o grau de pertinência 1 indica que o valor é uma representação completa do conjunto.

As funções de pertinência podem ser de diversos tipos (Zimmermann, 2001). Os tipos mais utilizados são triangular, trapezoidal e gaussiana e estão representadas respectivamente pelas equações (3.2), (3.3), (3.4).

$$
A(x)=\left\{\begin{array}{c}
0, \text { se } x<a \\
\frac{x-a}{b-a}, \text { se } x \in[a, b] \\
1, \text { se } x \in[b, c] \\
\frac{d-x}{d-c}, \text { se } x \in[d, c] \\
0, \text { se } x>d
\end{array}\right.
$$




$$
\begin{gathered}
A(x)=\left\{\begin{array}{c}
0, \text { se } x<a \\
\frac{x-a}{m-a}, \text { se } x \in[a, m] \\
1, \text { se } x \in[m, n] \\
\frac{b-x}{b-n}, \text { se } x \in[n, b] \\
0, \text { se } x>b
\end{array}\right. \\
A(x)=e^{-k(x-m)^{2}}
\end{gathered}
$$

A esse processo de mapear o valor real de uma variável do sistema para valores do conjunto fuzzy, ou seja, calcular o grau de pertinência da variável do mundo real para cada uma das variáveis linguísticas consideradas, dá-se o nome de fuzzificação (Zimmermann, 2001).

\subsection{4.}

\section{O sistema fuzzy}

O processo de inferência fuzzy avalia os níveis de compatibilidade das variáveis de entradas com os antecedentes das várias regras, ativando os conseqüentes com intensidades proporcionais aos mesmos. O resultado desta operação é um conjunto fuzzy que é convertido em um número, a resposta do sistema de inferência fuzzy. A estrutura básica de um sistema fuzzy é ilustrada na Figura 3.2 a seguir:

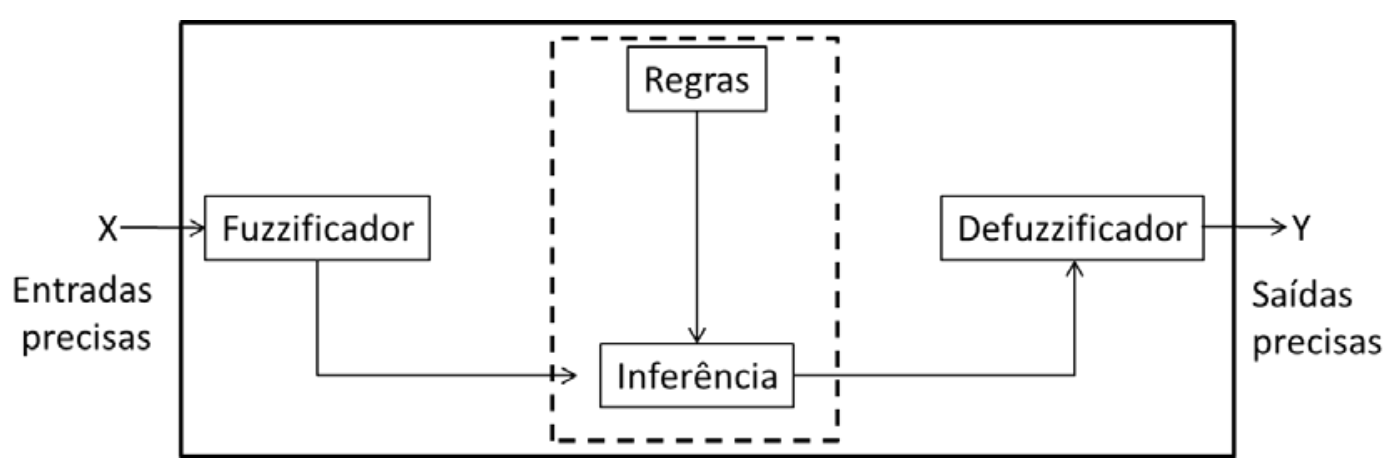

Figura 3.2 - Arquitetura geral de um sistema fuzzy.

Fonte: adaptado de Vellasco (2007). 
Primeiramente, na etapa do fuzzificador é feita a transformação das variáveis de entrada do problema em valores fuzzy. É aplicada uma função de pertinência para cada valor de entrada e um respectivo grau de pertinência é retornado.

Na etapa de regras, a extração destas pode ser fornecida por especialistas ou através de padrões dos dados numéricos. Nesta etapa, o conhecimento subjetivo é de grande importância, pois através das variáveis linguísticas é possível nomear os conjuntos e ainda qualificá-los, fazendo com que a modelagem do sistema se torne cada vez mais próxima da realidade.

Na inferência, as regras são aplicadas sobre os valores de entrada já fuzzificados, fazendo o mapeamento dos conjuntos fuzzy. Nesta etapa também é determinado como as regras são ativadas e combinadas, e é criada a região resultante da aplicação das regras.

Finamente, na etapa do defuzzificador as regiões resultantes da inferência são convertidas em valores para a variável de saída do sistema. Esta etapa corresponde à ligação funcional entre as regiões Fuzzy e o valor esperado do sistema.

Um exemplo de sistema de inferência fuzzy é ilustrado na Figura 4.3 por meio de um sistema tipo Mandani com duas regras, cujos antecedentes são definidos pela composição de dois conjuntos fuzzy A e B e que representam o comportamento das variáveis de entrada x e y respectivamente. Cada regra oferece como resposta um conjunto fuzzy de saída C:

$$
\begin{aligned}
& \text { se x é A1 e y é B1 então } z=C 1 \\
& \text { se x é A2 e y é B2 então } z=C 2
\end{aligned}
$$




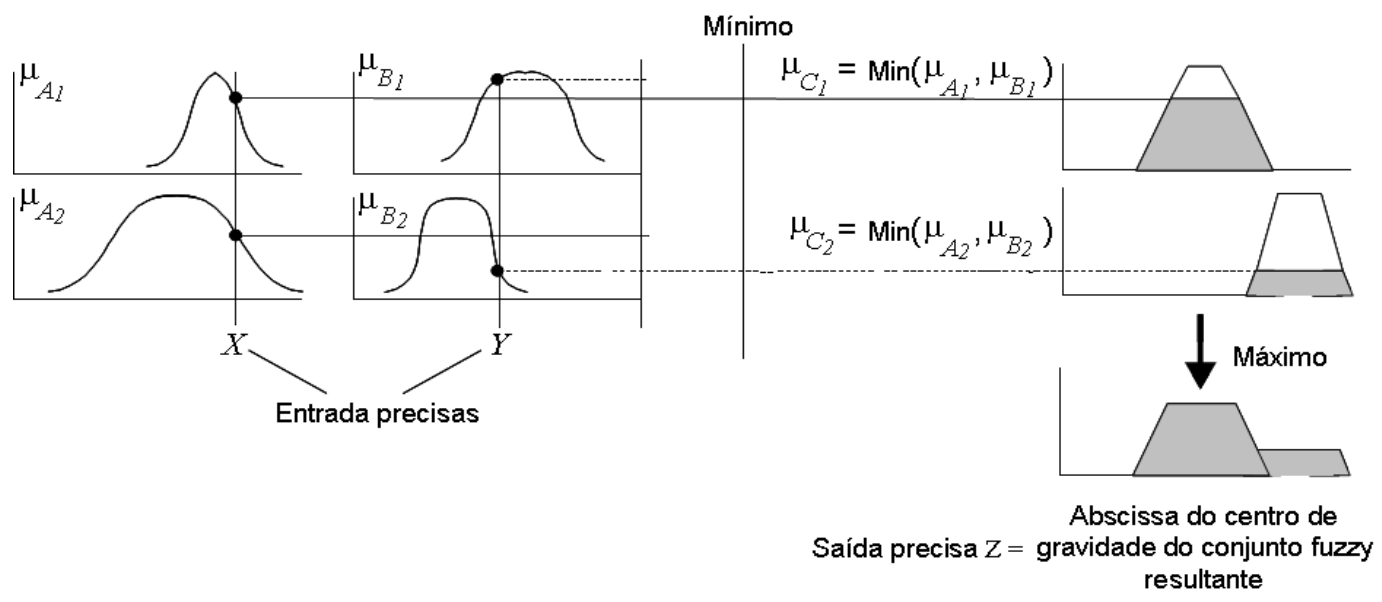

Figura 3.3 - Modelo Mandani.

Fonte: Jang, Sun, \& Mizutani (1997).

No modelo Mandami o processamento é denominado inferência Max-Min e corresponde às operações de união e interseção fuzzy (operadores máximo e mínimo). Os antecedentes de cada regra são processados por meio da interseção fuzzy, gerando um grau de disparo que limitará os valores máximos dos conjuntos de saída. Por exemplo, na Figura 3.3 o valor preciso da variável X tem pertinência $\mu_{\mathrm{A} 1}$ no conjunto fuzzy A1 e o valor da variável Y tem pertinência $\mu_{\mathrm{B} 1}$ no conjunto fuzzy B1. Assim, o cálculo das pertinências das variáveis de entrada nos conjuntos fuzzy é feito na etapa do fuzzificador, que converte os valores precisos das variáveis de entrada em uma representação das mesmas em termos de conjuntos nebulosos.

Pela inferência Max-Min o grau de ativação da regra é $\min \left(\mu_{\mathrm{A} 1}, \mu_{\mathrm{B} 1}\right)$ que neste caso é $\mu_{\mathrm{A} 1}$. A composição de todas as regras disparadas (ou ativadas) é realizada através da operação de união fuzzy que gera o conjunto fuzzy de saída.

Para obter uma saída precisa deve-se proceder à defuzzyficação do conjunto de saída. Há diversos métodos para realizar a transformação dos conjuntos fuzzy de saída em valores numéricos, tais como a Média dos Máximos e o Centro de Massa (também denominado Centro de Gravidade ou Centróide). 


\subsection{5.}

\section{Aplicação para séries temporais}

Com base nestes conceitos Wang \& Mendel (1992) propõem um algoritmo para extração das regras fuzzy a partir de dados numérico para uso, inclusive, em previsão de séries temporais.

Seja uma série temporal dada por $x(k), k=1,2, \ldots$, e supondo uma janela de tamanho n devemos fazer previsões i pontos a frente. Ou seja, dada uma janela $x_{k-}$ $n+1, x_{k-n+2}, \ldots, x_{k}$, com " $n$ " medidas de $x_{k}$ devemos determinar $x_{k+i}$ O método sugere uma seqüência de 5 passos para geração de regras fuzzy:

1) Divida os dados de entrada e de saída em conjuntos fuzzy: Para exemplificar foi modela a série histórica anual da variação do PIB Brasil, conforme ilustrado na figura 3.4. Assim, considere a repartição da série temporal em cinco conjuntos difusos, conforme ilustrado. Os conjuntos devem ser sobrepostos. Cada conjunto é associado a uma função de pertinência, neste caso funções gaussianas, que tem a finalidade de mapear o vetor de entrada. A partir do mapeamento serão definidos, posteriormente, os pares de dados que representarão a entrada (janela de previsão) e a saída (alvo).
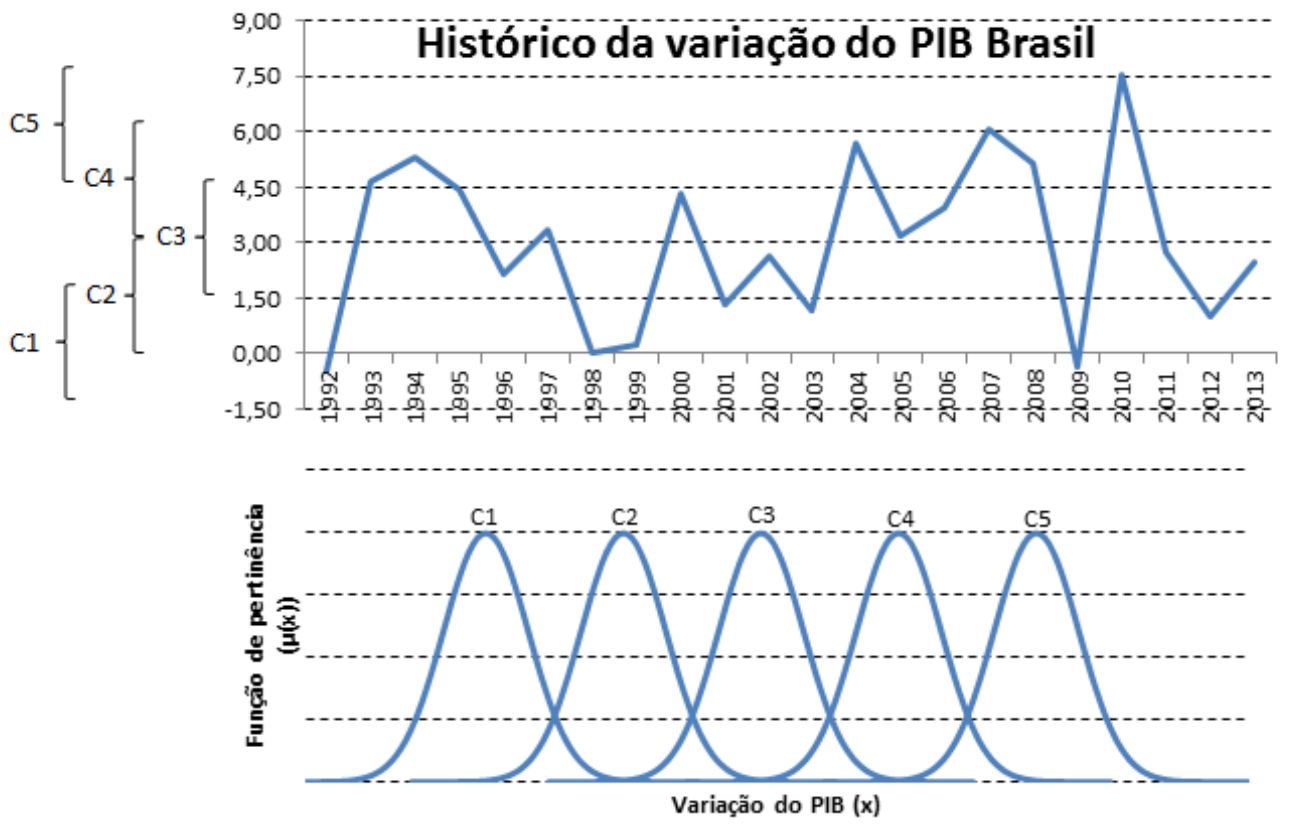

Figura 3.4 - Divisão dos intervalos de domínio em conjuntos fuzzy da série histórica do PIB Brasil.

Fonte: IBGE e o autor (2014). 
2) Construa pares entrada/saída e gere as regras fuzzy: Para geração de pares entrada/saída considere uma janela de entrada formada por valores passados e uma janela de saída com os valores futuros, por exemplo, considere uma janela de entrada de tamanho $3\left(z_{t-2}, z_{t-1}, z_{t}\right)$ e uma janela de saída de tamanho 1 (previsão um passo à frente, $z_{t+1}$, conforme ilustrado na Figura 3.5.

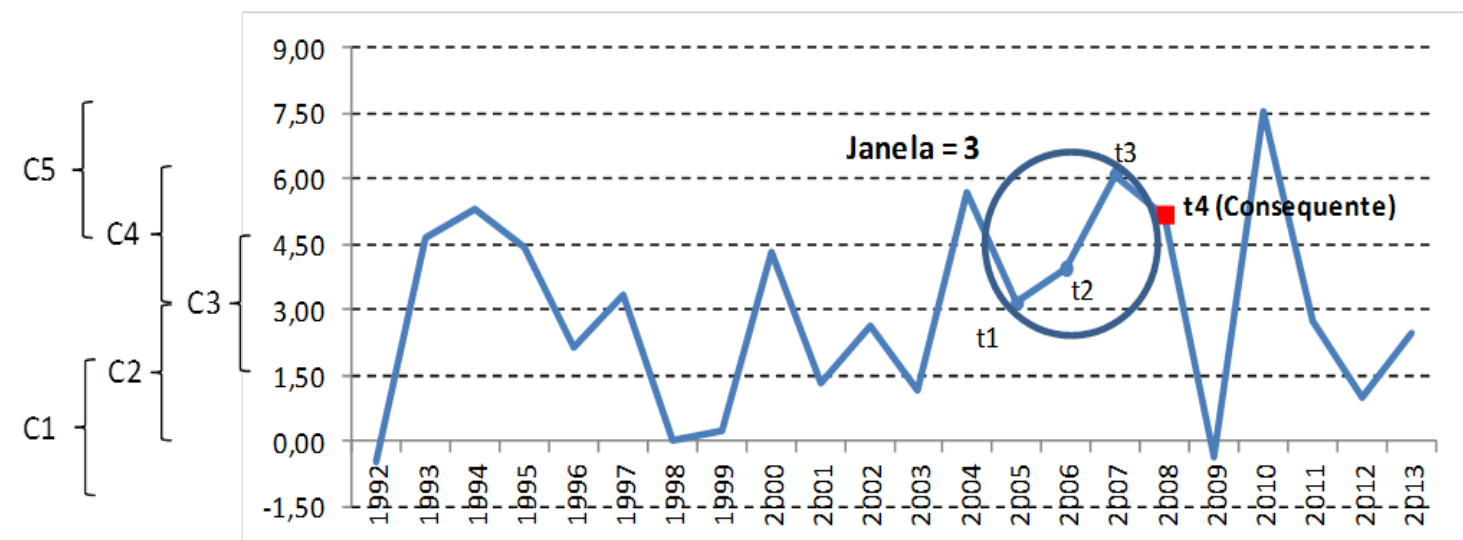

Figura 3.5 - Mapeamento das variáveis de entrada e saída.

Fonte: o autor (2014).

Cada variável da janela de entrada ou de saída pode ativar até dois conjuntos fuzzy (Figura 3.6). Neste caso, as variáveis associadas aos instantes t1, t2 ativam os conjuntos C3 e C4, enquanto as variáveis associadas ao instante t3 ativam o conjunto C5. Sejam x1, x2, x3 e x4 os valores da série temporal nos instantes t1, t2, t3 e t4 respectivamente. Cada valor tem um determinado grau de pertinência nos conjuntos fuzzy ativados, por exemplo, no instante $\mathrm{t} 1$, $\mathrm{x} 1$ tem pertinência 0,4 no conjunto C1 e pertinência 0,02 no conjunto C2. Já x2 tem pertinência 0,14 em C4 e pertinência 0,08 em C3. Um resumo das pertinências é apresentado na Tabela 3.1. 


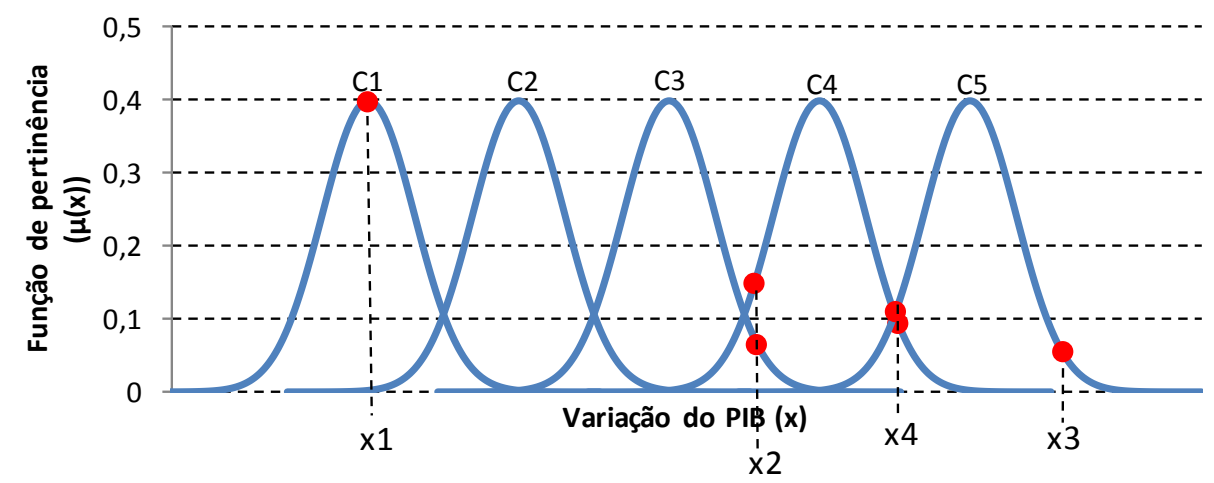

Figura 3.6 - Ativação dos conjuntos fuzzy.

Fonte: o autor.

Quadro 3.1 - Pertinências das variáveis de entrada e saída aos conjuntos fuzzy ativados.

\begin{tabular}{|l|r|r|r|r|}
\hline & \multicolumn{1}{|c|}{ x1 } & \multicolumn{1}{c|}{ X2 } & \multicolumn{1}{c|}{ X3 } & \multicolumn{2}{c|}{ X4 } \\
(Consequente)
\end{tabular}

Fonte: Ribeiro (2009).

Para cada variável de entrada e saída, o método calcula o grau de ativação da função de pertinência correspondente e seleciona a maior delas. Portanto, neste caso, o antecedente é formado pela sequência C1, C3, C5 e o consequente é definido pelo conjunto C4.

A geração de regras nebulosas é realizada por meio de sentenças do tipo:

$$
\text { Se < antecedentes }>\text { Então <consequente }>
$$

onde as variáveis de entrada são designadas como antecedentes e a variável de saída como consequente, então, para o exemplo proposto a regra gerada é: 
3) Atribua um grau à cada regra gerada: O grau de pertinência de uma regra é definido pelo produto das pertinências de todos os antecedentes e dos respectivos consequentes, neste caso: $0,4 \times 0,14 \times 0,07 \times 0,11=0,00043$.

4) Construa uma base de regras: Todas as regras geradas são armazenadas em uma base de conhecimento de onde as regras conflitantes (mesmos antecedentes) são excluídas, sendo preservadas aquelas que possuem maior grau.

5) Previsão de valores futuros (deffuzyficação): Para a previsão de valores futuros, os dados de entrada são recebidos e a base de regras previamente construída é aplicada, onde um processo de defuzzificação combina as saídas das regras ativadas e calcula o valor previsto pelo método do centro de gravidade. Maiores detalhes sobre o algoritmo em questão podem ser obtidos em (Wang \& Mendel, 1992).

$$
Z_{t+1}=\frac{\sum_{i=1}^{k} \mu\left(\text { antecedentes }_{i}\right) \cdot \bar{y}_{l}}{\sum_{i=1}^{k} \mu\left(\text { antecedentes }_{i}\right)}
$$

Onde $\mu$ (antecedentes) é o produto das pertinências de todas as variáveis que formam o antecedente da i-ésima regra, k é o número de regras ativadas pelo padrão de entrada e $\overline{y_{l}}$ é o centro de gravidade do conjunto fuzzy do conseqüente ativado pela i-ésima regra.

Em resumo, os quatro primeiros passos são responsáveis pela geração da base de regras e compõem a chamada etapa de treinamento ou extração de regras. O quinto passo realiza, a partir da base de regras gerada, a previsão dos dados propriamente dita. 


\section{4.}

\section{Modelos de séries temporais}

Para este estudo, com o intuito de comparar os modelos fuzzy estimados, iremos nos limitar a trabalhar com o modelo Holt de dois parâmetros.

O método Holt - 2 - parâmetros, representa um dos tipos de modelo dentro dos métodos de amortecimento exponencial para séries não sazonais. Considerando o modelo geral:

$$
Z=\mu(t)+\varepsilon_{\tau}
$$

Onde, $\varepsilon_{\tau}$ : ruído de média zero e variância $\sigma_{\varepsilon}^{2}$ e $\mu(t)=\alpha_{1}+\alpha_{2 t}$ (modelo linear)

Sejam as constantes de amortecimento $\alpha$ (nível: $\alpha_{1}$ ) e $\beta$ (crescimento: $\alpha_{2}$ ), onde $0<\alpha<1$ e $0<\beta<1$. A equação de previsão do modelo é dada por:

Onde deslocamos a origem $(\mathrm{T}=0)$ sem perda de generalidade.

Assim, a atualização dos parâmetros é feita da seguinte forma:

$$
\begin{gathered}
\hat{a}_{1}(T)=a Z_{T}+(1-a)\left[\hat{a}_{1}(T-1)+\hat{a}_{2}(T-1)\right] \\
\hat{a}_{2}(T)=\beta\left[\hat{a}_{1}(T)-\hat{a}_{1}(T-1)\right]+(1-\beta) \hat{a}_{2}(T-1)
\end{gathered}
$$

Para a previsão do modelo Holt com crescimento amortecido (Damped trend), supondo $0<\varphi<1$ a constante de amortecimento do crescimento, a previsão amortecida é dada por:

$$
\hat{Z}_{T}(\tau)=\hat{a}_{1}(T)+\left[\sum_{i=1}^{\tau} \varphi^{i}\right] \hat{a}_{2}(T)
$$

Com a atualização dos parâmetros feita da forma explicitada a seguir: 


$$
\hat{a}_{1}(T)=a \frac{z_{T}}{\hat{C}_{m(T)}(T-1)}+(1-a)\left[\hat{a}_{1}(T-1)+\hat{a}_{2}(T-1)\right]
$$

Onde, $\hat{C}_{m(T)}(T)=\gamma \frac{z_{T}}{\hat{a}_{1}(T)}+(1-\gamma) \hat{C}_{m(T)}(T-1)$, tal que: $\hat{C}_{j}(T)=\hat{C}_{j}(T-1)$; $J=1,2, \ldots, L ; J \neq m(T)$

E o parâmetro $\hat{a}_{2}(T)$ atualizado de forma análoga à equação $3.9, \operatorname{com} \alpha, \beta$, $\gamma$ sendo constantes de amortecimento assumindo valores entre 0 e 1 .

\section{5 .}

\section{Qualidade de ajuste}

De forma a testar a adequabilidade do modelo final, algumas estatísticas serão usadas para a análise de significância. Para se chegar ao melhor modelo central gerado através do sistema fuzzy, serão comparados modelos com diferentes tamanhos de janela e regiões. A conclusão do melhor modelo se dará pela análise dos resíduos através das seguintes estatísticas de ajuste:

Erro Absoluto Médio Porcentagem (MAPE)

$$
M A P E=\frac{1}{n} \sum_{t=1}^{n} \frac{\left|Y_{t}-\hat{Y}_{t}\right|}{Y_{t}},
$$

Onde $Y_{t}$ é o valor realizado da variável resposta no tempo t, $\hat{Y}_{t}$ sua respectiva previsão e $n$ o tamanho da amostra utilizada.

Erro Absoluto Médio (MAE)

$$
M A D=\frac{1}{n} \sum_{t=1}^{n}\left|Y_{t}-\hat{Y}_{t}\right|
$$

Para os modelos de séries temporais, além das análises feitas a partir das funções de autocorrelação e autocorrelação parcial, a definição do melhor modelo se dará através da comparação da estatística R Quadrado.

Para a validação do modelo final, serão feitos backtests do tipo out-ofsample, com o objetivo de identificar a precisão dos modelos sugeridos. Serão geradas amostras dos dados retirando a cada etapa um período anual determinado para que uma nova estimação do modelo seja gerada, nos dando assim, sempre duas amostras nesta fase de validação: uma amostra para o treinamento do modelo 
e outra para o teste. Feito isso, as projeções de cada modelo serão comparadas com os valores observados na amostra de teste. No final, o modelo com o melhor resultado no backtest será comparado com a formulação econométrica existente.

Tendo compreendido melhor a respeito da principal técnica a ser utilizada no estudo, o próximo capítulo traz ao leitor uma descrição da base de dados com todas as fontes e limitações encontradas assim como, uma breve análise exploratória dos dados. 


\section{3 \\ Análise exploratória e descrição da base}

\section{1. \\ Descrição da base}

A base de consumo de energia elétrica por classes foi obtida no portal do IPEA, cujos dados tem como fonte o boletim SIESE da Eletrobrás. Foram considerados dados de consumo a partir de 1979 até 2013 totalizando 35 observações das variáveis dependentes de consumo total Brasil e consumo por classe.

Para representar o PIB Brasil, foi utilizada para o histórico, a série de variação real anual do PIB Brasil total desde 1901 e com ano referência de 2000. Os dados têm como fonte o Sistema de Contas Nacionais de 2000 do Instituto Brasileiro de Geografia e Estatística (IBGE/SCN 2000 Anual).

Para o PIB Industrial, foi utilizada a série de variação real anual do valor adicionado a preços básicos também do Sistema de Contas Nacionais de referência do ano 2000 do IBGE.

Os cenários das variáveis representativas do PIB Brasil e industrial foram estimados com base em conjecturas da literatura. O PIB Brasil é dado pela variação real anual desde 2015 até 2030, sendo que para o ano de 2014 foi utilizado como cenário a projeção oficial mais recente do Banco Central.

Já o PIB industrial é dado pela variação da média das projeções dos valores adicionados da indústria geral e de transformação, também na mesma periodicidade citada. Para se determinar o valor de 2014, foi estimada uma regressão linear simples entre as variáveis PIB Brasil (variável explicativa) e PIB industrial (variável resposta).

Na variável população foi utilizada a taxa de crescimento anual calculada a partir de estimativas das populações residentes em nível municipal, calculadas com data de referência em $1^{\circ}$ de julho de cada ano civil. A fonte dos dados é da Projeção da População por Sexo e Idade do IBGE para o Período 1980 até 2050 com revisão de 2008. 
Sendo assim, com o objetivo de padronizar a base de dados na mesma periodicidade para as futuras análises de validação, a base de dados usada na primeira etapa de modelagem (modelos univariados) é com base em 1979 até 2030 e a base utilizada para a segundo etapa (modelos causais) e com base em 1980 até 2030, pelo fato da variável de população residente estar limitada a este período. O quadro 4.1 traz um resumo das variáveis utilizadas na base de dados deste estudo

Quadro 4.1 - Resumo das variáveis consideradas no estudo.

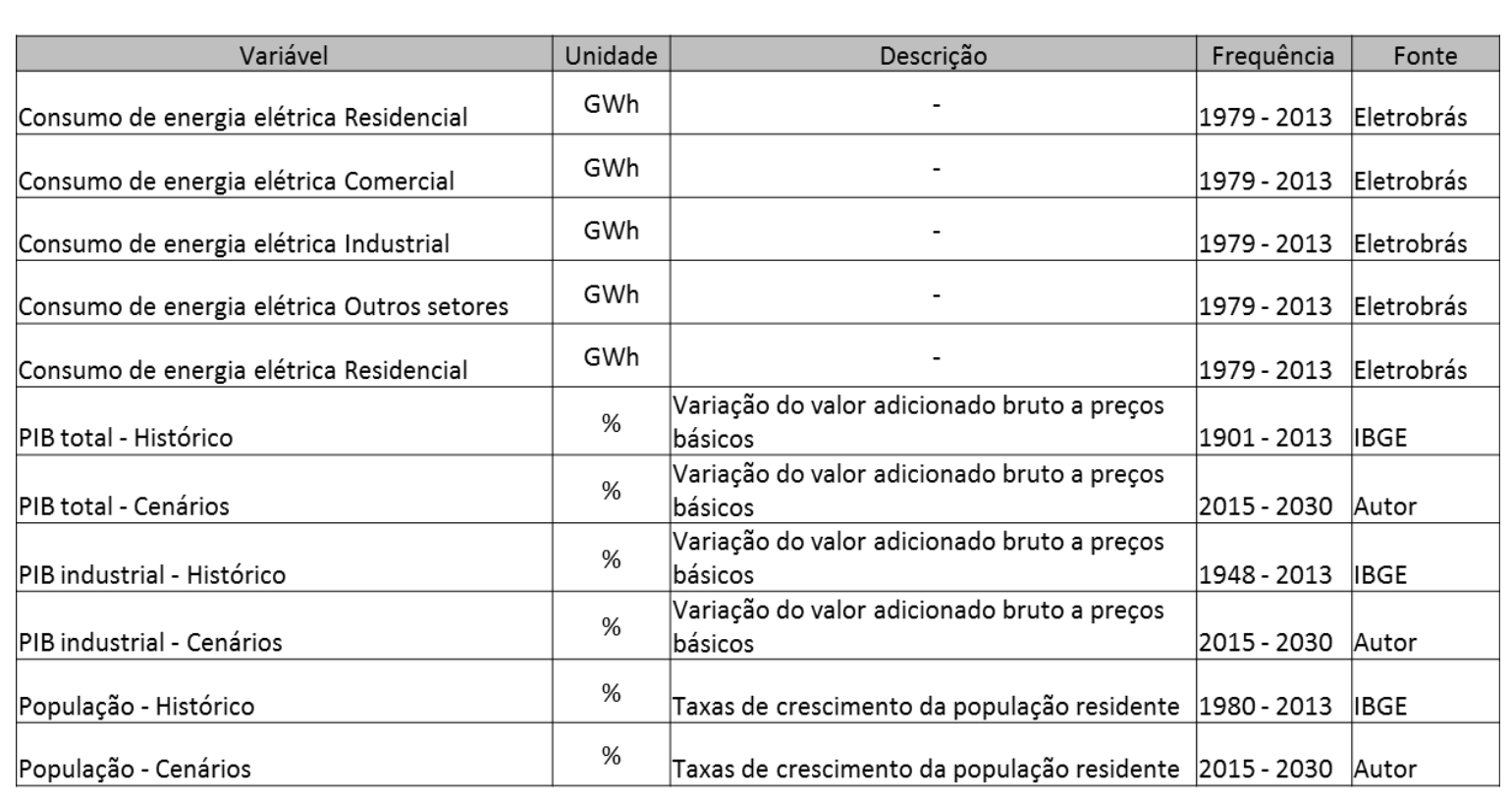

Fonte: o autor (2014).

\section{2.}

\section{Análise de tendência e sazonalidade}

\subsection{1.}

\section{Análise de tendência}

Tendo em vista que a aplicação de um modelo de lógica fuzzy tem como premissa a definição de grupos por patamar de valores da série. É quase que uma condição para se obter maior eficiência da metodologia, que a série em questão seja estacionária.

Para a análise da componente de tendência nas séries de consumo de energia elétrica, foi analisado o número de diferenças necessárias para a estacionariedade 
das séries em questão. A figura 4.1 representa o gráfico das séries de consumo por classes.

\section{Consumo de energia elétrica por setores}

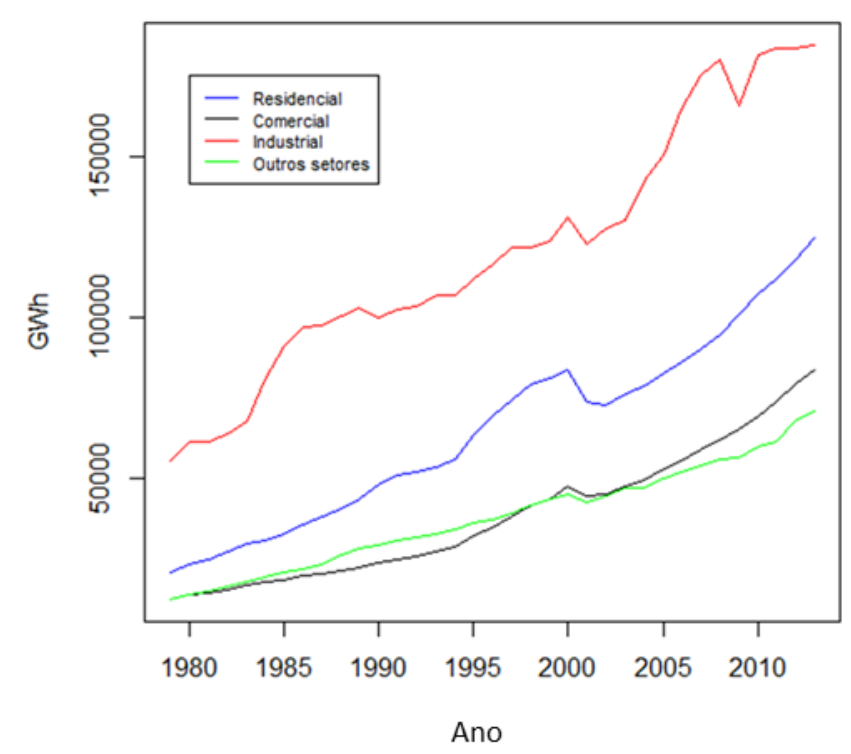

Figura 4.1 - Séries de consumo de energia elétrica por classes de consumo.

Fonte: uww.ipeadata.gov.br/.

Pode-se observar uma quebra de estrutura nas séries no ano de 2001, que pode ser explicada pelo plano de racionamento imposto pelo governo na época, o qual incentivava uma redução de $20 \%$ no consumo de energia. É possível notar também a presença de um decaimento abrupto principalmente na serie de consumo industrial no final de 2008 para 2009, o qual pode ser explicado pela crise econômica ocorrida na época.

A componente de tendência é evidente através da análise gráfica das séries. É possível notar o alto crescimento da variável de consumo de energia elétrica, para eliminar esta componente das séries, foi aplicada uma diferença em cada uma das séries conforme pode ser observado na figura 4.2. 

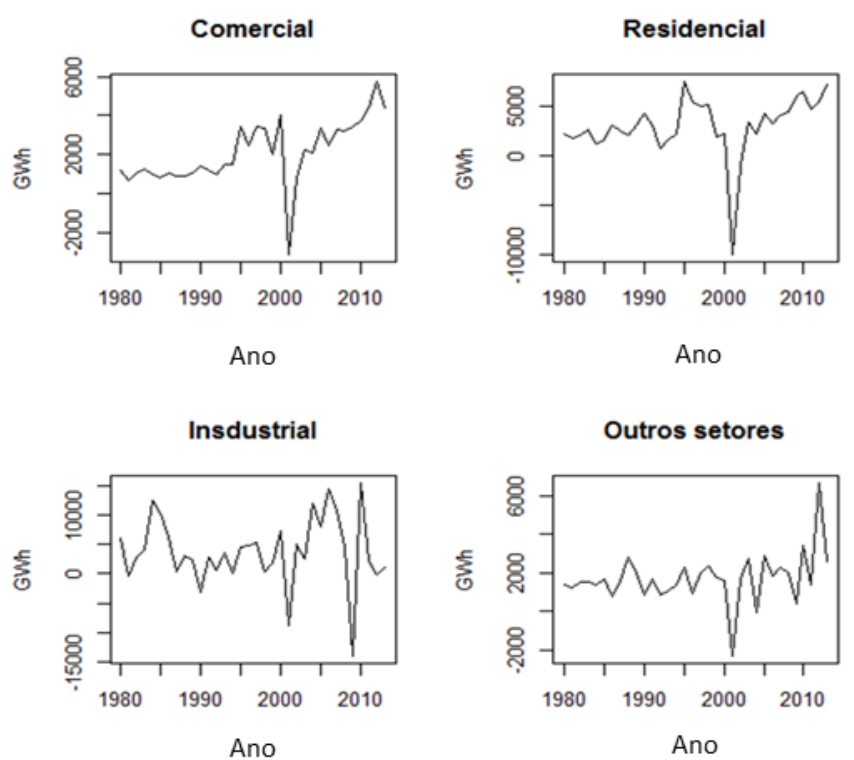

Figura 4.2 - Séries de consumo de energia elétrica por classes com a aplicação de uma diferença.

Fonte: o autor (2014).

\subsection{2. \\ Decomposição dos fatores sazonais}

Para a análise da componente de sazonalidade foi estimado um modelo de Holt-Winters de fatores sazonais multiplicativos com o objetivo de definir o valor para cada um destes fatores mensais. O quadro 4.2 apresenta os valores estimados para as series das classes de consumo.

Quadro 4.2 - Fatores sazonais multiplicativos por classes de consumo.

\begin{tabular}{|l|r|r|r|r|r|}
\hline \multirow{2}{*}{ Mês } & \multicolumn{5}{|c|}{ Fator sazonal } \\
\cline { 2 - 6 } & Nordeste & Norte & \multicolumn{1}{c|}{ Sul } & $\begin{array}{c}\text { Centro-Oeste e } \\
\text { Sudeste }\end{array}$ & Total Brasil \\
\hline Janeiro & 1,00 & 1,03 & 0,99 & 0,99 & 1,02 \\
\hline Fevereiro & 1,02 & 1,22 & 0,99 & 0,98 & 0,99 \\
\hline Março & 0,99 & 1,13 & 0,96 & 0,95 & 0,97 \\
\hline Abril & 0,96 & 1,06 & 0,97 & 0,95 & 0,98 \\
\hline Maio & 0,92 & 1,01 & 0,97 & 0,94 & 0,99 \\
\hline Junho & 0,97 & 1,02 & 1,00 & 0,98 & 0,97 \\
\hline Julho & 1,00 & 1,03 & 1,00 & 1,01 & 0,97 \\
\hline Agosto & 1,04 & 0,80 & 1,05 & 1,04 & 0,99 \\
\hline Setembro & 1,10 & 0,92 & 1,00 & 1,05 & 1,01 \\
\hline Outubro & 0,99 & 1,01 & 1,02 & 1,03 & 1,02 \\
\hline Novembro & 1,00 & 1,01 & 1,02 & 1,03 & 1,07 \\
\hline Dezembro & 1,01 & 0,98 & 1,02 & 1,03 & 1,04 \\
\hline
\end{tabular}

Fonte: o autor (2014). 
A figura 4.3 demonstra o comportamento destes fatores para cada mês. Pode-se observar que o pico de maior fator para as séries das classes acontece geralmente entre Julho e Agosto enquanto que o menor valor é geralmente ocorrido no mês de Novembro.

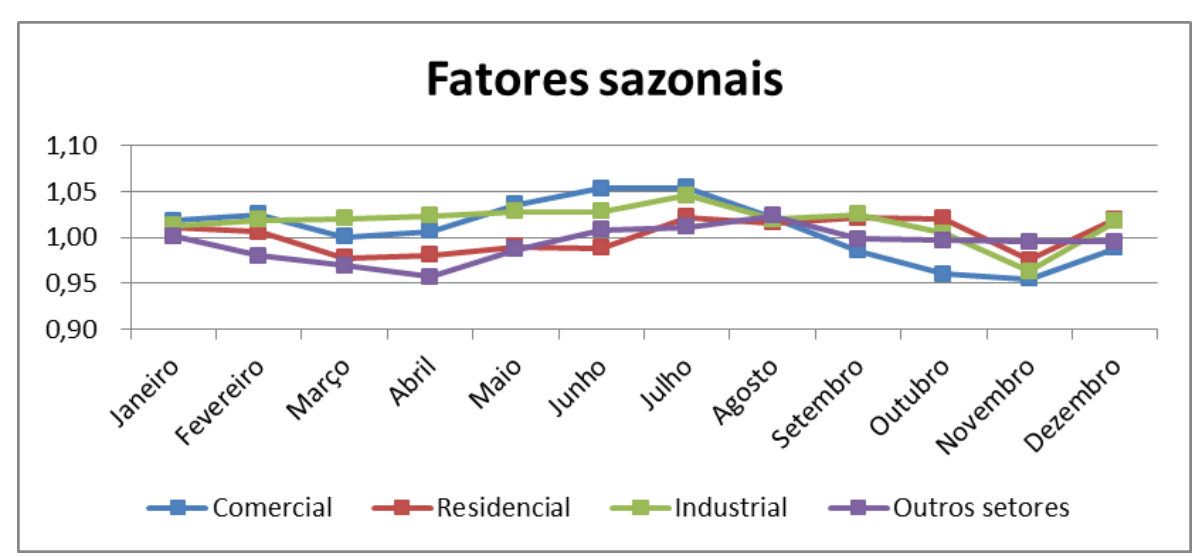

Figura 4.3 - Fatores sazonais multiplicativos por classes de consumo.

Fonte: o autor (2014).

O próximo capítulo trata do desenvolvimento principal deste estudo, trazendo ao leitor a especificação dos modelos utilizados, assim como, suas aplicações e resultados. 


\section{4}

\section{Aplicação e resultados dos modelos propostos}

\section{1. \\ Especificação dos modelos}

Com o objetivo de comparação, serão apresentadas diferentes modelagens do problema, de modo que cada modelo possa ter seu potencial diferido através de suas estatísticas de ajuste. Serão apresentados os seguintes modelos:

- Modelo Holt com dois parâmetros

- Modelo Fuzzy univariado

- Modelos Fuzzy causais

- Modelo Total Brasil

- Modelos por classes de consumo

Os dois primeiros modelos serão estimados somente para a série do total Brasil, enquanto que, ao aprofundarmos mais os modelos fuzzy, incluindo novas variáveis causais, estes serão usados também para a abordagem das séries dos totais Brasil segregados por classes de consumo.

Para a estimação dos modelos, foi utilizado o software R (versão 3.1.2) através dos pacotes stats, forecast e principalmente o pacote frbs (modelos de lógica de fuzzy). As tabelas expostas neste estudo foram geradas no software Microsoft Excel 2010.

Como citado anteriormente, para que a previsão de séries temporais com o uso de lógica fuzzy seja possível, é necessário que as séries de cada variável utilizada não apresentem tendência. Sendo assim, cada variável abordada foi diferenciada e posteriormente normalizada, de modo que, seus parâmetros fossem distribuídos no intervalo $[0,1]$.

A previsão feita a partir dos modelos é multi-step, ou seja, foram realizadas previsões com mais de um passo a frente. 


\section{2.}

\section{Modelo Holt com dois parâmetros}

Feita a análise dos fatores sazonais da série, os dados são agrupados em valores anuais para que se obtenham as previsões no horizonte até 2030. O modelo Holt com dois parâmetros considera somente duas componentes da série: nível e tendência. A estimativa destes componentes pode ser observada graficamente na figura 5.1, a qual demonstra a desagregação da série do total Brasil por estes fatores. Feitas estas estimativas são geradas os ajustes dos modelos e os valores observados são comparados com os valores ajustados. A figura 5.2 traz a comparação para as séries de classes de consumo.

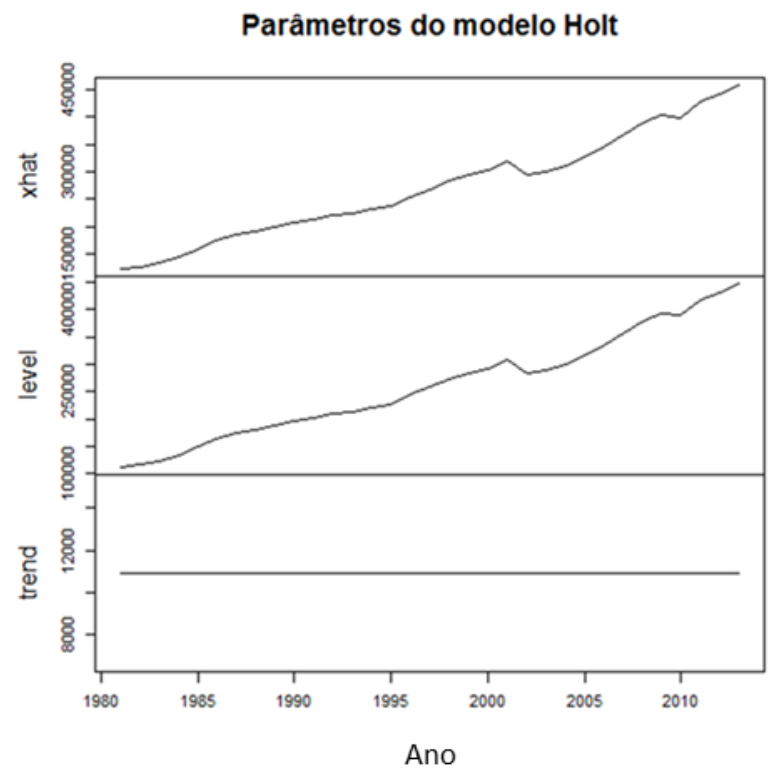

Figura 5.1 - Gráfico das componentes do modelo Holt para o total Brasil.

Fonte: o autor (2014). 

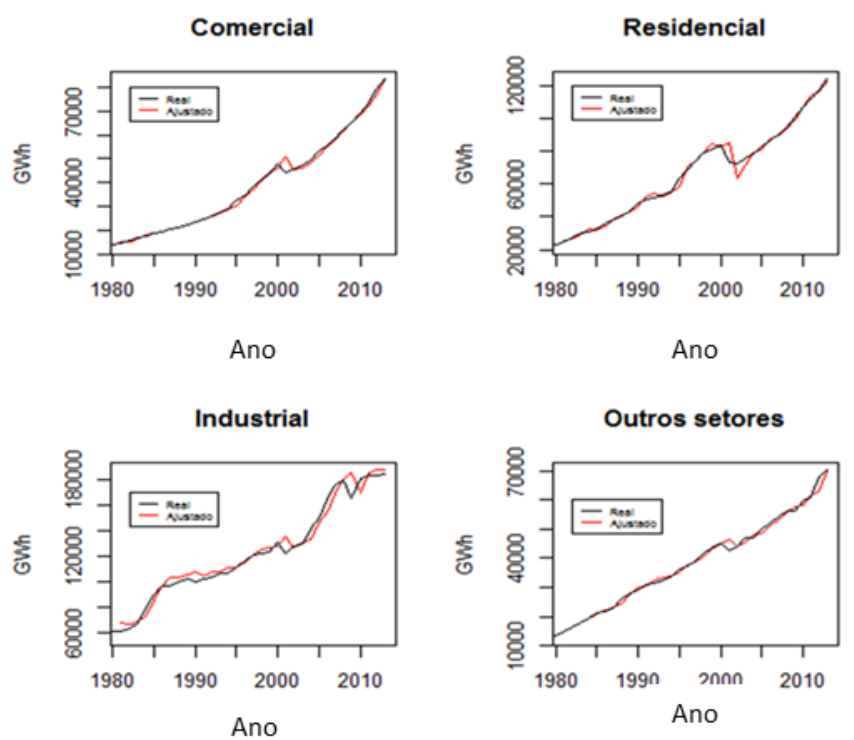

Figura 5.2 - Valores ajustados $x$ realizados do modelo Holt para classes de consumo.

Fonte: o autor (2014).

Pode-se observar que o ajuste inicial proposto pelo modelo Holt com dois parâmetros se demonstra adequado quando comparado aos valores reais das séries. O quadro 5.1 e a figura 5.3 trazem respectivamente os valores das previsões para a série do total Brasil no horizonte de 2030 e o gráfico das previsões deste modelo para as séries de consumo por classe

Quadro 5.1 - Previsões do modelo Holt para o total de consumo no Brasil.

\begin{tabular}{|l|r|r|r|}
\hline Ano & $\begin{array}{l}\text { Previsão-Total } \\
\text { Brasil (GWh) }\end{array}$ & Ano & $\begin{array}{l}\text { Previsão - Total } \\
\text { Brasil (GWh) }\end{array}$ \\
\hline $\mathbf{2 0 1 4}$ & 474588 & $\mathbf{2 0 2 3}$ & 572769 \\
\hline $\mathbf{2 0 1 5}$ & 485497 & $\mathbf{2 0 2 4}$ & 583678 \\
\hline $\mathbf{2 0 1 6}$ & 496406 & $\mathbf{2 0 2 5}$ & 594587 \\
\hline $\mathbf{2 0 1 7}$ & 507315 & $\mathbf{2 0 2 6}$ & 605496 \\
\hline $\mathbf{2 0 1 8}$ & 518224 & $\mathbf{2 0 2 7}$ & 616405 \\
\hline $\mathbf{2 0 1 9}$ & 529133 & $\mathbf{2 0 2 8}$ & 627314 \\
\hline $\mathbf{2 0 2 0}$ & 540042 & $\mathbf{2 0 2 9}$ & 638223 \\
\hline $\mathbf{2 0 2 1}$ & 550951 & $\mathbf{2 0 3 0}$ & 649132 \\
\hline $\mathbf{2 0 2 2}$ & 561860 & & \\
\hline
\end{tabular}

Fonte: o autor (2014). 

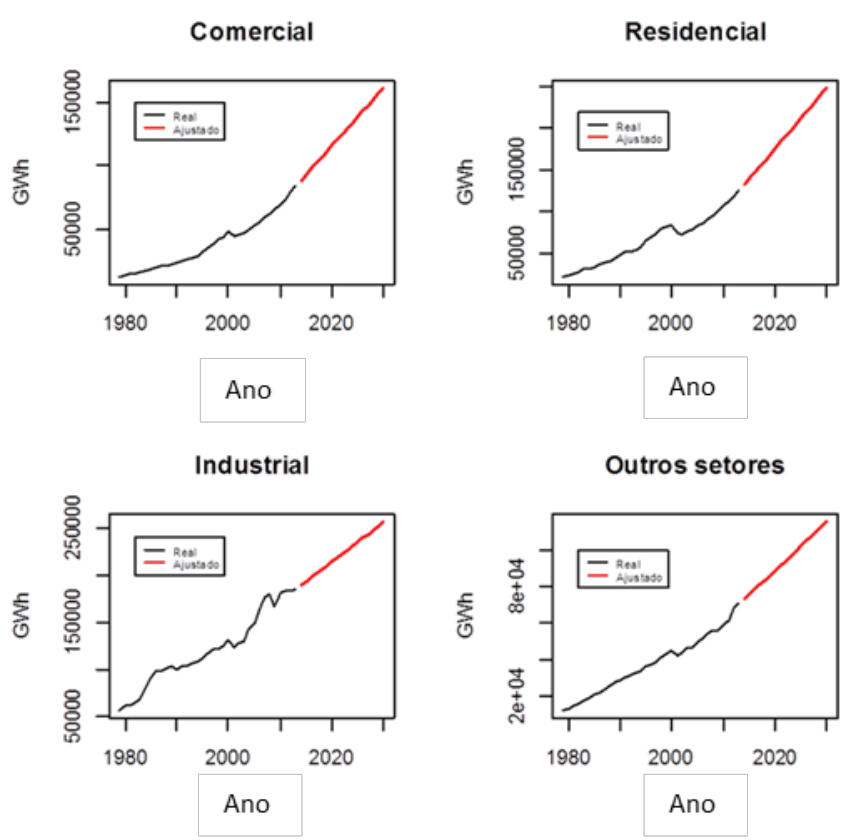

Figura 5.3 - Gráfico das previsões do modelo de Holt por classes de consumo.

Fonte: o autor (2014).

\section{3.}

\section{Modelo Fuzzy univariado}

Para a determinação do modelo fuzzy foram considerados como parâmetros de análise do modelo o número de antecedentes, o total de conjuntos fuzzy e o tipo de função de pertinência a ser usada nos conjuntos. Para se chegar ao melhor modelo, foram estimados nesta primeira etapa modelos com cinco conjuntos fuzzy fixos, representando os seguintes cenários de crescimento: muito baixo, baixo, moderado, alto e muito alto. Para cada um destes conjuntos foram utilizadas funções pertinência do tipo gaussiana. Quanto ao tamanho das janelas do modelo, foram testadas janelas variando de 3 à 5 antecedentes.

De modo a comparar os modelos através de estatísticas de ajuste foi feita uma partição na amostra da serie dividindo-a em uma amostra de treinamento com observações de 1979 a 2003 (25 observações) e uma amostra de validação com observações de 2004 a 2013 (10 observações). Assim a amostra de treinamento é utilizada para a estimação do modelo e a amostra de validação é utilizada para a comparação com as previsões dez passos à frente do modelo obtido na amostra de treinamento. 
As figuras 5.4, 5.5 e 5.6 demonstram respectivamente para os diferentes tamanhos de janela, a comparação dos valores reais e estimados para a amostra de validação. Foram comparados também os resultados da estatística MAPE para cada modelo apresentado.

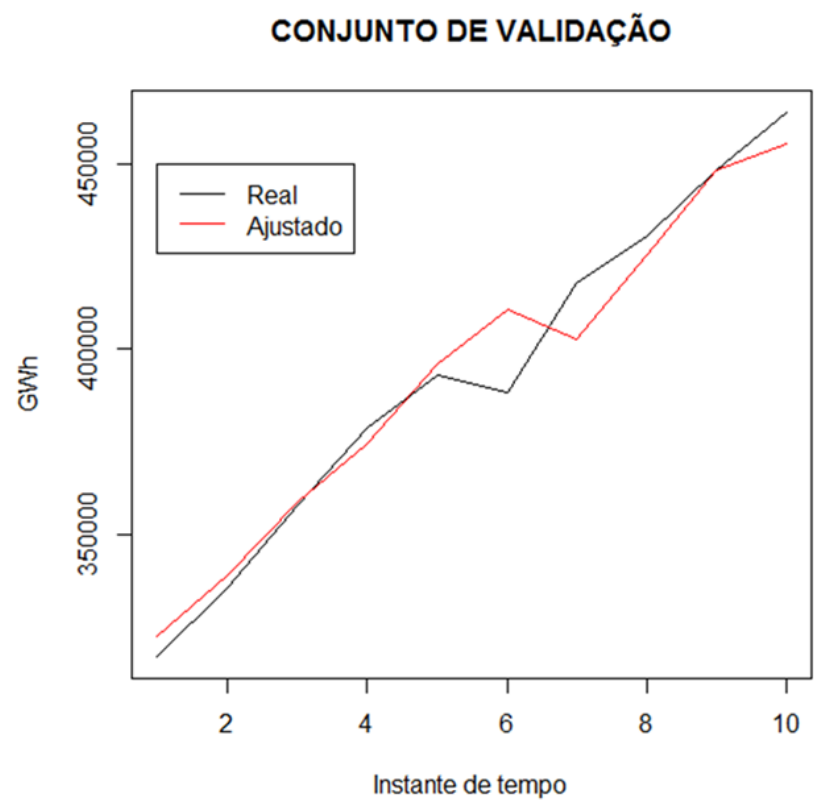

Figura 5.4 - Valores Ajustado x Realizado para amostra de validação do modelo fuzzy com janela de três antecedentes.

Fonte: o autor (2014). 


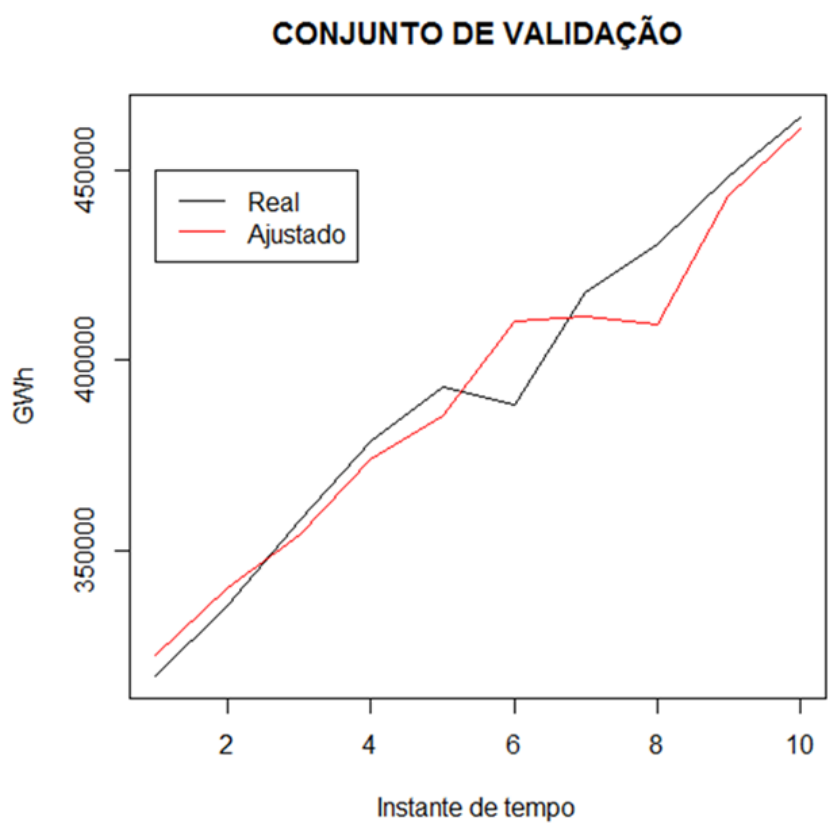

Figura 5.5 - Valores Ajustado x Realizado para amostra de validação do modelo fuzzy com janela de quatro antecedentes.

Fonte: o autor (2014).

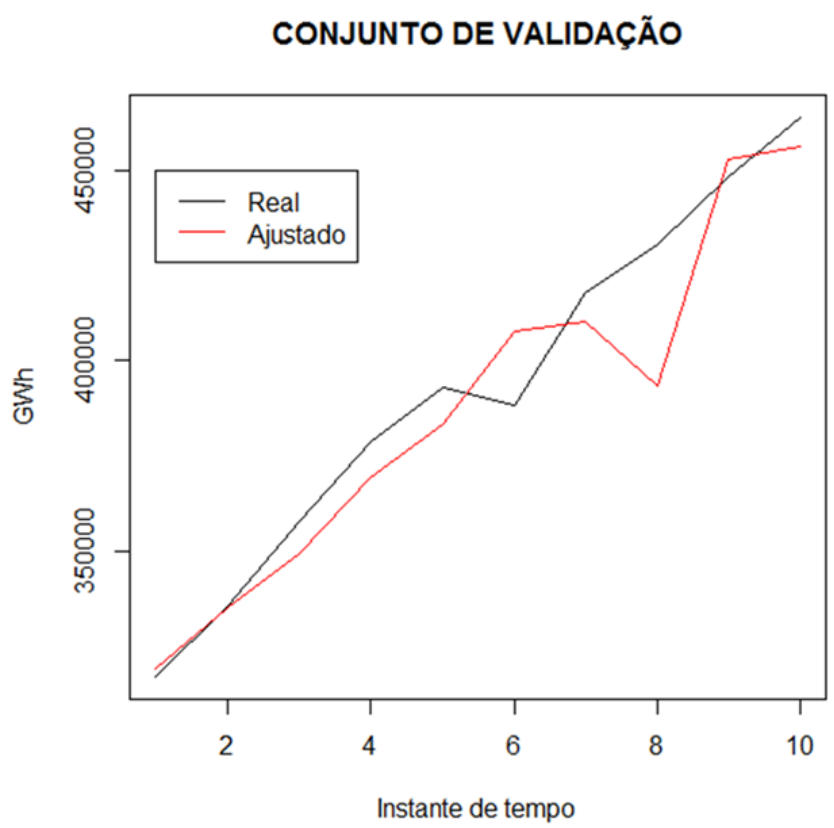

Figura 5.6 - Valores Ajustado x Realizado para amostra de validação do modelo fuzzy com janela de cinco antecedentes.

Fonte: o autor (2014).

A partir do quadro 5.2 pode-se observar que o resultado obtido através do modelo com janela de três antecedentes é mais satisfatório do que os demais, 
sendo assim, o modelo utilizado para estimativa das previsões será um modelo composto por uma janela de três antecedentes e cinco conjuntos fuzzy.

Pode-se observar através da figura 5.7, as funções de pertinência geradas de forma gaussiana. Os parâmetros das funções geradas foram obtidos de modo que se distribuíssem dentro do intervalo [0,1]. Assim, como foram usados 5 conjuntos fuzzy, consequentemente foram geradas curvas com médias $0,0.25,0.5,0.75$ e 1 , representando respectivamente os conjuntos muito baixo, baixo, moderado, alto e muito alto, com variância estimada no valor de 0.0875 para cada conjunto.

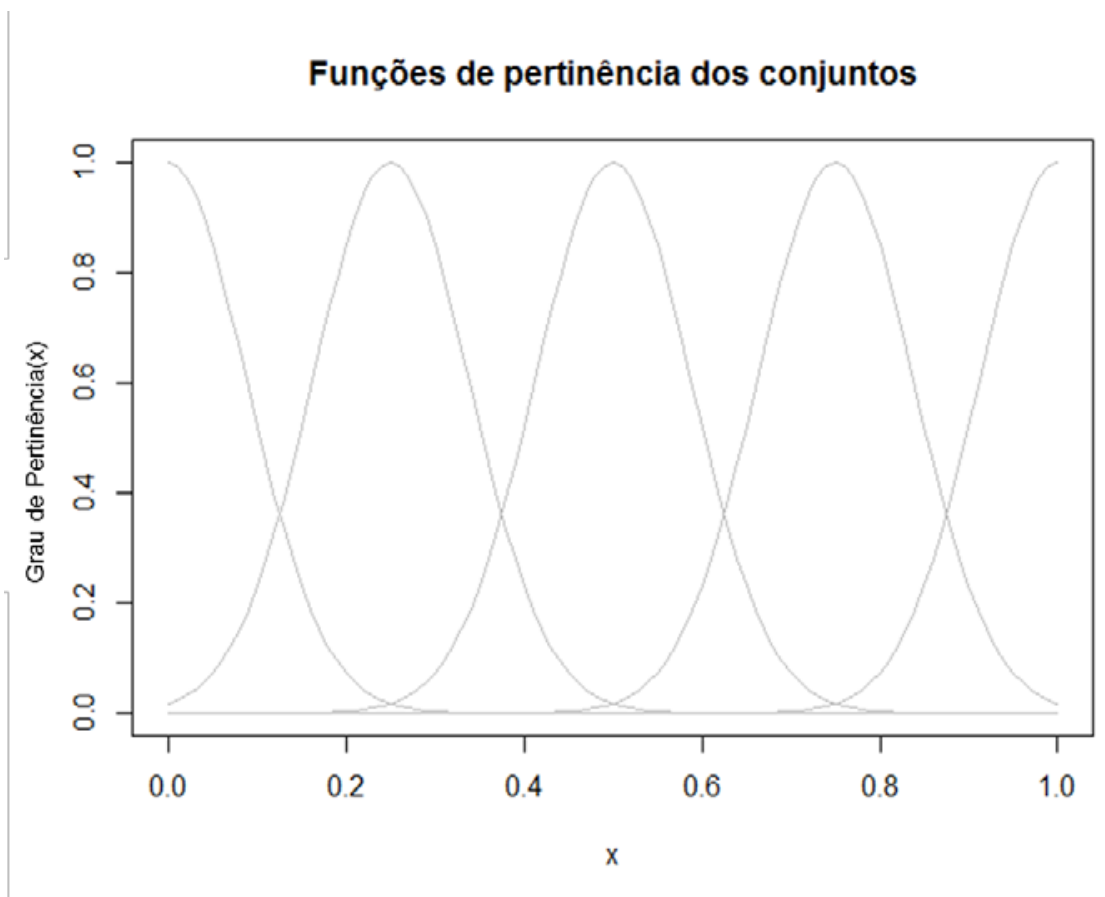

Figura 5.7 - Funções de pertinência estimadas para um padrão de 5 conjuntos fuzzy. Fonte: o autor (2014).

A figura 5.8 mostra uma comparação gráfica do modelo estatístico de Holt com o modelo Fuzzy para os dados de consumo total do Brasil. É adicionado também uma comparação do modelo Holt utilizando-se damped trend como um fator de suavização da tendência da série. Observa-se que o modelo fuzzy fornece previsões em patamares de escala maior do que a do modelo Holt e Holt com damped trend. Pode-se observar também através da estatística MAPE que modelo fuzzy retornou estimativas mais próximas à realidade do que ambos os modelos Holt. 
Quadro 5.2 - MAPE da etapa de validação dos modelos propostos.

\begin{tabular}{|l|r|}
\cline { 2 - 2 } \multicolumn{1}{c|}{} & MAPE da validação \\
\hline Modelo Holt & 5,8150 \\
\hline Modelo Fuzzy & 2,0003 \\
\hline Holt com damped trend & 10,7229 \\
\hline
\end{tabular}

Fonte: o autor (2014).

\section{Projeção do consumo de energia elétrica no Brasil}

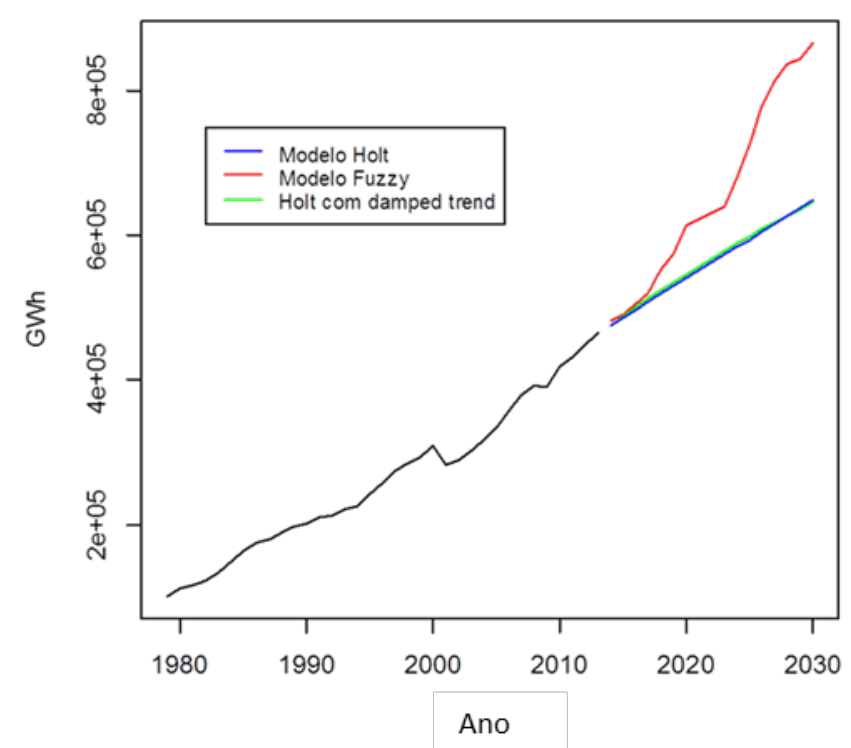

Figura 5.8 - Comparação da projeção dos modelos propostos para o consumo total de energia elétrica no Brasil.

Fonte: o autor (2014) 
Quadro 5.3 - Valores da projeção anual no horizonte 2030 dos modelos propostos.

\begin{tabular}{|r|r|r|r|}
\hline Ano & $\begin{array}{c}\text { Modelo Fuzzy } \\
\text { (GWh) }\end{array}$ & $\begin{array}{c}\text { Modelo Holt } \\
\text { (GWh) }\end{array}$ & $\begin{array}{c}\text { Holt com Damped } \\
\text { trend (GWh) }\end{array}$ \\
\hline $\mathbf{2 0 1 4}$ & 482.440 & 474.588 & 476.174 \\
\hline $\mathbf{2 0 1 5}$ & 489.852 & 485.497 & 488.419 \\
\hline $\mathbf{2 0 1 6}$ & 506.148 & 496.406 & 500.420 \\
\hline $\mathbf{2 0 1 7}$ & 520.107 & 507.315 & 512.180 \\
\hline $\mathbf{2 0 1 8}$ & 551.370 & 518.224 & 523.705 \\
\hline $\mathbf{2 0 1 9}$ & 574.530 & 529.133 & 535.000 \\
\hline $\mathbf{2 0 2 0}$ & 612.278 & 540.042 & 546.069 \\
\hline $\mathbf{2 0 2 1}$ & 622.603 & 550.951 & 556.916 \\
\hline $\mathbf{2 0 2 2}$ & 630.137 & 561.860 & 567.547 \\
\hline $\mathbf{2 0 2 3}$ & 640.656 & 572.769 & 577.965 \\
\hline $\mathbf{2 0 2 4}$ & 681.858 & 583.678 & 588.174 \\
\hline $\mathbf{2 0 2 5}$ & 727.185 & 594.587 & 598.179 \\
\hline $\mathbf{2 0 2 6}$ & 778.523 & 605.496 & 607.985 \\
\hline $\mathbf{2 0 2 7}$ & 812.816 & 616.405 & 617.594 \\
\hline $\mathbf{2 0 2 8}$ & 837.803 & 627.314 & 627.011 \\
\hline $\mathbf{2 0 2 9}$ & 843.404 & 638.223 & 636.239 \\
\hline $\mathbf{2 0 3 0}$ & 864.989 & 649.132 & 645.283 \\
\hline
\end{tabular}

Fonte: o autor (2014).

Finalmente, é feita uma comparação das estimativas pontuais dos modelos obtidos com as previsões pontuais feitas pela EPE para o ano de 2030 em quatro cenários. É possível observar que a previsão que chega mais perto dos cenários da EPE é modelo fuzzy, fornecendo uma estimativa de valor entre os cenários $\mathrm{C}$ e B2.

Quadro 5.4 - Valores da projeção pontual do ano de 2030 para os modelos proposto e cenários da EPE.

\begin{tabular}{|l|r|}
\hline Projeções para 2030 (GWh) \\
\hline EPE Cenário A1 & 1.300 .300 \\
\hline EPE Cenário B1 & 1.095 .300 \\
\hline EPE Cenário B2 & 912.600 \\
\hline EPE Cenário C & 775.700 \\
\hline Modelo Fuzzy & 864.989 \\
\hline Modelo Holt & 649.132 \\
\hline
\end{tabular}

Fonte: o autor (2014). 


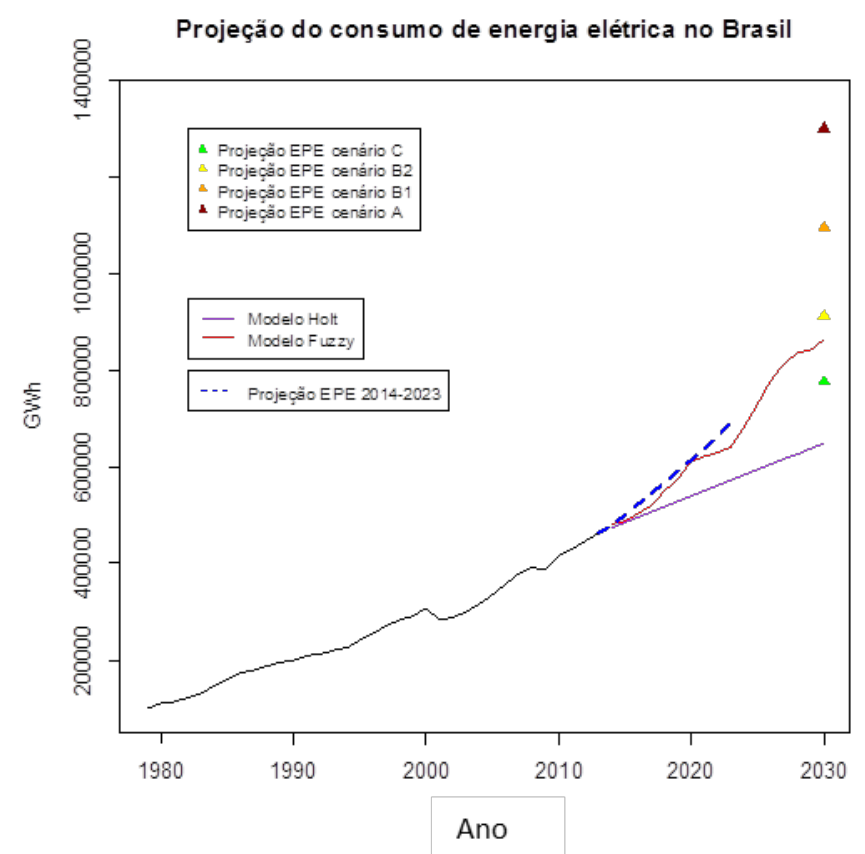

Figura 5.9 - Gráfico de comparação da projeção de consumo de energia elétrica dos modelos propostos e cenários da EPE.

Fonte: autor e PNE 2030.

Conclui-se a partir desta primeira etapa de modelagem, que a abordagem fuzzy retornou resultados satisfatórios quando comparados aos modelos estatísticos propostos. Diferentemente do modelo estimado pelo método de Holt, o modelo fuzzy se mostrou eficiente quanto captar a estrutura de não linearidade das séries. Estes resultados geram uma boa expectativa para a próxima etapa de modelagem bivariada, utilizando a abordagem fuzzy para estimar um modelo de previsão do consumo de energia elétrica com o PIB representando uma variável explicativa.

Como resultado, são apresentadas na figura 5.10 as previsões do modelo fuzzy por classes. 

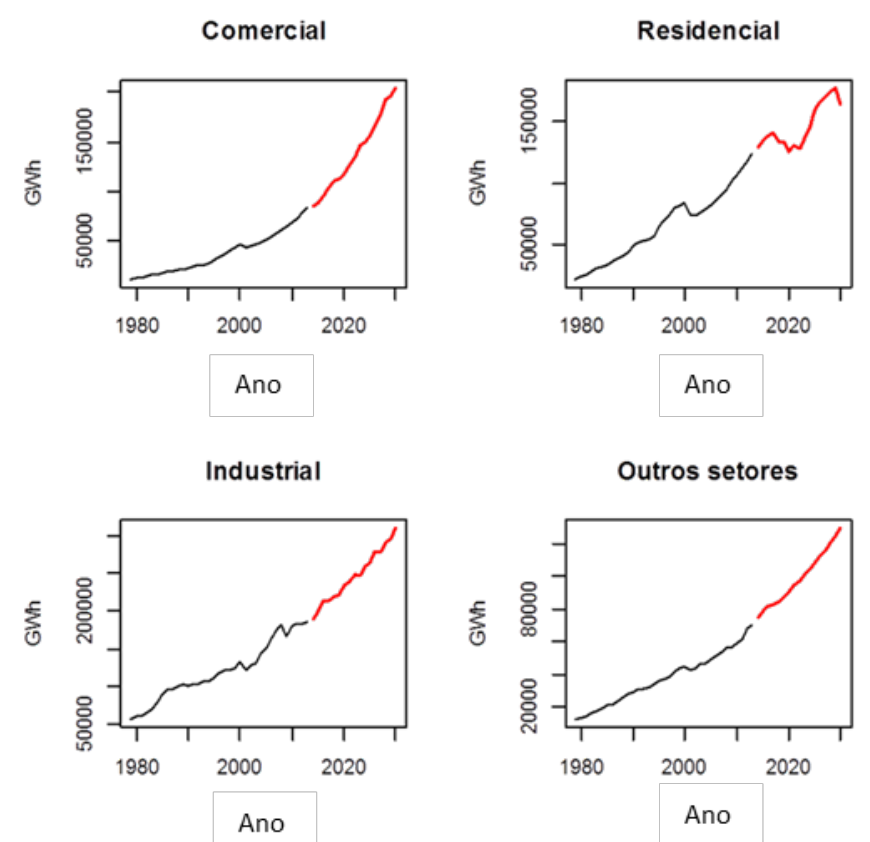

Figura 5.10 - Gráfico das previsões até 2030 do modelo fuzzy univariado para o consumo de energia elétrica por classes.

Fonte: o autor (2014).

É possível notar, principalmente na previsão feita para a classe residencial, que o modelo fuzzy fornece projeções mais detalhadas e específicas para cada comportamento de série, sugerindo que esta abordagem é mais suscetível a captar mudanças de comportamento ou efeitos cíclicos. No quadro 5.7, são fornecidos os resultados das projeções no horizonte 2030 para as classes de consumo. 
Quadro 5.5 - Valores das previsões até 2030 do modelo fuzzy para o consumo de energia elétrica por classes.

\begin{tabular}{|r|r|r|r|r|}
\hline Ano & $\begin{array}{c}\text { Comercial } \\
\text { (GWh) }\end{array}$ & $\begin{array}{c}\text { Residencial } \\
\text { (GWh) }\end{array}$ & $\begin{array}{c}\text { Industrial } \\
\text { (GWh) }\end{array}$ & $\begin{array}{c}\text { Outros setores } \\
\text { (GWh) }\end{array}$ \\
\hline $\mathbf{2 0 1 4}$ & 85.587 & 130.090 & 189.762 & 74.909 \\
\hline $\mathbf{2 0 1 5}$ & 89.049 & 135.380 & 200.775 & 78.632 \\
\hline $\mathbf{2 0 1 6}$ & 94.991 & 138.522 & 212.426 & 82.194 \\
\hline $\mathbf{2 0 1 7}$ & 102.537 & 142.078 & 212.172 & 83.139 \\
\hline $\mathbf{2 0 1 8}$ & 110.501 & 133.697 & 218.963 & 85.283 \\
\hline $\mathbf{2 0 1 9}$ & 112.972 & 133.727 & 221.595 & 87.774 \\
\hline $\mathbf{2 0 2 0}$ & 117.650 & 125.841 & 234.458 & 90.932 \\
\hline $\mathbf{2 0 2 1}$ & 125.200 & 131.245 & 237.742 & 94.195 \\
\hline $\mathbf{2 0 2 2}$ & 135.339 & 128.905 & 247.330 & 97.589 \\
\hline $\mathbf{2 0 2 3}$ & 145.486 & 137.317 & 247.046 & 101.108 \\
\hline $\mathbf{2 0 2 4}$ & 148.784 & 145.769 & 258.607 & 104.753 \\
\hline $\mathbf{2 0 2 5}$ & 154.946 & 159.686 & 262.892 & 108.531 \\
\hline $\mathbf{2 0 2 6}$ & 164.863 & 165.810 & 278.193 & 112.445 \\
\hline $\mathbf{2 0 2 7}$ & 178.199 & 172.261 & 278.007 & 116.500 \\
\hline $\mathbf{2 0 2 8}$ & 191.551 & 175.096 & 291.304 & 120.701 \\
\hline $\mathbf{2 0 2 9}$ & 195.890 & 178.624 & 294.768 & 125.054 \\
\hline $\mathbf{2 0 3 0}$ & 204.003 & 165.034 & 309.196 & 129.564 \\
\hline
\end{tabular}

Fonte: o autor (2014).

\section{4.}

\section{Modelos Fuzzy causais}

\subsection{1. Modelo Brasil}

Tendo em vista a adequabilidade da abordagem fuzzy na etapa anterior, os parâmetros que foram determinados para os modelos univariados serão mantidos nesta nova etapa. Sendo assim, foram adotados novamente como parâmetros de entrada dos modelos fuzzy: um tamanho de janela com três antecedentes, a utilização de funções de pertinência do tipo gaussiana e um total de cinco conjuntos representando novamente as classificações de cenários de crescimento muito baixo, baixo, moderado, alto e muito alto.

Primeiramente, com o objetivo de determinar relações de interdependência das variáveis de classes de consumo, foi gerada no Quadro 5.6 uma matriz de correlação. Pode-se perceber que todas as variáveis em questão demonstram alta correlação positiva entre si. Especificamente, as classes Outros Setores e Residencial apresentam o valor mais alto chegando à quase unitário $(0,99)$. Isto pode ser explicado pelo fato da classe de Outros Setores conter os setores de iluminação pública, serviços e poderes públicos, os quais estão relacionados com urbanização e domicílios, que por si só já fazem referência a classe Residencial. 
Portanto, temos indícios que as variáveis Residencial e Outros Setores poderiam apresentar ganhos significativos quando fossem incluídas no respectivo modelo de uma e de outra.

Quadro 5.6 - Matriz de correlação das classes de consumo de energia elétrica.

\begin{tabular}{|l|r|r|r|r|}
\cline { 2 - 5 } \multicolumn{1}{c|}{} & \multicolumn{1}{c|}{ Comercial } & \multicolumn{1}{c|}{ Residencial } & Industrial & Outros Setores \\
\hline Comercial & 1,000 & 0,985 & 0,967 & 0,987 \\
\hline Residencial & 0,985 & 1,000 & 0,961 & 0,992 \\
\hline Industrial & 0,967 & 0,961 & 1,000 & 0,976 \\
\hline Outros Setores & 0,987 & 0,992 & 0,976 & 1,000 \\
\hline
\end{tabular}

Fonte: o autor (2014)

O primeiro modelo a ser gerado foi o de consumo total Brasil. Inicialmente, foi testado uma abordagem com somente a taxa de variação do PIB Brasil e a parte autoregressiva para explicar o comportamento da série de consumo em questão.

A Figura 5.11 apresenta o gráfico do realizado versus o ajustado na amostra de validação para o modelo explicado pela variável PIB somente. Percebe-se que quando comparado com o modelo fuzzy explicado apenas pela parte autoregressiva, os valores ajustados estão mais distantes do real, fato este pode também ser comprovado através da análise das estatísticas de ajuste apresentadas no Quadro 5.10.

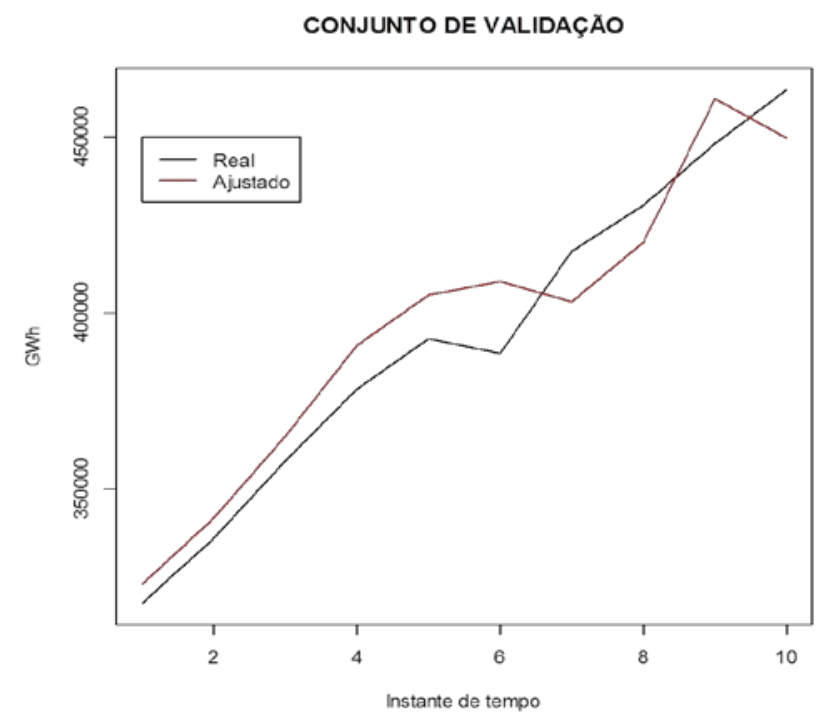

Figura 5.11 - Valores Ajustado x Realizado para amostra de validação do modelo fuzzy Brasil com PIB.

Fonte: o autor (2014). 
A Figura 5.12 traz novamente a comparação das previsões do modelo com as projeções pontuais de 2030 e de 2014 à 2023 da EPE. Nota-se que o valor da previsão do modelo fuzzy para 2030 aproxima-se da projeção do cenário B2 da EPE.

Para exemplificar melhor o processo de geração de regras para este modelo, o quadro 5.7 apresenta a base de regras determinada para o modelo Brasil sendo explicado pelo PIB e sua parte autoregressiva. Onde, as três primeiras variáveis representam respectivamente as variáveis de consumo de energia elétrica total Brasil com três, duas e uma defasagem, a quarta variável representa a variação do PIB Brasil e última o consumo de energia elétrica no instantes em questão.

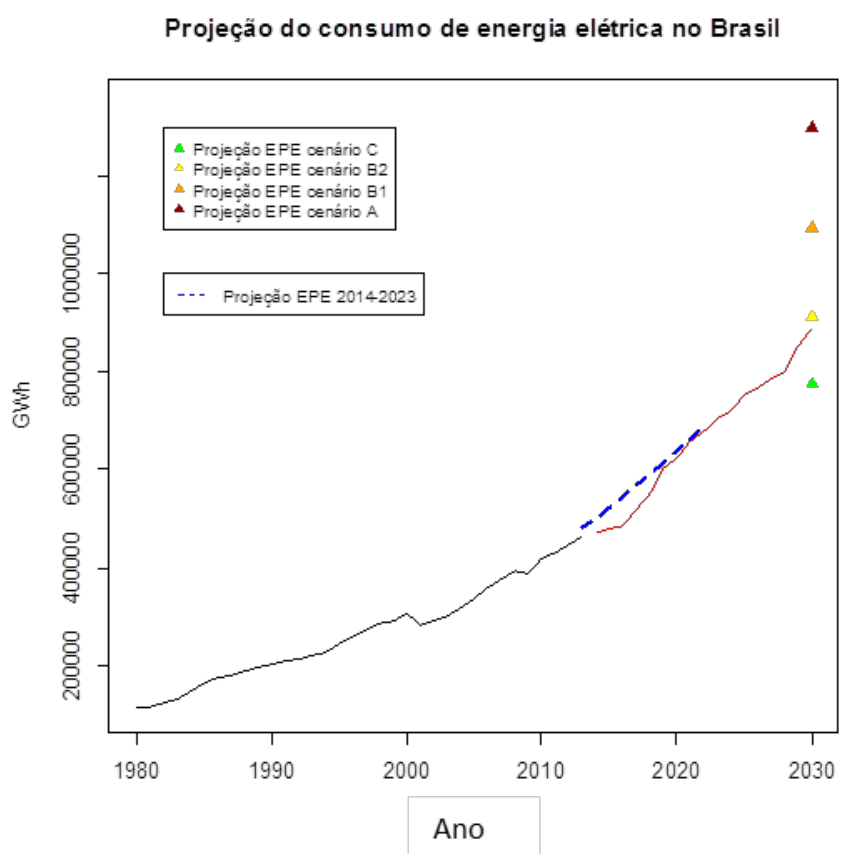

Figura 5.12 - Gráfico de comparação da projeção de consumo de energia elétrica do modelo fuzzy Brasil com PIB versus cenários da EPE.

Fonte: autor e PNE 2030. 
Quadro 5.7 - Base de regras do modelo total Brasil com o PIB.

\begin{tabular}{|c|c|c|c|c|c|c|c|c|c|c|c|c|c|c|c|c|c|c|}
\hline $\mathrm{Se}$ & Consumo(-3) & é & Moderado & $\mathrm{e}$ & Consumo(-2) & \begin{tabular}{l|l} 
é & Alto \\
\end{tabular} & e & Consumo(-1) & é & Alto & e & PIB & é & Alto & Então & Consumo & é & Muito alto \\
\hline $\mathrm{Se}$ & Consumo(-3) & é & Moderado & $\mathrm{e}$ & Consumo(-2) & é Alto & $1 \mathrm{e}$ & Consumo(-1) & é & Muito baixo & e & PIB & é & Moderado & Então & Consumo & $\epsilon$ & Moderado \\
\hline Se & Consumo(-3) & é & Alto & e & Consumo(-2) & é & 10 & Consumo(-1) & é & Alto & e & PIB & é & Baixo & Então & Consumo & 6 & Alto \\
\hline $\mathrm{Se}$ & Consumo(-3) & é & Alto & $\mid \mathrm{e}$ & Consumo(-2) & \begin{tabular}{l|l} 
é & Alto \\
\end{tabular} & 1 & Consumo(-1) & é & Moderado & $\mathrm{e}$ & PIB & é & Moderado & Então & Consumo & 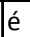 & Alto \\
\hline $\mathrm{Se}$ & Consumo(-3) & é & Moderado & $\mathrm{e}$ & Consumo(-2) & \begin{tabular}{l|l} 
élto \\
\end{tabular} & 4 & Consumo(-1) & é & Moderado & $\mathrm{e}$ & PIB & é & Alto & Então & Consumo & é & Moderado \\
\hline Se & Consumo(-3) & é & Alto & e & Consumo(-2) & é Alto & Je & Consumo(-1) & é & Muito alto & e & PIB & é & Muito alto & Então & Consumo & é & Muito alto \\
\hline Se & Consumo(-3) & é & Alto & $\mathrm{e}$ & Consumo(-2) & \begin{tabular}{l|l} 
é & Muito alto \\
\end{tabular} & et & Consumo(-1) & é & Muito alto & $\mathrm{e}$ & PIB & é & Muito alto & Então & Consumo & é & Alto \\
\hline $\mathrm{Se}$ & Consumo(-3) & é & Muito alto & e & Consumo(-2) & é Alto & e & Consumo(-1) & é & Moderado & e & PIB & é & Baixo & Então & Consumo & é & Alto \\
\hline $\mathrm{Se}$ & Consumo(-3) & é & Alto & $\mathrm{e}$ & Consumo(-2) & é Moderado & $\mathrm{e}$ & Consumo(-1) & é & Alto & $\mathrm{e}$ & PIB & é & Moderado & Então & Consumo & é & Alto \\
\hline $\mathrm{Se}$ & Consumo(-3) & é & Alto & $\mathrm{e}$ & Consumo(-2) & $\begin{array}{l}\text { é } \\
\text { Muito baixo } \\
\end{array}$ & $\mathrm{e}$ & Consumo(-1) & é & Moderado & $\mathrm{e}$ & PIB & é & Moderado & Então & Consumo & é & Moderado \\
\hline $\mathrm{Se}$ & Consumo(-3) & é & Muito alto & $\mathrm{e}$ & Consumo(-2) & \begin{tabular}{l|l} 
é & Muito alto
\end{tabular} & | & Consumo(-1) & é & Alto & $\mathrm{e}$ & PIB & é & Alto & Então & Consumo & é & Moderado \\
\hline Se & Consumo(-3) & é & Alto & $\mathrm{e}$ & Consumo(-2) & $\begin{array}{l}\text { é } \\
\text { Alto }\end{array}$ & $\mathrm{e}$ & Consumo(-1) & é & Moderado & $\mathrm{e}$ & PIB & é & Alto & Então & Consumo & é & Alto \\
\hline $\mathrm{Se}$ & Consumo(-3) & é & Moderado & e & Consumo(-2) & \begin{tabular}{l|l} 
é & Moderado \\
\end{tabular} & $\mathrm{e}$ & Consumo(-1) & é & Moderado & e & PIB & é & Alto & Então & Consumo & $\epsilon$ & Alto \\
\hline Se & Consumo(-3) & é & Alto & $\mathrm{e}$ & Consumo(-2) & é Alto & $\mathrm{e}$ & Consumo(-1) & é & Alto & e & PIB & é & Moderado & Então & Consumo & é & Moderado \\
\hline $\mathrm{Se}$ & Consumo(-3) & é & Moderado & e & Consumo(-2) & é Moderado & $\mathrm{e}$ & Consumo(-1) & é & Alto & e & PIB & é & Moderado & Então & Consumo & é & Alto \\
\hline Se & Consumo(-3) & é & Alto & 10 & Consumo(-2) & é $\mid$ Moderado & $\mathrm{e}$ & Consumo(-1) & Jé & Moderado & e & PIB & é & Alto & Então & Consumo & é & Moderado \\
\hline Se & Consumo(-3) & é & Moderado & $\mathrm{e}$ & Consumo(-2) & \begin{tabular}{l|l} 
é & Alto \\
\end{tabular} & $\mathrm{e}$ & Consumo(-1) & é & Alto & $\mathrm{e}$ & PIB & é & Alto & Então & Consumo & é & Alto \\
\hline $\mathrm{Se}$ & Consumo(-3) & & Moderado & e & Consumo(-2) & é Alto & e & Consumo(-1) & é & Alto & e & PIB & é & Muito baixo & Então & Consumo & é & Moderado \\
\hline Se & Consumo(-3) & é & Alto & $\mathrm{e}$ & Consumo(-2) & é Moderado & $\mathrm{e}$ & Consumo(-1) & é & Alto & $\mathrm{e}$ & PIB & é & Baixo & Então & Consumo & e & Moderado \\
\hline $\mathrm{Se}$ & Consumo(-3) & é & Alto & $\mathrm{e}$ & Consumo(-2) & \begin{tabular}{l|l} 
é & Moderado
\end{tabular} & e & Consumo(-1) & é & Alto & e & PIB & é & Moderado & Então & Consumo & $\underline{\underline{\varepsilon}}$ & Muito baixo \\
\hline
\end{tabular}

Fonte: o autor (2014)

O segundo modelo para o consumo total Brasil foi proposto com a intensão de explicar a variação de consumo, através da taxa de variação do PIB Brasil, a parte autoregressiva e adicionalmente a taxa de crescimento populacional. Percebe-se pela figura 5.13 que o modelo proposto apresenta uma precisão mais acentuada em relação ao modelo com somente o PIB. As estatísticas de ajuste presentes no Quadro 5.7 também evidenciam esta melhora no rendimento do modelo apresentando o valor para o MAPE da amostra de validação, quase mais de $50 \%$ menor

O resultado das projeções deste último modelo pode ser observado no gráfico 5.13. Nota-se que a projeção pontual para 2030 do modelo fuzzy agora está quase que fixado no cenário de menor valor da EPE (cenário C).

O quadro 5.8 apresenta a base de regras determinada para o modelo Brasil completo. Onde, as variáveis var.1, var.2, var.3 representam respectivamente as variáveis de consumo de energia elétrica total Brasil com três, duas e uma defasagem. As variáveis var.4 e var.5 representam a variação do PIB Brasil e a taxa de variação da população residente respectivamente. 


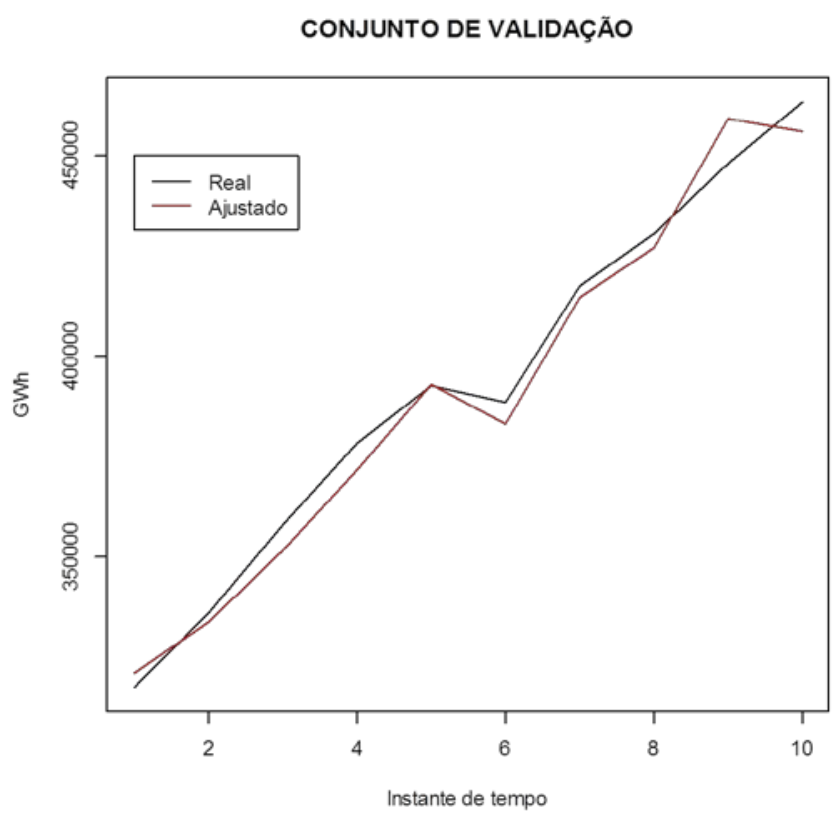

Figura 5.13 - Valores Ajustado x Realizado para amostra de validação do modelo fuzzy Brasil com PIB e População.

Fonte: o autor (2014).

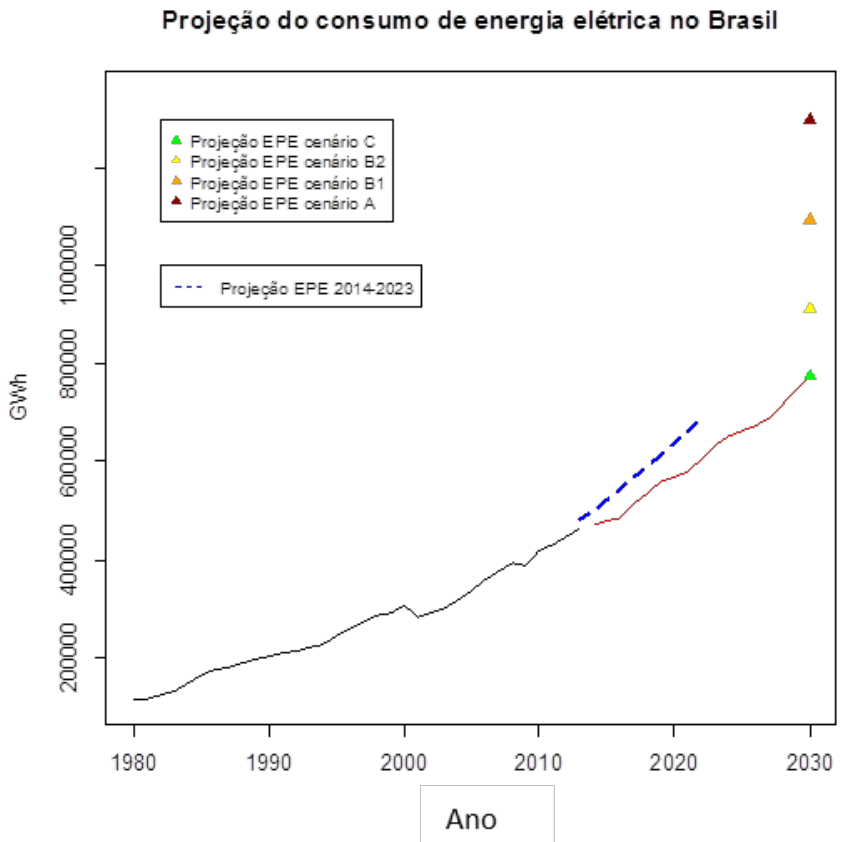

Figura 5.14 - Gráfico de comparação da projeção de consumo de energia elétrica do modelo fuzzy Brasil com PIB e População versus cenários da EPE.

Fonte: o autor e EPE (NOTA TÉCNICA DEA 28/13). 
Quadro 5.8 - Base de regras do modelo total Brasil completo.

\begin{tabular}{|c|c|c|c|c|c|c|c|c|c|c|c|c|c|c|c|c|c|}
\hline$|\mathrm{Se}|$ & Consumo(-3) & |é $\mid$ Moderado & & Consumo(-2) & Alto & e & \begin{tabular}{|l|} 
Consumo(-1) \\
\end{tabular} & \begin{tabular}{|l|l|} 
é & Alto \\
\end{tabular} & $|e|$ & \begin{tabular}{|l|l|} 
PIB & é \\
\end{tabular} & Alto & le & População & Muito alto & Então & Consumo & é|Muito alto \\
\hline $\mathrm{Se}$ & Consumo(-3) & \begin{tabular}{l|l|} 
é & Moderado \\
\end{tabular} & e & Consumo(-2) & \begin{tabular}{|l|l|} 
Alto \\
\end{tabular} & $\mathrm{e}$ & Consumo(-1) & \begin{tabular}{l|l} 
é & Muito baixo \\
\end{tabular} & & \begin{tabular}{|l|l|} 
PIB & é \\
\end{tabular} & Moderado & e & População & Moderado & Então & Consumo & Moderado \\
\hline $\mathrm{Se}$ & \begin{tabular}{|l|} 
Consumo(-3) \\
\end{tabular} & \begin{tabular}{l|l} 
é Alto \\
\end{tabular} & $\mathrm{e}$ & Consumo(-2) & Alto & e & Consumo(-1) & é Alto & & PIB é & Baixo & $\mathrm{e}$ & População & Moderado & Então & Consumo & Alto \\
\hline $\mathrm{Se}$ & Consumo(-3) & \begin{tabular}{|l|l|} 
é & Baixo \\
\end{tabular} & t & Consumo(-2) & Alto & & Consumo(-1) & \begin{tabular}{|l|l|l|} 
é & Moderado \\
\end{tabular} & & PIB & Modera & & População & aixo & Então & Consumo & fillo \\
\hline $\mathrm{Se}$ & Consumo(-3) & \begin{tabular}{l|l|l|l|} 
é & Alto \\
\end{tabular} & $\mathrm{e}$ & Consumo(-2) & Alto & & Consumo(-1) & \begin{tabular}{|l|l|} 
é & Moderado \\
\end{tabular} & e & \begin{tabular}{|l|l|} 
PIB & é \\
\end{tabular} & Baixo & e & População & Baixo & Então & Consumo & Baixo \\
\hline $\mathrm{Se}$ & Consumo(-3) & \begin{tabular}{l|l} 
é & Alto \\
\end{tabular} & $\mathrm{e}$ & Consumo(-2) & Alto & & Consumo(-1) & $\begin{array}{l}\text { é Moderado } \\
\end{array}$ & e & \begin{tabular}{|l|l|} 
PIB é \\
\end{tabular} & Moderado & E & População & Moderado & Então & Consumo & Alto \\
\hline $\mathrm{Se}$ & Consumo(-3) & \begin{tabular}{l|l|} 
é & Alto \\
\end{tabular} & H & Consumo(-2) & Muito & & Consumo(-1) é & \begin{tabular}{|l|l|} 
é & Moderado \\
\end{tabular} & e & \begin{tabular}{|l|l|} 
PIB & é \\
\end{tabular} & Moderado & & População & Moderado & Então & Consumo & ado \\
\hline $\mathrm{Se}$ & Consumo(-3) & é Moderado & & $10(-2)$ & Alto & $\mathrm{e}$ & Consumo(-1) & \begin{tabular}{l|l} 
é & Mod \\
\end{tabular} & $\mathrm{e}$ & \begin{tabular}{|l|l|} 
PIB & \\
\end{tabular} & Alto & e & ação & ado & Então & umo & do \\
\hline $\mathrm{Se}$ & Consumo(-3) & \begin{tabular}{l|l|l|l|} 
é & Alto \\
\end{tabular} & 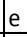 & $(-2)$ & Alto & e & Consumo(-1) & $\begin{array}{l}\text { é } \\
\text { Mui }\end{array}$ & $\mathrm{e}$ & \begin{tabular}{|l|l|} 
PIB & é \\
\end{tabular} & Muito alto & e & ação & Ito & Então & imo & $\mathrm{Mu}$ \\
\hline $\mathrm{Se}$ & Consumo(-3) & \begin{tabular}{l|l} 
é & Muito alto \\
\end{tabular} & $\mathrm{e}$ & $0(-2)$ & $\begin{array}{l}\text { Alto } \\
\text { Alto }\end{array}$ & e & Consumo(-1) & \begin{tabular}{|l|l|} 
é & Moderado \\
\end{tabular} & $\mathrm{e}$ & \begin{tabular}{|l|l|l|} 
PIB & é \\
\end{tabular} & Ba & & ção & Alto & Então & umo & é Alto \\
\hline $\mathrm{Se}$ & $o(-3)$ & \begin{tabular}{l|l|l|} 
é & Alto \\
\end{tabular} & $\mathrm{e}$ & $(-2)$ & Mode & e & $o(-1) \mid \bar{e}$ & \begin{tabular}{l|l|l|} 
é & Alto \\
\end{tabular} & e & \begin{tabular}{|l|l|} 
PIB & é \\
\end{tabular} & Moderado & & ção & Alt & Então & umo & Alto \\
\hline $\mathrm{Se}$ & \begin{tabular}{|l|} 
Consumo(-3) \\
\end{tabular} & \begin{tabular}{|l|l|} 
é & Alto \\
\end{tabular} & $\mathrm{e}$ & Consumo(-2) & $\begin{array}{l}\text { Alto } \\
\end{array}$ & e & Consumo(-1) & \begin{tabular}{|l|l|l|} 
é & Alto \\
\end{tabular} & $\mathrm{e}$ & PIB é & Alto & le & População & Bai & Então & Consumo & rado \\
\hline $\mathrm{Se}$ & Consumo(-3) & \begin{tabular}{|l|l|} 
é & Alto \\
\end{tabular} & $\mathrm{e}$ & Consumo(-2) & Moderado & e & Consumo(-1) & \begin{tabular}{l|l} 
é & Alto \\
\end{tabular} & $\mathrm{e}$ & \begin{tabular}{|l|l|} 
PIB & é \\
\end{tabular} & Moderado & e & População & baixo & Então & Consumo & Moderado \\
\hline Se & Consumo(-3) & é Moderado & $\mathrm{e}$ & Consumo(-2) & \begin{tabular}{|l|l|} 
Baixo \\
\end{tabular} & $\mathrm{e}$ & Consumo(-1) & \begin{tabular}{l|l|l|l|} 
é & Alto \\
\end{tabular} & $\mathrm{e}$ & \begin{tabular}{|l|l|} 
PIB & é \\
\end{tabular} & Moderado & e & População & Muito baixo & Então & Consumo & Moderado \\
\hline $\mathrm{Se}$ & Consumo(-3) & é Muito alto & $\mathrm{e}$ & Consumo(-2) & Muito alto & $\mathrm{e}$ & Consumo(-1) & é Alto & $\mathrm{e}$ & PIB é & Alto & le & População & to & Então & Consumo & Moderado \\
\hline Se & Consumo(-3) & \begin{tabular}{l|l|l|l|} 
é & Alto \\
\end{tabular} & $\mathrm{e}$ & Consumo(-2) & $\begin{array}{l}\text { Alto } \\
\end{array}$ & $\mathrm{e}$ & Consumo(-1) & é & e & \begin{tabular}{|l|l|l|} 
PIB & é \\
\end{tabular} & Alto & e & População & loderado & Então & Consumo & Alto \\
\hline Se & Consur & lé Muito baixo & & $0(-2)$ & Moderado & e & $o(-1) e^{o}$ & \begin{tabular}{l|l} 
é & Moc \\
\end{tabular} & fᄃㄴ & \begin{tabular}{|l|l|} 
PIB & é \\
\end{tabular} & Alto & $e_{-}$ & ação & Bai & Então & Consumo & to \\
\hline $\mathrm{Se}$ & Consumo(-3) & \begin{tabular}{|l|l|} 
é & Moderado \\
\end{tabular} & e & Consumo(-2) & Mode & e & Consumo(-1) & \begin{tabular}{l|l} 
é & Mode \\
\end{tabular} & $\mathrm{e}$ & \begin{tabular}{|l|l|} 
PIB & é \\
\end{tabular} & Alto & & População & ado & Então & Consumo & Alto \\
\hline Se & Consumo(-3) & \begin{tabular}{|l|l|} 
é & Alto \\
\end{tabular} & & Consumo(-2) & $\begin{array}{l}\text { Alto } \\
\end{array}$ & & Consumo(-1) & \begin{tabular}{l|l|l|l|} 
é & Alto \\
\end{tabular} & $\mathrm{e}$ & \begin{tabular}{|l|l|l|} 
PIB & é \\
\end{tabular} & Moderado & $\mathrm{e}$ & População & rado & Então & Consumo & Moderado \\
\hline Se & Consumo(-3) & é Moderado & & Consumo(-2) & Moderado & & Consumo(-1) é & é Alto & 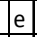 & \begin{tabular}{|l|l|} 
PIB & é \\
\end{tabular} & Moderado & $\mathrm{e}$ & População & Moderado & Então & Consumo & Alto \\
\hline $\mathrm{Se}$ & Consumo(-3) & \begin{tabular}{l|l|l|} 
& Alto \\
\end{tabular} & & Consumo(-2) & Alto & e & Consumo(-1) & é Alto & $\mathrm{e}$ & PIB é & Alto & e & População & Baixo & Então & Consumo & Alto \\
\hline Se & Consumo(-3) & \begin{tabular}{l|l|} 
é & Moderado \\
\end{tabular} & e & Consumo(-2) & Moderado & & Consumo(-1) & \begin{tabular}{l|l|l|} 
é & Alto \\
\end{tabular} & $\mathrm{e}$ & \begin{tabular}{|l|l|} 
PIB & é \\
\end{tabular} & Moderado & & População & Baixo & Então & Consumo & Alto \\
\hline Se & Consumo(-3) & \begin{tabular}{l|l|l|} 
é & Alto \\
\end{tabular} & & Consumo(-2) & Moderado & & Consumo(-1) & é Moderado & & PIB & Alto & e & População & Moderado & Então & Consumo & Moderado \\
\hline $\mathrm{Se}$ & Consumo(-3) & é Alto & & Consumo(-2) & Moderado & & Consumo(-1) & \begin{tabular}{l|l} 
& Baixo \\
\end{tabular} & e & PIB é & Muito alto & & População & Muito baixo & Então & Consumo & Alto \\
\hline$s^{n}$ & Iransumo(-3) & \begin{tabular}{l|l} 
é & Moderado \\
\end{tabular} & & Consumo(-2) & $\begin{array}{l}\text { Alto } \\
\end{array}$ & & Consumo(-1) & \begin{tabular}{l|l} 
é & Alto \\
\end{tabular} & $\mathrm{e}$ & \begin{tabular}{|l|l|l|} 
PIB & é \\
\end{tabular} & Alto & & População & Moderado & Então & Consumo & Alto \\
\hline sm & nsumo(-3) & \begin{tabular}{l|l|l|l|} 
é & Alto \\
\end{tabular} & & Consumo(-2) & Muito alto & $e_{e},{ }_{1}$ & Consumo(-1) é & \begin{tabular}{l|l} 
é & Mito alto \\
\end{tabular} & r & \begin{tabular}{|l|l|} 
PIB & é \\
\end{tabular} & Muito alto & & População & Alto & Então & Consumo & Alto \\
\hline 28 & insumo(-3) & é Moderado & & Consumo(-2) & \begin{tabular}{|l|l|} 
Alto \\
\end{tabular} & $e_{e}$ & Consumo(-1) & \begin{tabular}{l|l|l|l|} 
é & Alto \\
\end{tabular} & $\mathrm{e}$ & PIB é & Muito baixo & & População & Alto & Então & Consumo & é $\mid$ Moderado \\
\hline$s \frac{-}{m}$ & nsumo(-3) & \begin{tabular}{|l|l|} 
é & Moderado \\
\end{tabular} & & Consumo(-2) & \begin{tabular}{l|l} 
Alto \\
\end{tabular} & & Consumo(-1) & é Alto & $\mathrm{e}$ & \begin{tabular}{|l|l|l|} 
PIB & é \\
\end{tabular} & Alto & & População & \begin{tabular}{l|l} 
é & Baixo \\
\end{tabular} & Então & Consumo & é Alto \\
\hline sm & insumo(-3) & é Alto & & Consumo(-2) & Moderado & & Consumo(-1) & é Alto & & \begin{tabular}{|l|l|l|} 
PIB & é \\
\end{tabular} & Baixo & & População & Moderado & Então & Consumo & Moderado \\
\hline ESN & nsumo(-3) & \begin{tabular}{l|l} 
é & Alto \\
\end{tabular} & & Consumo(-2) & Moderado & & Consumo(-1) & \begin{tabular}{l|l|l|} 
é & Alto \\
\end{tabular} & & \begin{tabular}{|l|l|l|} 
PIB & é \\
\end{tabular} & Moderado & & População & Moderado & Então & Consumo & Muito baix \\
\hline
\end{tabular}

Fonte: o autor (2014)

Quadro 5.9 - Projeções dos modelos Brasil estimados e expectativas da EPE.

\begin{tabular}{|l|r|}
\hline \multicolumn{2}{|c|}{ Projeções para 2030 (GWh) } \\
\hline EPE Cenário A1 & 1.300 .300 \\
\hline EPE Cenário B1 & 1.095 .300 \\
\hline EPE Cenário B2 & 912.600 \\
\hline EPE Cenário C & 775.700 \\
\hline Modelo Holt & 649.132 \\
\hline Modelo Fuzzy univariado & 864.989 \\
\hline Modelo Fuzzy com PIB & 890.007 \\
\hline $\begin{array}{l}\text { Modelo Fuzzy com PIB + } \\
\text { População }\end{array}$ & 773.901 \\
\hline
\end{tabular}

Fonte: o autor (2014) e EPE. 


\subsection{2. \\ Modelos por classes de consumo}

Para as classes de consumo estudadas aqui, foram propostas as seguintes estruturas de modelo:

I. Modelo residencial: Parte autoregressiva + PIB Brasil + População residente

II. Modelo comercial: Parte autoregressiva + PIB Brasil

III. Modelo industrial: Parte autoregressivel + PIB industrial

IV. Modelo outros serviços: Parte autoregressiva e consumo residencial

Para a classe residencial, primeiramente, foi estimado o modelo englobando somente a parte autoregressiva de três antecedentes e o PIB. Os resultados mostram melhoras de precisão tanto com base na amostra de validação quanto na de treinamento.

Porém, a grande melhoria do modelo ocorre na inclusão da variável representativa da população residente, a qual podemos explicar esta melhora pelo fato população ser uma "proxy” do número de domicílios, sendo que estes são as unidades consumidoras residenciais. Todas as estatísticas de ajustes caem expressivamente quanto ao desvio em relação aos dados reais e ajustados, o MAPE da amostra de validação vai de 3,72 no modelo com somente o PIB para 1,67 no modelo com a população residente incluída. O Quadro 5.11 traz estas estatísticas de ajuste para comparação.

Na classe comercial o modelo foi estimado com a parte autoregressiva e o PIB. As estatísticas do Quadro 5.12 mostram que apesar do MAPE da validação ter piorado com inclusão do PIB versus o modelo univariado, quando calculamos esta estatística para a amostra de treinamento vemos uma melhora de precisão do novo modelo proposto.

Na classe industrial, houve uma pequena mudança em relação à classe comercial, pois passamos a utilizar o PIB do setor industrial e não mais o PIB Brasil. Através do Quadro 5.13 percebe-se que há um leve aumento no valor do MAPE de 0,1 pontos percentuais para a amostra de validação. Enquanto que, para 
a amostra de treinamento, o modelo com o PIB se saiu melhor diminuindo o erro em por volta de 0,9 pontos percentuais.

Para a classe de Outros Serviços foi utilizado o histórico do consumo da classe residencial assim como as saídas das previsões do modelo proposto para esta classe. Os resultados podem ser analisados através do Quadro 5.14. Nota-se a expressiva melhora no erro percentual obtido para as duas amostras, principalmente na amostra de validação. A melhora deste modelo com a inclusão da série residencial serve para reforçar a ideia inicial da abordagem fuzzy mostrando a adequabilidade destes tipos de modelo para séries com certo grau de imprecisão.

Quadro 5.10 - Estatísticas de ajuste para os modelos fuzzy Total Brasil.

\begin{tabular}{|l|c|c|c|c|}
\hline \multirow{2}{*}{\multicolumn{1}{|c|}{ Total Brasil }} & \multicolumn{2}{c|}{ Validação } & \multicolumn{2}{c|}{ Treinamento } \\
\cline { 2 - 5 } & MAPE & MAD & MAPE & MAD \\
\hline Modelo Fuzzy univariado & 2,0003 & 6786,6660 & 2,0497 & 4861,3310 \\
\hline Modelo Fuzzy com PIB & 3,3941 & 11493,0600 & 1,7831 & 4342,6820 \\
\hline Modelo Fuzzy com PIB + População & 1,4627 & 4971,7620 & 1,3103 & 3890,6370 \\
\hline
\end{tabular}

Fonte: o autor (2014).

Quadro 5.11 - Estatísticas de ajuste para os modelos fuzzy do setor residencial.

\begin{tabular}{|l|c|c|c|c|}
\hline \multirow{2}{*}{ Residencial } & \multicolumn{2}{c|}{ Validação } & \multicolumn{2}{c|}{ Treinamento } \\
\cline { 2 - 5 } & MAPE & MAD & MAPE & MAD \\
\hline Modelo Fuzzy univariado & 3,7590 & 3136,5020 & 2,7280 & 1448,0740 \\
\hline Modelo Fuzzy com PIB & 3,7235 & 3079,2810 & 2,0058 & 1093,3400 \\
\hline Modelo Fuzzy com PIB + População & 1,6658 & 1366,9410 & 1,5931 & 1085,7710 \\
\hline
\end{tabular}

Fonte: o autor (2014).

Quadro 5.12 - Estatísticas de ajuste para os modelos fuzzy do setor comercial.

\begin{tabular}{|l|c|c|c|c|}
\hline \multirow{2}{*}{ Comercial } & \multicolumn{2}{c|}{ Validação } & \multicolumn{2}{c|}{ Treinamento } \\
\cline { 2 - 5 } & MAPE & MAD & MAPE & MAD \\
\hline Modelo Fuzzy univariado & 4,1409 & 2269,2320 & 2,3595 & 759,6820 \\
\hline Modelo Fuzzy com PIB & 5,7309 & 3334,7350 & 1,6638 & 555,1220 \\
\hline
\end{tabular}

Fonte: o autor (2014). 
Quadro 5.13 - Estatísticas de ajuste para os modelos fuzzy do setor industrial.

\begin{tabular}{|l|c|c|c|c|}
\hline \multirow{2}{*}{ Industrial } & \multicolumn{2}{c|}{ Validação } & \multicolumn{2}{c|}{ Treinamento } \\
\cline { 2 - 5 } & MAPE & MAD & MAPE & MAD \\
\hline Modelo Fuzzy univariado & 5,5290 & 8147,9990 & 2,9920 & 3213,8030 \\
\hline Modelo Fuzzy com PIB & 5,6267 & 8347,6000 & 2,1047 & 2274,4740 \\
\hline
\end{tabular}

Fonte: o autor (2014).

Quadro 5.14 - Estatísticas de ajuste para os modelos fuzzy de outros setores.

\begin{tabular}{|l|c|c|c|c|}
\hline \multirow{2}{*}{ Outros setores } & \multicolumn{2}{c|}{ Validação } & \multicolumn{2}{c|}{ Treinamento } \\
\cline { 2 - 5 } & Mape & MAD & Mape & MAD \\
\hline Modelo Fuzzy univariado & 3,9100 & 1952,5980 & 1,7587 & 565,6386 \\
\hline $\begin{array}{l}\text { Modelo Fuzzy com Consumo } \\
\text { residencial }\end{array}$ & 3,8776 & 1943,8890 & 1,0030 & 335,2318 \\
\hline
\end{tabular}

Fonte: o autor (2014).

Finalmente as figuras 5.15 e 5.16 são trazem respectivamente as projeções dos modelos fuzzy por classes de consumo e a comparação destas projeções com os valores mais recentes previstos pela a EPE. Nota-se que as projeções do modelo fuzzy se aproximam mais das projeções da EPE nas classes comercial e residencial. Assim, é possível visualizar no Quadro 5.15, as projeções feitas para 2014 até 2023 pela EPE. Consequentemente, é fornecido para o leitor no quadro 5.16, todas as projeções feitas pelos últimos modelos fuzzy propostos neste estudo.

Para fins de comparação com as projeções adotadas pela EPE o quadro 5.17 fornece os desvios relativos das previsões por classe da EPE em relação às previsões geradas pelos modelos finais adotados. 

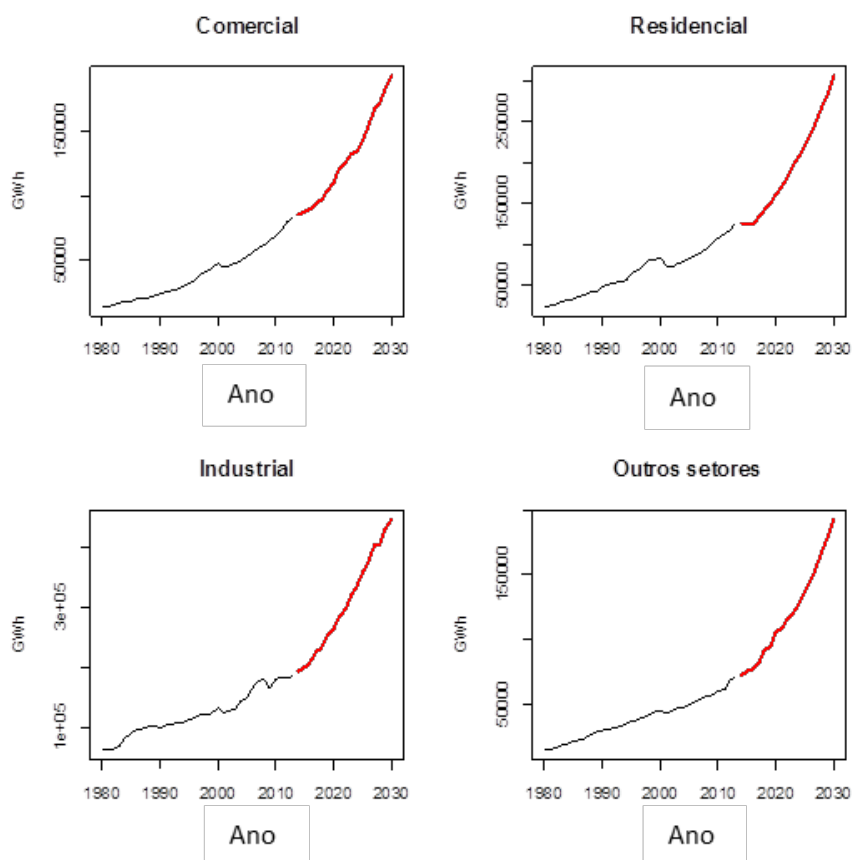

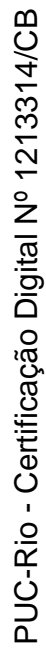

Figura 5.15 - Gráfico das previsões até 2030 do modelo fuzzy causal para o consumo de energia elétrica por classes.

Fonte: o autor (2014).
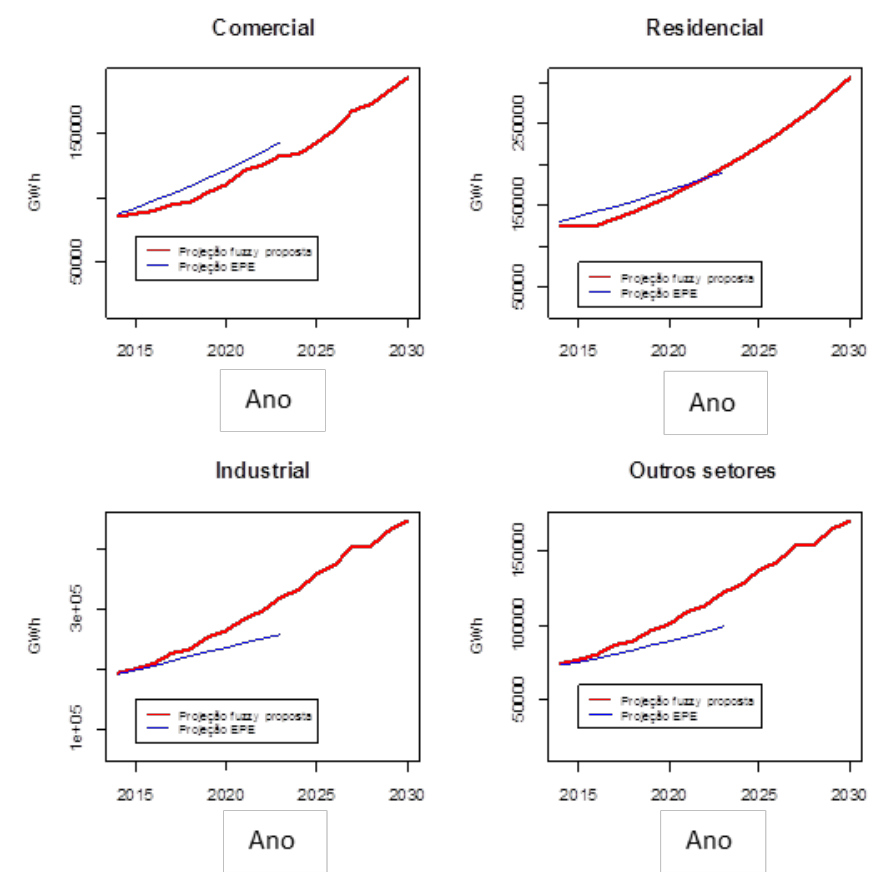

Figura 5.16 - Previsões do modelo fuzzy proposto versus previsões EPE.

Fonte: o autor e EPE (NOTA TÉCNICA DEA 28/13). 
Quadro 5.15 - Valores das previsões fornecidas da EPE para 2014 - 2023.

\begin{tabular}{|r|r|r|r|r|r|}
\multicolumn{1}{|c|}{ Ano } & $\begin{array}{c}\text { Comercial } \\
\text { (GWh) }\end{array}$ & $\begin{array}{c}\text { Residencial } \\
\text { (GWh) }\end{array}$ & $\begin{array}{c}\text { Industrial } \\
\text { (GWh) }\end{array}$ & $\begin{array}{c}\text { Outros setores } \\
\text { (GWh) }\end{array}$ & $\begin{array}{c}\text { Total } \\
\text { Brasil } \\
\text { (GWh) }\end{array}$ \\
\hline $\mathbf{2 0 1 4}$ & 87.378 & 129.983 & 191.333 & 72.691 & 481.385 \\
\hline $\mathbf{2 0 1 5}$ & 91.971 & 135.785 & 198.367 & 75.138 & 501.261 \\
\hline $\mathbf{2 0 1 6}$ & 97.179 & 142.078 & 205.600 & 77.800 & 522.657 \\
\hline $\mathbf{2 0 1 7}$ & 102.605 & 148.390 & 213.401 & 80.487 & 544.884 \\
\hline $\mathbf{2 0 1 8}$ & 108.359 & 154.879 & 222.148 & 83.271 & 568.657 \\
\hline $\mathbf{2 0 1 9}$ & 114.455 & 161.535 & 228.866 & 86.152 & 591.009 \\
\hline $\mathbf{2 0 2 0}$ & 120.914 & 168.368 & 236.013 & 89.131 & 614.426 \\
\hline $\mathbf{2 0 2 1}$ & 127.755 & 175.378 & 243.211 & 92.211 & 638.556 \\
\hline $\mathbf{2 0 2 2}$ & 134.997 & 182.568 & 250.009 & 95.395 & 662.969 \\
\hline $\mathbf{2 0 2 3}$ & 142.660 & 189.934 & 257.714 & 98.682 & 688.990 \\
\hline
\end{tabular}

Fonte: NOTA TÉCNICA DEA 28/13.

Quadro 5.16 - Valores das previsões até 2030 do modelo fuzzy para o consumo de energia elétrica por classes.

\begin{tabular}{|r|r|r|r|r|r|}
\hline Ano & $\begin{array}{c}\text { Comercial } \\
\text { (GWh) }\end{array}$ & $\begin{array}{r}\text { Residencial } \\
\text { (GWh) }\end{array}$ & $\begin{array}{c}\text { Industrial } \\
\text { (GWh) }\end{array}$ & $\begin{array}{c}\text { Outros setores } \\
\text { (GWh) }\end{array}$ & $\begin{array}{c}\text { Total Brasil } \\
\text { (GWh) }\end{array}$ \\
\hline $\mathbf{2 0 1 4}$ & 85.500 & 124.886 & 192.653 & 72.752 & 471.050 \\
\hline $\mathbf{2 0 1 5}$ & 87.320 & 124.914 & 201.128 & 75.004 & 478.539 \\
\hline $\mathbf{2 0 1 6}$ & 89.179 & 124.941 & 209.975 & 77.326 & 486.146 \\
\hline $\mathbf{2 0 1 7}$ & 94.584 & 133.194 & 225.677 & 81.952 & 515.623 \\
\hline $\mathbf{2 0 1 8}$ & 96.945 & 141.992 & 234.177 & 91.461 & 537.567 \\
\hline $\mathbf{2 0 1 9}$ & 103.685 & 151.371 & 252.960 & 94.293 & 561.182 \\
\hline $\mathbf{2 0 2 0}$ & 110.249 & 161.369 & 263.130 & 105.691 & 570.099 \\
\hline $\mathbf{2 0 2 1}$ & 120.619 & 172.028 & 284.206 & 108.963 & 579.832 \\
\hline $\mathbf{2 0 2 2}$ & 125.633 & 183.391 & 296.096 & 116.614 & 605.869 \\
\hline $\mathbf{2 0 2 3}$ & 132.291 & 195.504 & 319.822 & 120.225 & 632.480 \\
\hline $\mathbf{2 0 2 4}$ & 133.723 & 208.418 & 333.006 & 128.667 & 653.718 \\
\hline $\mathbf{2 0 2 5}$ & 142.841 & 222.185 & 359.688 & 137.701 & 664.234 \\
\hline $\mathbf{2 0 2 6}$ & 152.590 & 236.860 & 374.413 & 147.370 & 674.907 \\
\hline $\mathbf{2 0 2 7}$ & 167.303 & 252.506 & 404.379 & 157.718 & 690.850 \\
\hline $\mathbf{2 0 2 8}$ & 171.734 & 269.184 & 405.631 & 168.793 & 716.746 \\
\hline $\mathbf{2 0 2 9}$ & 182.564 & 286.965 & 432.293 & 180.645 & 748.236 \\
\hline $\mathbf{2 0 3 0}$ & 192.587 & 305.920 & 447.058 & 193.329 & 773.901 \\
\hline & & & & & \\
\hline
\end{tabular}

Fonte: o autor (2014). 
Quadro 5.17 - Desvios relativos das previsões por classe da EPE em relação às projeções geradas pelos modelos fuzzy.

\begin{tabular}{|r|r|r|r|r|r|}
\hline Ano & $\begin{array}{r}\text { Residencial } \\
\text { (GWh) }\end{array}$ & $\begin{array}{r}\text { Industrial } \\
\text { (GWh) }\end{array}$ & $\begin{array}{c}\text { Comercial } \\
\text { (GWh) }\end{array}$ & $\begin{array}{c}\text { Outros setores } \\
\text { (GWh) }\end{array}$ & $\begin{array}{c}\text { Total Brasil } \\
\text { (GWh) }\end{array}$ \\
\hline $\mathbf{2 0 1 4}$ & $-4,08 \%$ & $0,69 \%$ & $-2,20 \%$ & $0,08 \%$ & $-2,19 \%$ \\
\hline $\mathbf{2 0 1 5}$ & $-8,70 \%$ & $1,37 \%$ & $-5,33 \%$ & $-0,18 \%$ & $-4,75 \%$ \\
\hline $\mathbf{2 0 1 6}$ & $-13,72 \%$ & $2,08 \%$ & $-8,97 \%$ & $-0,61 \%$ & $-7,51 \%$ \\
\hline $\mathbf{2 0 1 7}$ & $-11,41 \%$ & $5,44 \%$ & $-8,48 \%$ & $1,79 \%$ & $-5,67 \%$ \\
\hline $\mathbf{2 0 1 8}$ & $-9,08 \%$ & $5,14 \%$ & $-11,77 \%$ & $8,95 \%$ & $-5,78 \%$ \\
\hline $\mathbf{2 0 1 9}$ & $-6,71 \%$ & $9,52 \%$ & $-10,39 \%$ & $8,63 \%$ & $-5,32 \%$ \\
\hline $\mathbf{2 0 2 0}$ & $-4,34 \%$ & $10,31 \%$ & $-9,67 \%$ & $15,67 \%$ & $-7,78 \%$ \\
\hline $\mathbf{2 0 2 1}$ & $-1,95 \%$ & $14,42 \%$ & $-5,92 \%$ & $15,37 \%$ & $-10,13 \%$ \\
\hline $\mathbf{2 0 2 2}$ & $0,45 \%$ & $15,56 \%$ & $-7,45 \%$ & $18,20 \%$ & $-9,42 \%$ \\
\hline $\mathbf{2 0 2 3}$ & $2,85 \%$ & $19,42 \%$ & $-7,84 \%$ & $17,92 \%$ & $-8,93 \%$ \\
\hline
\end{tabular}

Fonte: o autor (2014).

Concluída a etapa de aplicação e resultados dos modelos, o próximo capítulo traz as conclusões finais deste estudo, juntamente com as sugestões de aprimoramento para próximas análises. 


\section{Conclusões e considerações finais}

O consumo de energia elétrica no Brasil vem sendo estudado há muitos anos, sendo abordado com diferentes metodologias e premissas. A importância da previsão de longo prazo desta variável, como já comentado neste estudo, acaba por despertar interesse em diferentes áreas da estatística aplicada, principalmente em áreas cujas técnicas são relativamente novas na literatura e que possam apresentar uma perspectiva de inovação no setor elétrico brasileiro.

Neste estudo, a abordagem de Lógica Fuzzy se mostrou bastante satisfatória quando comparada às técnicas clássicas de análise de séries temporais. Os modelos finais propostos alcançaram excelentes resultados nas estatísticas de ajuste tanto na amostra original da série quanto na etapa de validação. A inclusão das variáveis independentes PIB e População também se mostrou significativa nos modelos testados.

Para a classe residencial, o melhor modelo se deu quando foram incluídas no modelo univariado as variáveis de PIB e população residente. Os resultados das previsões deste modelo se situaram também abaixo das projeções feitas pela a EPE para os anos de 2014 à 2023.

Na classe comercial, o modelo proposto com o PIB resultou em previsões também abaixo do que está sendo projetado no mercado para os anos 2014 e 2023. Este modelo apresentou bons resultados nas suas estatísticas de ajuste quando comparadas principalmente ao modelo Holt de dois parâmetros.

$\mathrm{Na}$ classe industrial, o modelo proposto utilizando o PIB do setor da indústria gera bons resultados quando comparado aos modelos estatístico e fuzzy univariado. Quando comparado às projeções da EPE para o mercado até 2023 o modelo proposto resulta em previsões de patamar superior, sobrestimando às expectativas oficiais para este setor. Neste caso, vale ressaltar que no modelo industrial o cenário de PIB da indústria não foi o mesmo considerado pela a EPE.

No modelo de outros setores os resultados obtidos com a inclusão da variável de consumo residencial retornaram grandes ganhos em relação aos 
modelos estatístico e fuzzy univariado. Quando comparadas às expectativas oficiais para o setor, o modelo proposto se mostra menor otimista, apontando previsões acima das esperadas.

Finalmente, para a série de consumo total Brasil, o melhor ajuste se deu com um modelo englobando uma parte autoregressiva de três antecedentes, o PIB e a população residente. Quando comparadas às projeções divulgadas pela a EPE, as previsões do modelo proposto fornecem expectativas de consumo menores do que a divulgada para os anos até 2023 e praticamente igual em 2030 o cenário oficial de menor nível (cenário C).

Portanto, os resultados finais da maioria dos modelos propostos, com exceção do setor industrial e dos outros setores, são de projeções subestimando as expectativas oficiais fornecidas pela a EPE.

Como futuras investigações, a ideia de inclusão de outras variáveis explicativas nos modelos do setor comercial e de outros setores poderia aprimorada, como por exemplo: a distribuição de renda, conservação de energia, tarifas e a difusão de eletrodomésticos.

O desdobramento destes modelos com a mesma abordagem para os subsistemas das regiões do Brasil poderia ser considerado também. Uma abordagem bottom-up forneceria um total de 20 modelos considerando as quatro classes de consumos, os quatro subsistemas existentes e o total Brasil por subsistema. 


\section{6 Refe rências Bibliográficas}

Abbud, O. A. (23 de 04 de 2014). Brasil Economia e Governo: Infraestrutura e governo. Acesso em 25 de 11 de 2014, disponível em Brasil Economia e Governo: http:/www.brasil-economia-governo.org.br/2014/04/23/porque-o-brasil-esta-correndo-risco-de-racionamento-de-energia-eletrica/

Achanta, R. (Janeiro - de 2012). Long Term Electric Load Forecasting using Neural Networks and Support Vector Machines. International Journal of Computer Scicience And Technology, 266-269.

Al-Hamadi, H. M. (2011). Long-Term Electric Power Load Forecasting Using Fuzzy Linear Regression Techinique.

Amlabu, C. A., Agber, J. U., Onah, C. O., \& Mohammed, S. Y. (2013). Eletric Load Forecasting: A Case Study of the Nigerian Power Sector. International Journal of Engineering and Innovative Technology (IJEIT), 23-27.

Ardakani, F. J., \& Ardehali, M. M. (2014). Novel effects of demand side management data on accuracy of electrical energy consumptiom modeling and long-term forecastin. Energy Conversion and Management, 745-752.

Barakat, E., \& Al-Rashid, S. A. (1992). Long-term peak demand forecasting under conditions of high growth. IEEE Trans. Power Systems, pp. 1483-6.

Campos, A. F., \& Moraes, N. G. (2012). Tópicos em Energia. Rio de Janeiro: Synergia.

Cho, M. Y., Hwang, J. C., \& Chen, C. S. (1955). Customer Short-Term Load Forecasting by using ARIMA Transfer Function Model. In: M. Y. Cho, J. C. Hwang, \& C. S. Chen, Proceedings of the International Conference on Energy Management and Power Delivery (pp. 317 - 322).

Chow, M.-y., \& Tram, H. (Agosto de 1997). Application of Fuzzy Logic Technology for Spatial Load Forecasting. IEEE, pp. 1360-1366.

Cox, E. (1994). The Fuzzy Systems Handbook: A Practitioner's Guide to Building, Using, and Maintaining Fuzzy Systems. AP Professional. 
Cox, E. (1995). Fuzzy Logic for Business and Industry. Delmar Thompson Learning.

Fan, J. Y., \& McDonald, J. D. (1994). A Real Time Implementation of ShortTerm Lod Forecasting for Distribution Power System. IEEE Transactions on Power Systems, pp. 988 - 994.

Feinberg, E. A., \& Genethliou, D. (2002, 2003). Load Forecasting. In: E. A. Feinberg, Load Forecasting (pp. 269 - 278).

Ghelardoni, L., \& Ghio, A. (12 de 2012). Long-Term energy forecasting using Auto-Regressive and approximating Support Vector Regression. IEEE, pp. 842-847.

Ghelardoni, L., Ghio, A., \& Anguita, D. (2013). Energy Load Forecasting Using Empirical Mode Decomposition and Support Vector Regression. IEEE, pp. 549-556.

Ghods, L., \& Kalantar, M. (Dezembro de 2011). Different Methods of Long-Term Electric Load Demand Forecasting; A Comprehensive Review.

Herédia, T. (09 de Janeiro de 2013). As vítimas econômicas da crise energética. Acesso em Abril de 2014, disponível em http://g1.globo.com/: http://g1.globo.com/platb/thaisheredia/2013/01/09/as-vitimas-economicasda-crise-energetica/

Hongyan, L., Liya, C., \& Xiaojuan, W. (04 de 2008). Grey-RBF Neural Network Prediction Model for City. IEEE, pp. 1-5.

Huayllas, T. E., \& Ramos, D. S. (September de 2010). Electric Power Forecasting Methodologies of Some South American Countries: A Comparative Analysis. IEEE LATIN AMERICA TRANSACTIONS, pp. 519-525.

Imtiaz A K, N. B. (2006). Evaluation and Forecasting of Long Term Electricity. First International Power and Energy Coference PECon, (pp. 257-262). Puntrajaya, Malaysia.

Iranmanesh, H., Abdollahzade, M., \& Miranian, A. (2011). Forecasting Energy Consumption using fuzzy transform and local linear neuro fuzzy models. International Journal on Soft Computing ( IJSC ), Vol.2, N.4.

Irffi, G., Castelar, I., Siqueira, M. L., \& Linhares, F. C. (2009). Previsão da demanda por energia elétrica para classes de consumo na região Nordeste, usando OLS dinâmico e mudança de regime. Econ. Aplic., 69-98. 
Jang, J.-S. R., Sun, C. T., \& Mizutani, E. (1997). Neuro-Fuzzy and Soft Computating: A Computational Approach to Learning and Machine Intelligence. Prentice Hall Inc.

Jebaraj, S., \& Iniyan, S. (2006). Renewable and Sustainable Energy Reviews. In: S. Jebaraj, A review of energy models (pp. 281 - 3011).

Karabulut, K., Alkan, A., \& Yilmaz, A. (2008). Long Term Energy Consuption Forecasting Using Genetic Programming. Mathematical and Computational Applications, 71-80.

Khoa, T., Phuong, L., Binh,, P., \& Lien, N. (2004). Application of Wavelet and Neural Network. IEEE, pp. 840-844.

Klir, G. J., \& Yuan, B. (1995). Fuzzy Sets and Fuzzy Logic - Theory and Applications. Prentice Hall PTR.

KLIR, G. J., \& YUAN, B. (1995). Fuzzy Sets and Fuzzy Logic: Theory and Applications. . Prentice Hall.

Kucukali, S., \& Baris, K. (28 de Julho de 2009). Turkey’s short-term gross annual electricity demand forecast by fuzzy. Energy Policy.

Mahmoud, H. M., Elkhodary, S. M., \& El-Debeiky, S. (3 de 08 de 2008). SPECIAL FEATURES OF ENERGY FORECAST. IEEE, pp. 555-559.

Mendel, J. M. (1995). Fuzzy Logic Systems for Engineering: a Tutorial. IEEE, pp. 345-377.

Morettin, P. A., \& Toloi, C. M. (2006). Análise de Séries Temporais. São Paulo: Edgard Blucher LTDA.

Neeland, H. (2009). The Residential Demand for Electricity in the United States. ECONOMIC ANALYSIS \& POLICY, 193-105.

Nguyen, T., \& Fu, C. W. (06 de 2003). Models for Long-Term Energy Forecasting. IEEE, pp. 235-239.

Pacheco, M., \& Vellasco, M. (2007). Sistemas inteligentes de apoio à decisão: análise econômica de projetos de desenvolvimento de campo de petróleo sob incerteza. Rio de Janeiro: PUC-Rio.

Pires, A. (24 de 07 de 2014). Valor Econômico - Opinião. Acesso em 09 de 12 de 2014, disponível em Valor Econômico: http://www.valor.com.br/opiniao/3624434/tempos-ruins-e-saidas-dificeispara-o-setor-eletrico 
Pires, J. C., Giambiagi, F., \& Sales, A. F. (2002). As Perspectivas do Setor Elétrico Após Racionamento. Rio de Janeiro: BNDES.

Ribeiro, C. V. (2009). Um ambiente para previsão de séries temporais utilizando comitês de aprendizado. Dissertação de mestrado. Rio de Janeiro, Instituto Militar de Engenharia.

Ronald Reagan, C. P., \& Sari, S. R. (Março de 2014). Long Term Load Forecasting in Tamil Nadu Using Fuzzy-Neural Technology. International Journal of Engineering and Innovative Technology (IJEIT), p. Vol 3.

Ross, T. J. (2004). Fuzzy Logic with Engineering Applications. University of New Mexico, USA: John Wiley \& Sons Ltd.

Shelton, J. (Outrubro de 1969). Power Mrket Study and Forecast - PMS \& F.

Souza, R. C., \& Cyrino, F. (2014). Statistical analysis of the brazilian electricity sector: a top-down long range energy consumption and supply.

Spackman, D., Sivakumar, G., C. Nair, N.-K., \& Yeung, P. (2006). Long Term Demand Forecast for an Electricity. IEEE, pp. 1-6.

Srinivas, E., \& Jain, A. (2011). A Methodollogy for Short Term Load Forecasting Using Fuzzy Logic and Similarity. IEEE, pp. 1-6.

Tanaka, K., \& Nimura, T. (2007). An Introduction to Fuzzy Logic for Practical Applications. Springer.

Terpathy, S. (1997). Demand forecasting in a power system. In: T. S.C., Energy Conversion and Management. 1457 - 1481.

Vellasco, M. (2007). Notas de Aula. www.ica.ele.puc-rio.br.

Wang, L., \& Mendel, J. M. (1992). Generating Fuzzy Rules by Learning from example. IEEE Transactions on System, Man and Cybernetics.

Yang, H. T., \& Huang, C. M. (1998). A New Short-Term Load Forecast Approach using Self-Organizing Fuzzy ARMAX Models. IEEE Trasactions on Power Systems, pp. 217 - 225.

Yang, H. T., Huang, C. M., \& Huang, C. L. (1996). Identification of ARMAX Model for Short-Term Load Forecasting. IEEE Transactions on Power Systems, pp. 403 - 408.

ZADEH, L. A. (1996). Fuzzy logic = computing with words. IEEE Transactions on Systems, Man, and Cybernetics, pp. 103-111.

Zimmermann, H. J. (2001). Fuzzy Sets and Fuzzy Logic: Theory and Applications. Prentice Hall. 


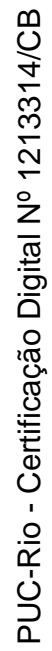




\section{Apêndice A - Rotina gerada no R}

\# PREVISOR ATRAVÉS DO MODELO FUZZY

\# EXEMPLO GENÉRICO COM A SÉRIE RESIDENCIAL

lag = 3 \# lags autoregressivos (PARAMETRO DE ENTRADA DEFINIDO PELO ANALISTA)

nvalida $=10$ \# número de padroes na validação (PARAMETRO INFORMADO PELO ANALISTA)

num_con_fuzzy $=5$ \# número de conjuntos fuzzy (PARAMETRO INFORMADO PELO ANALISTA)

\section{\# CARREGA OS PACOTES NECESSÁRIOS}

library(frbs) \# carrega pacote frbs (inferência fuzzy) previamente instalado \# pacote frbs http://cran.r-project.org/web/packages/frbs/frbs.pdf library(XLConnect) \# carrega pacote XLConnect (interface com Excel) previamente instalado

\# ESTABELECE DIRETÓRIO DE TRABALHO

setwd('F: $\ \backslash$ Engenharia $\quad$ Elétrica $\quad$ - $\quad$ PUCl\Dissertação de mestrado \\Bases $\backslash \backslash$ Bases preparadas') \#Alterei o código para ler direto do meu pendrive,

\# LEITURA DA PLANILHA DE DADOS DE MERCADO (GWh)

wb = loadWorkbook('Base de dados - Final2.xls') \# Lê o arquivo

data $=$ readWorksheet $(w b$, sheet=1,header=TRUE) \# Lê a primeira aba com o histórico das variávei dependentes

\#SEPARA A SÉRIE DE VARIAÇÃO DO PIB data2 $=$ readWorksheet $($ wb,sheet $=2$,header=TRUE $)$ 
seriepib $=$ data2[,2]

\# NÚMERO DE OBSERVAÇÕES DA SÉRIE ORIGINAL

nobs_original $=\operatorname{dim}(\operatorname{data})[1]$

\#MATRIZ DE CORRELAÇÃO DOS DADOS DE CONSUMO

$\mathrm{mc}=\operatorname{cor}(\operatorname{data}[, 2: 5])$

\# SEPARA AS SÉRIES DE INTERESSE

serie $=$ data[,3] \# coluna 3 é do total Brasil para a série residencial

resid $=\operatorname{ts}($ data[,3], start $=1980$, frequency $=1)$

\# TOMA O LOG DAS SÉRIES

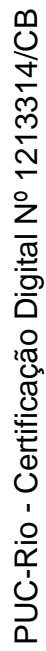

serie_log $=\log ($ serie $)$

\# DIFERENCIA A SÉRIE LOG PARA RETIRAR TENDÊNCIA

serie_log_1dif = serie_log[2:nobs_original]-serie_log[1:(nobs_original-1)]

serie_log_1dif2 $=\operatorname{diff}(\log ($ serie $))$

\# NÚMERO DE OBSERVAÇÕES DA SÉRIE LOG E PRIMEIRA DIFERENÇA

nobs = length(serie_log_1dif2)

\#\#\#\#\#\#\#\#\#\#\#\#\# RODANDO O MODELO SOMENTE COM A PARTE AUTO REGRESSIVA \#\#\#\#\#\#\#\#\#\#\#\#

\# PREPARA CONJUNTO DE PADROES ENTRADA/SAIDA

inic $=$ lag +1

ifim $=$ nobs

for (i in inic:ifim) \{

$\mathrm{X}=$ serie_log_1dif[(i-lag):(i-1)] \# janela de valores passados

$\mathrm{Y}=$ serie_log_1dif[i] \# saída desejada

if (i==inic) \{ 


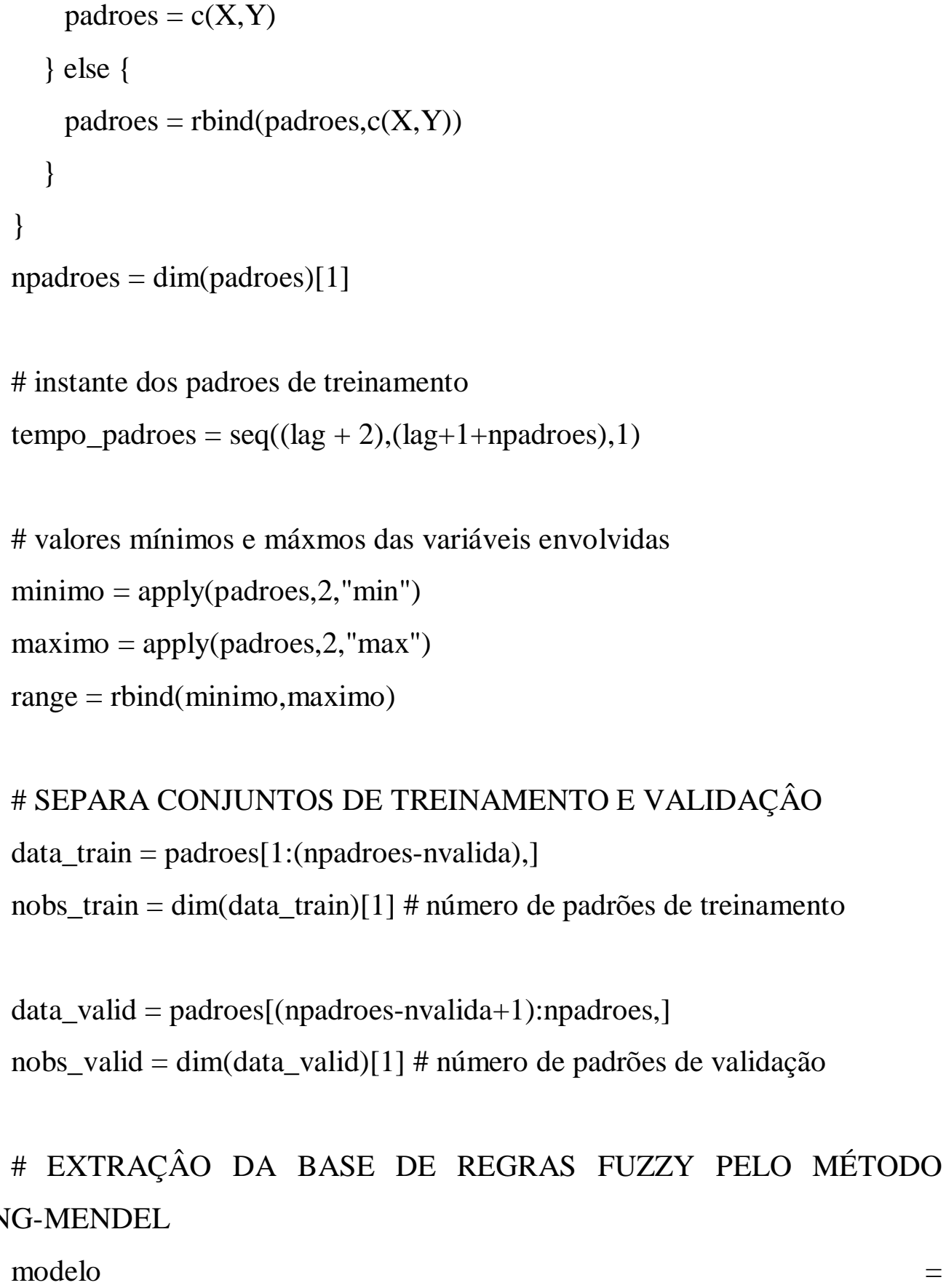

frbs.learn(data_train,range, method.type=c("WM"),control=list(num.labels=num_c on_fuzzy, type.mf="GAUSSIAN"))

base_de_regras = modelo\$rule \# base de regras fuzzy

\#CANÀLISE DOS RESULTADOS PARA O CONJUNTO DE TREINAMENTO

previsao_dif_log = predict(modelo,data_train[,1:lag])

windows() 
plot(data_train[,(lag+1)],previsao_dif_log,xlab="realizado",ylab="previsto", main="CONJUNTO DE TREINAMENTO") \# previsto x realizado

\# INTEGRA E SÉRIE E CALCULA O EXPONENCIAL (PREVISÂO 1 PASSO A FRENTE)

previsao_log=rep(0,nobs_train)

for (i in 1:nobs_train) \{ previsao_log[i] = $\log ($ serie[tempo_padroes[i]-1])+previsao_dif_log[i] \}

previsao_GWh_train $=\exp ($ previsao_log)

\# Gráfico real x estimado

windows()

plot(serie[tempo_padroes[1:nobs_train]],main="CONJUNTO

DE

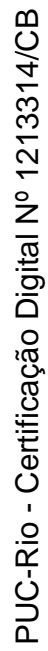

TREINAMENTO",ylab="GWh",type="l")

lines(1:nobs_train,previsao_GWh_train,col="red")

\# resíduos

residuos = serie[tempo_padroes[1:nobs_train]]-previsao_GWh_train

windows()

hist(residuos,30,main="CONJUNTO

DE

TREINAMENTO",xlab="Resíduos")

mape $=0$

for (i in 1:length(residuos)) \{

mape $=$ mape $+\operatorname{abs}($ residuos[i] $) /$ serie[tempo_padroes[i]]

\}

mape_res1 $=100 *$ mape/length(residuos) \# valor $\%$

mad_res1 = mean(abs(residuos)) \# valor em GWh

\# ANÁLISE DO CONJUNTO DE VALIDAÇÂO

previsao_dif_log_valid=predict(modelo,data_valid[,1:lag])

windows() 
plot(data_valid[,(lag+1)],previsao_dif_log_valid,xlab="real",ylab="previsto ",main="CONJUNTO DE VALIDAÇÃO") \# previsto x realizado

\# INTEGRA E SÉRIE E CALCULA O EXPONENCIAL (PREVISÂO 1 PASSO A FRENTE)

previsao_log_valid=rep(0,nobs_valid)

for (i in 1:nobs_valid) \{

$\mathrm{j}=$ nobs_train $+\mathrm{i}$

previsao_log_valid[i]=log(serie[tempo_padroes[j]-

1])+previsao_dif_log_valid[i]

\}

previsao_GWh_valida=exp(previsao_log_valid)

\# GRÁFICO REAL X ESTIMADO

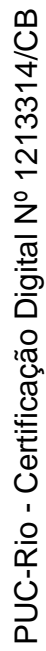

windows()

plot(serie[tempo_padroes[(nobs_train+1):npadroes]],main="CONJUNTO

DE VALIDAÇÃO",ylab="GWh",type="l",xlab="Instante de tempo")

legend(1,120000,legend=c("Real","Ajustado"),col=c("black","red"),lty=c(1, 1), cex=1)

lines(1:nobs_valid,previsao_GWh_valida,col="red")

\# resíduos

residuos_valid=serie[tempo_padroes[(nobs_train+1):npadroes]]-

previsao_GWh_valida

hist(residuos_valid,10,main="CONJUNTO

DE

VALIDAÇÃO",xlab="Resíduos")

mape_valid $=0$

for (i in 1:length(residuos_valid)) \{

$\mathrm{j}=$ nobs_train $+\mathrm{i}$

mape_valid $=$ mape_valid + abs(residuos_valid[i])/serie[j]

\}

mape_valid_res1 $=100 *$ mape_valid/length(residuos_valid)

mad_valid_res1 = mean(abs(residuos_valid)) \# valor em GWh 
\# PREVISÕES ATÉ 2030

\# O PROGRAMA ABAIXO GERA A BASE DE REGRAS COM TODA A SÉRIE E FAZ PREVISÕES H PASSOS A FRENTE

todos_padroes $=$ padroes[1:npadroes, $]$

modelo

frbs.learn(todos_padroes,range,method.type=c("WM"),control=list(num.labels=nu m_con_fuzzy, type.mf="GAUSSIAN"))

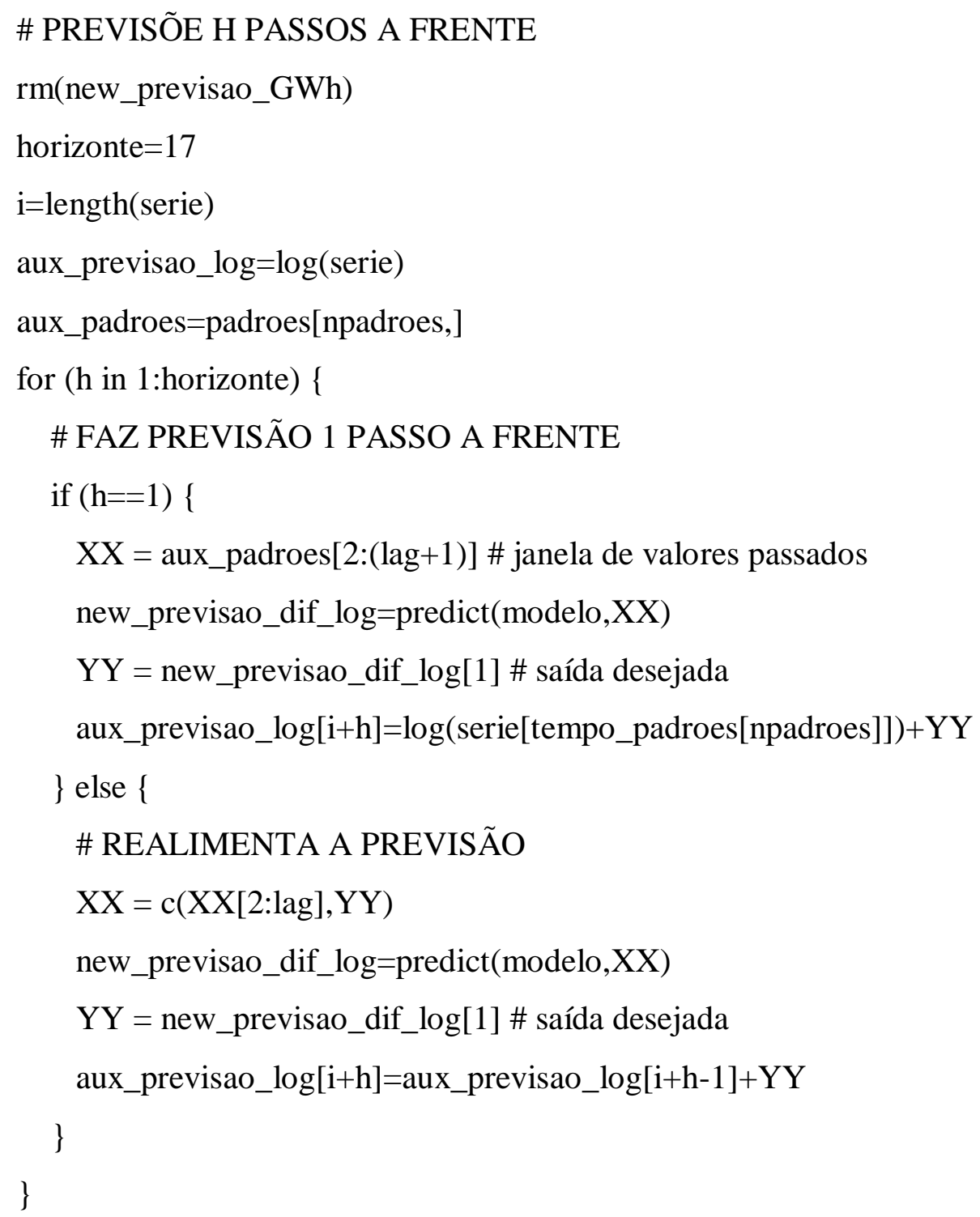


X1prev = seriepib[35:51] \#Projeção do PIB

$\mathrm{Y}=$ serie_log_1dif

padroes_pib $=\operatorname{cbind}(\mathrm{X} 1, \mathrm{Y})$

npadroes $=\operatorname{dim}($ padroes_pib)[1]

\# PREPARA CONJUNTO DE PADROES ENTRADA/SAIDA PARA UM

MODELO COM O PIB E A JANELA DE VALORES PASSADOS

\#\#INSERINDO O PIB

inic $=$ lag +1

ifim $=$ nobs

for (i in inic:ifim) \{

X1 = serie_log_1dif[(i-lag):(i-1)] \# janela de valores passados

$\mathrm{X} 2$ = seriepib[i+1] \# valores do PIB

$\mathrm{Y}=$ serie_log_1dif[i] \# saída desejada

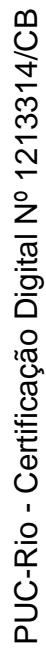

if ( $\mathrm{i}==$ =inic) \{

padroes_pib2 $=\mathrm{c}(\mathrm{X} 1, \mathrm{X} 2, \mathrm{Y})$

\} else \{

padroes_pib2 = rbind(padroes_pib2,c(X1,X2,Y))

\}

\}

npadroes $=$ dim(padroes_pib2) $[1]$

\# INSTANTE DOS PADRÕES DE TREINAMENTO

tempo_padroes = seq((lag +2$),($ lag $+1+$ npadroes $), 1)$

\# valores mínimos e máxmos das variáveis envolvidas

minimo = apply(padroes_pib2,2,"min")

maximo $=$ apply(padroes_pib2,2,"max")

range $=\operatorname{rbind}(\operatorname{minimo}$, maximo $)$

\# SEPARA CONJUNTOS DE TREINAMENTO E VALIDAÇÂO

data_train = padroes_pib2[1:(npadroes-nvalida), ] 
nobs_train = dim(data_train)[1] \# número de padrões de treinamento

data_valid = padroes_pib2[(npadroes-nvalida+1):npadroes, $]$

nobs_valid = dim(data_valid)[1] \# número de padrões de validação

\# EXTRAÇÂO DA BASE DE REGRAS FUZZY PELO MÉTODO WANG-MENDEL

modelo

frbs.learn(data_train,range,method.type $=\mathrm{c}($ "WM"),control=list(num.labels=num_c on_fuzzy, type.mf="GAUSSIAN"))

\# ANÀlise DOS RESUltados PARA O CONJUNTO DE TREINAMENTO

previsao_dif_log $=$ predict(modelo,data_train[,1:(lag+1)])

windows()

plot(data_train[,(lag+2)],previsao_dif_log,xlab="realizado",ylab="previsto", main="CONJUNTO DE TREINAMENTO") \# previsto x realizado

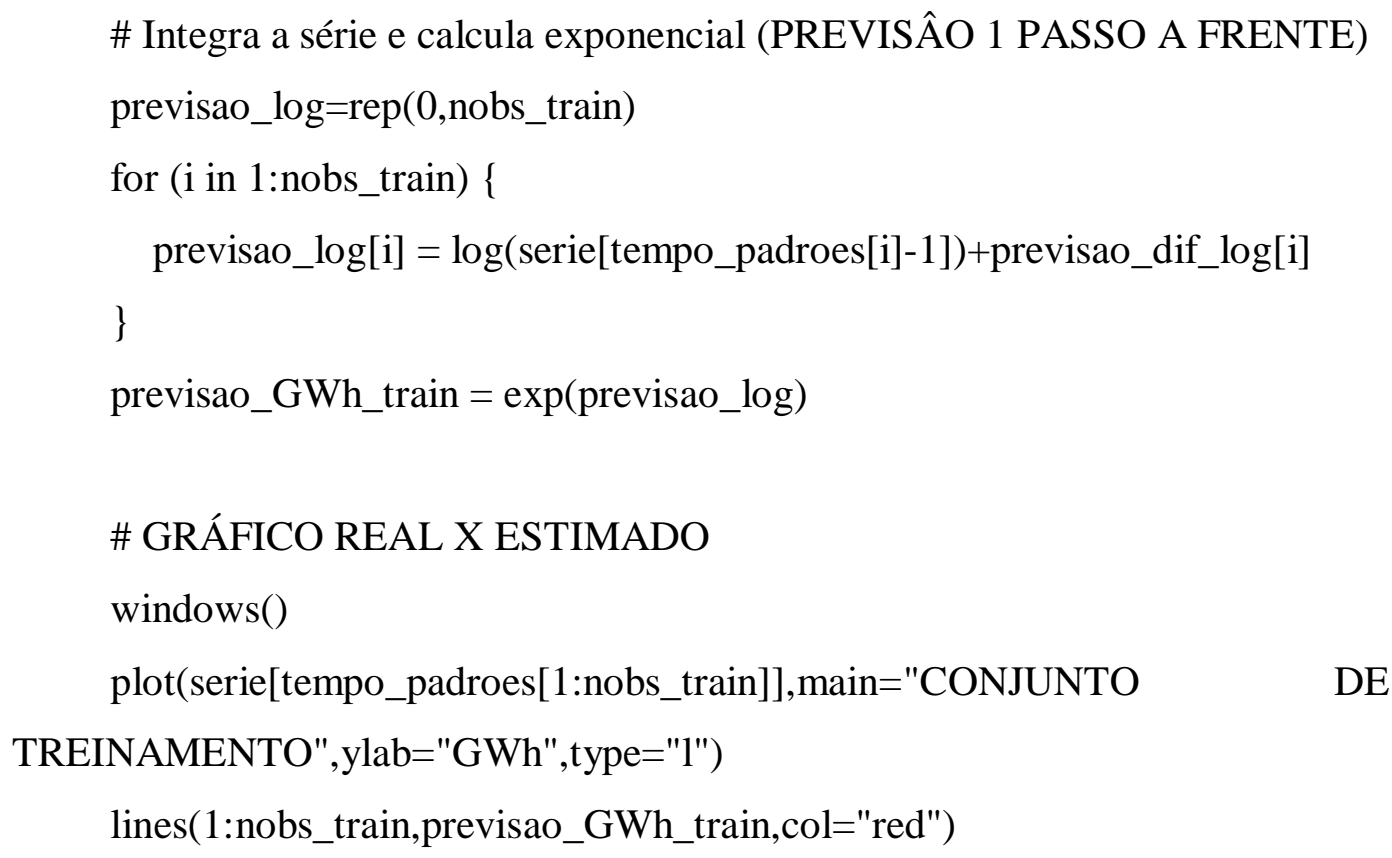




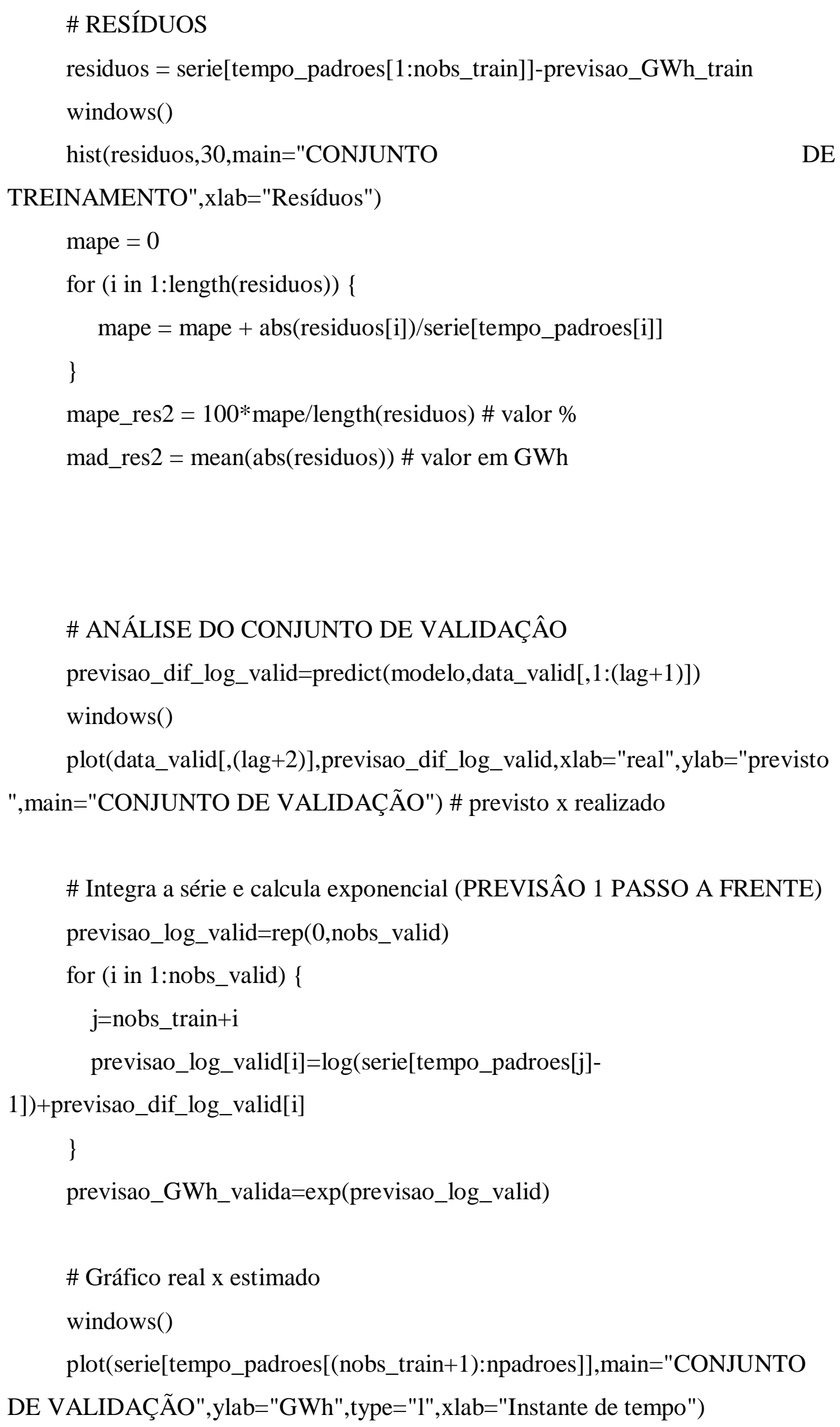


legend(1,450000,legend=c("Real","Ajustado"),col=c("black","red"),lty=c(1, 1), $c e x=1)$

lines(1:nobs_valid,previsao_GWh_valida,col="red")

\# RESÍDUOS

residuos_valid=serie[tempo_padroes[(nobs_train+1):npadroes]]-

previsao_GWh_valida

hist(residuos_valid,10,main="CONJUNTO

DE

VALIDAÇÃO",xlab="Resíduos")

mape_valid $=0$

for (i in 1:length(residuos_valid)) \{

$\mathrm{j}=$ nobs_train $+\mathrm{i}$

mape_valid $=$ mape_valid + abs(residuos_valid[i])/serie[j]

\}

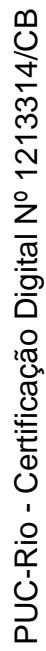

mape_valid_res2 $=100 *$ mape_valid/length(residuos_valid)

mad_valid_res2 = mean(abs(residuos_valid)) \# valor em GWh

\# PREVISÕES ATÉ 2030

todos_padroes = padroes_pib2[1:npadroes,]

modelo

frbs.learn(todos_padroes,range,method.type $=c(" W M ")$, control=list(num.labels=nu

m_con_fuzzy, type.mf="GAUSSIAN"))

\# previsão h passos à frente

rm(new_previsao_GWh)

horizonte $=17$

$\mathrm{i}=$ length(serie)

aux_previsao_log=log(serie)

aux_padroes=padroes_pib2[npadroes,]

for (h in 1:horizonte) \{

\# faz previsão um passo a frente

if $(\mathrm{h}==1)\{$

XX = aux_padroes[2:(lag+2)] \# janela de valores passados

new_previsao_dif_log=predict(modelo,XX) 


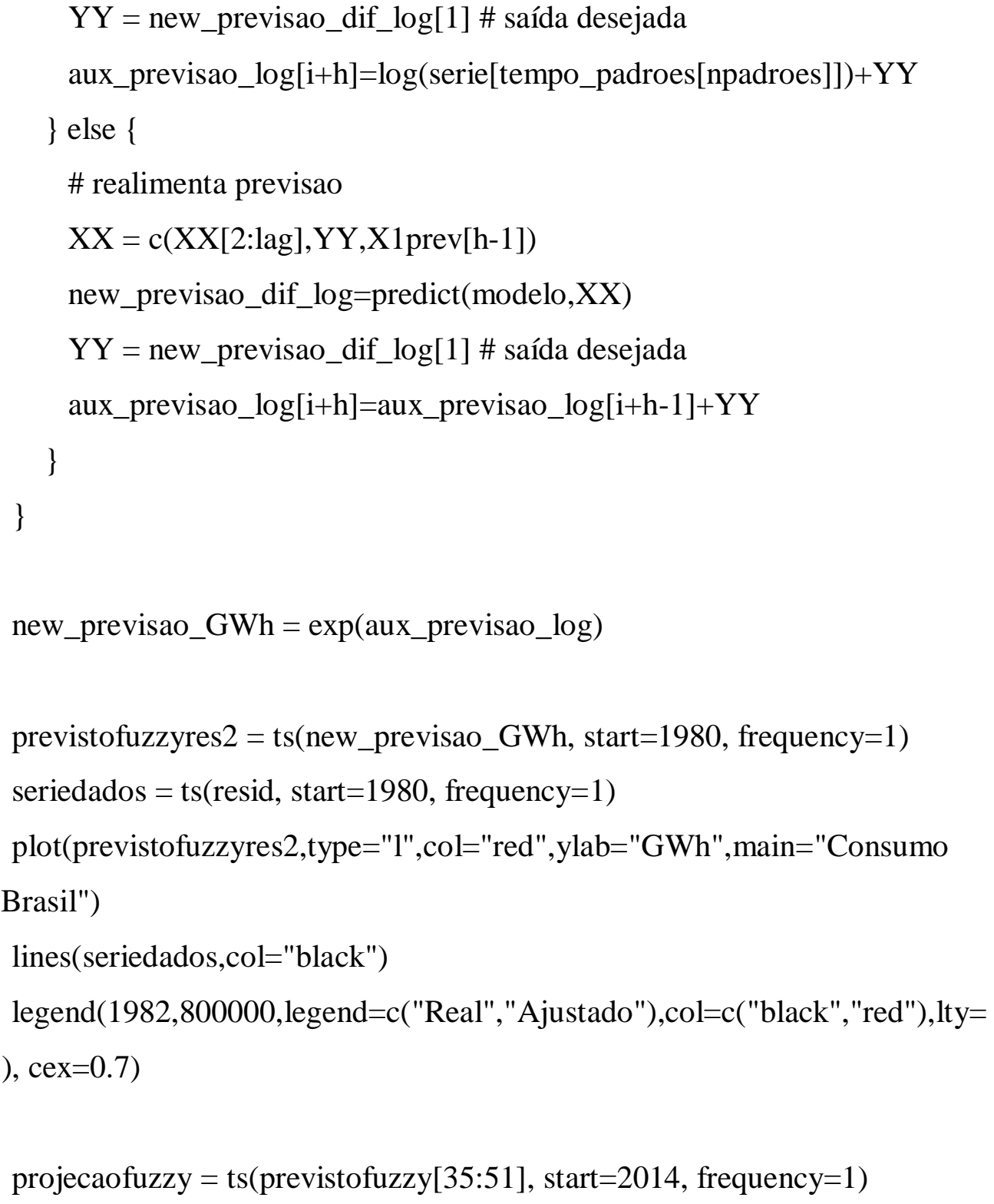

\#\#\#\#\#\#\#\#\#\#\#\#\# RODANDO O MODELO INCLUINDO A POPULAÇÃO RESIDENTE, A PARTE AUTO REGRESSIVA E O PIB \#\#\#\#\#\#\#\#\#\#\#

\#SEPARA A SÉRIE DE VARIAÇÃO DA POPULAÇÃO

data3 $=$ readWorksheet $(w b$, sheet $=3$,header $=$ TRUE $)$

seriepop $=$ data3[,2]

\# NÚMERO DE OBSERVAÇÕES DA SÉRIE ORIGINAL nobs_original $=$ length $($ seriepop[1:34]) 
\# TOMA LOG DAS SÉRIES

serie_log $=\log ($ serie $)$

\# DIFERENCIA A SERIE LOG RETIRAR TENDENCIA

serie_log_1dif = serie_log[2:nobs_original]-serie_log[1:(nobs_original-1)]

\# número de observações da série após log e primeira diferença

nobs = length(serie_log_1dif)

\#Separa a série de variação da Popualação

data3 $=$ readWorksheet $(w b$, sheet $=3$,header $=$ TRUE $)$

seriepop $=$ data3[,2]

\# 4) PREPARA CONJUNTO DE PADROES ENTRADA/SAIDA PARA

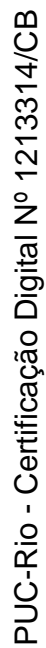
UM MODELO COM PIB E POPULAÇÃO

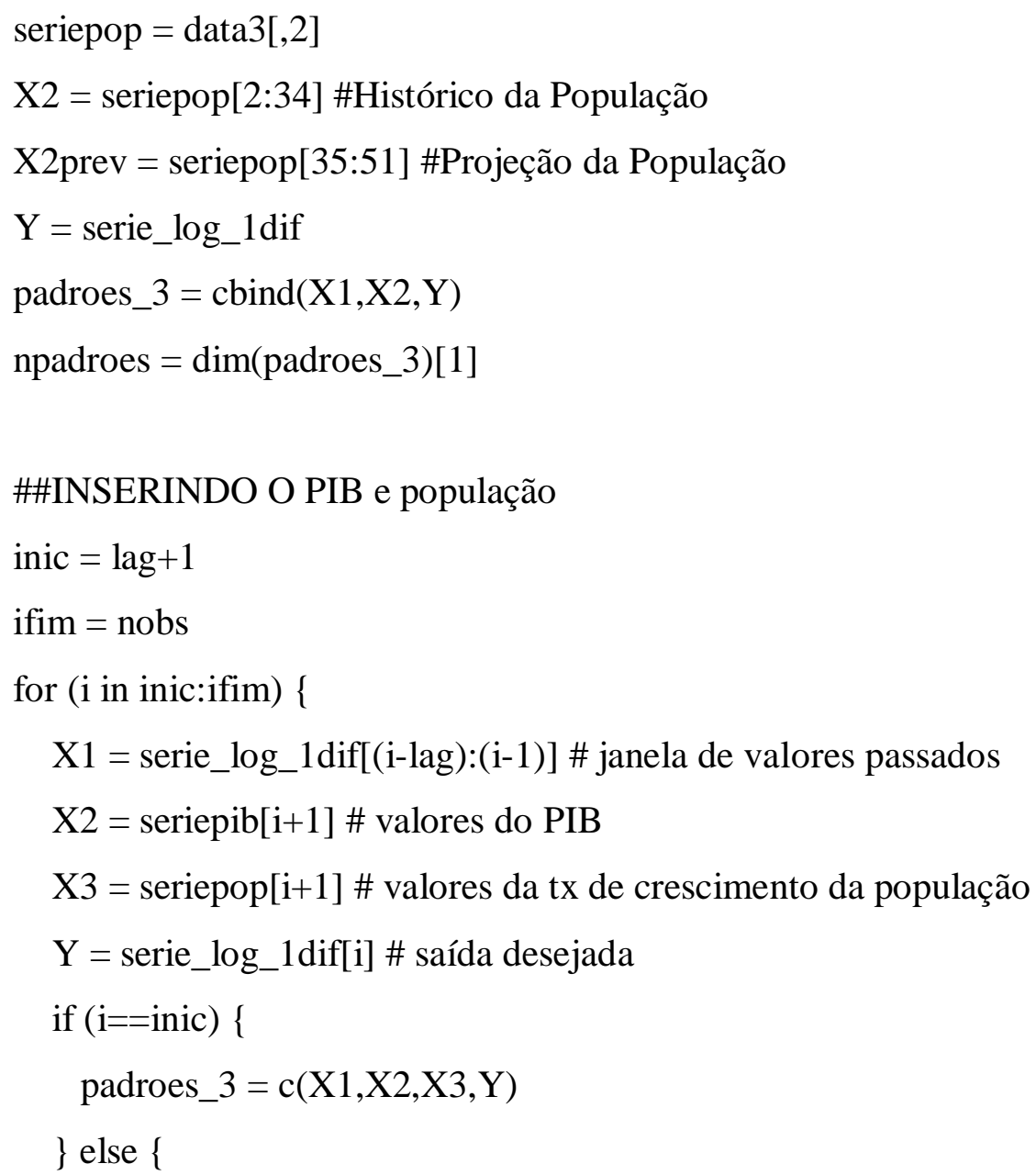




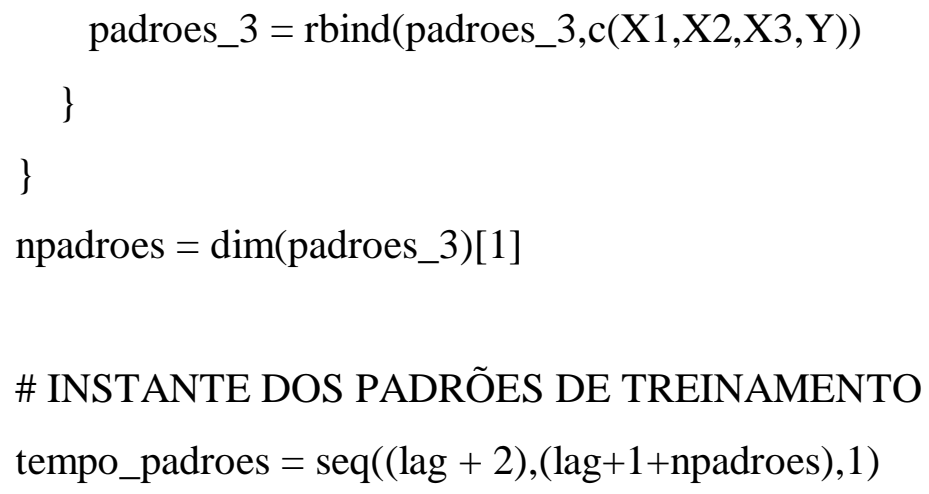

\# EXTRAÇÂO DA BASE DE REGRAS FUZZY PELO MÉTODO WANG-MENDEL

modelo

frbs.learn(padroes_3,range,method.type=c("WM"),control=list(num.labels=num_ con_fuzzy, type.mf="GAUSSIAN"))

\# ANÀlise DOS RESUltados PARA O CONJUNTO DE TREINAMENTO

windows()

plot(padroes_3[,(lag+3)],previsao_dif_log,xlab="realizado",ylab="previsto" ,main="CONJUNTO DE TREINAMENTO") \# previsto x realizado

nobs_pad = length(padroes_3[,1])

\# Integra a série e calcula exponencial (PREVISÂO 1 PASSO A FRENTE) 


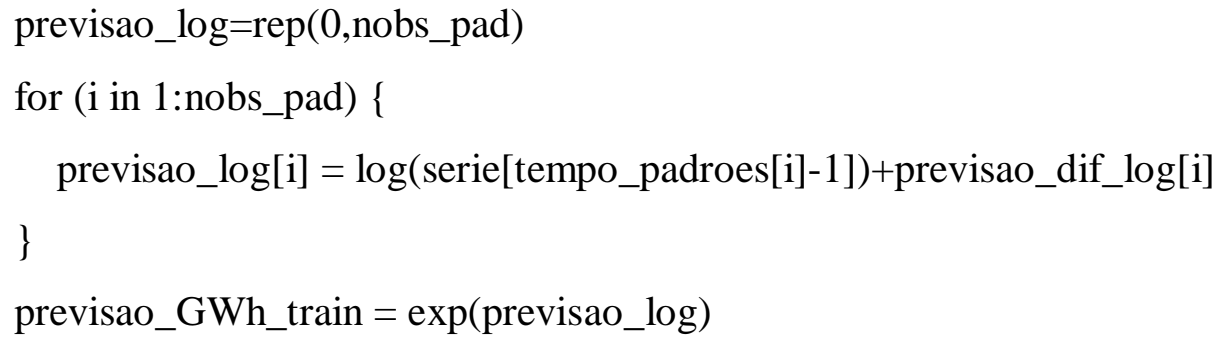

\# Integra a série e calcula exponencial (PREVISÂO 1 PASSO A FRENTE) previsao_log_valid=rep(0,nobs_valid)

for (i in 1:nobs_valid) \{ $\mathrm{j}=$ nobs_train $+\mathrm{i}$ 
previsao_log_valid[i]=log(serie[tempo_padroes[j]-

1])+previsao_dif_log_valid[i]

\}

previsao_GWh_valida_res=exp(previsao_log_valid)

\# GRÁFICO REAL X ESTIMADO

windows()

plot(serie[tempo_padroes[(nobs_train+1):npadroes]],main="CONJUNTO

DE VALIDAÇÃO",ylab="GWh",type="l",xlab="Instante de tempo")

legend(1,450000,legend=c("Real","Ajustado"),col=c("black","red"),lty=c(1, 1), cex=1)

lines(1:nobs_valid,previsao_GWh_valida_res,col="red")

\# RESÍDUOS

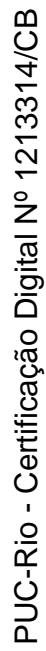

residuos_valid=serie[tempo_padroes[(nobs_train+1):npadroes]]-

previsao_GWh_valida_res

hist(residuos_valid,10,main="CONJUNTO

DE

VALIDAÇÃO",xlab="Resíduos")

mape_valid $=0$

for (i in 1:length(residuos_valid)) \{

$\mathrm{j}=$ nobs_train $+\mathrm{i}$

mape_valid $=$ mape_valid + abs(residuos_valid[i])/serie[j]

\}

mape_valid_res3 $=100 *$ mape_valid/length(residuos_valid)

mad_valid_res3 = mean(abs(residuos_valid)) \# valor em GWh

\# PREVISÕES ATÉ 2030

todos_padroes $=$ padroes_3[1:npadroes, $]$

modelo

frbs.learn(todos_padroes,range, method.type=c("WM"),control=list(num.labels=nu m_con_fuzzy, type.mf="GAUSSIAN"))

\# previsão h passos à frente

rm(new_previsao_GWh) 


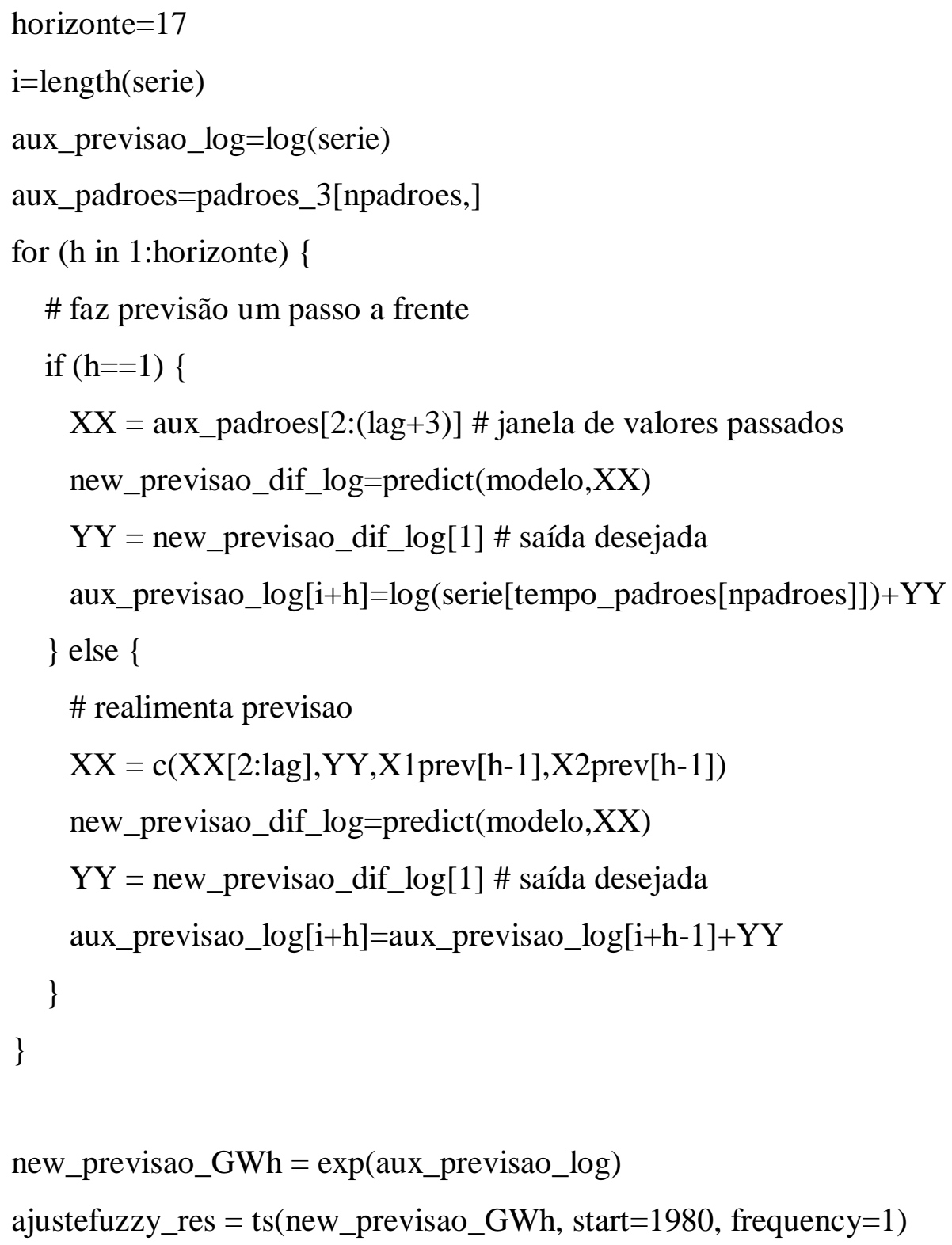

previstofuzzyres3 $=$ ts(new_previsao_GWh[35:51], start=2014, frequency $=1$ )

serieres $=$ ts $($ resid, start $=1980$, frequency $=1)$

plot(previstofuzzyres3,type="l",ylim=c(min(serieres), $\max ($ previstofuzzyres 3)), $x \lim =c(1980,2030)$, col="red",ylab="GWh",lwd=2.5, main="Residencial") lines(serieres,col="black") 